Development Center

\title{
Prediction of Long Term Degradation of Insulating Materials
}

L. D. Stephenson, Andrew Heffron, Brenda B. Mehnert, Jedediah B. Alvey, May 2015 Veera Boddu, Elizabeth J. Gao, Deborah J. Lawrence, and Ashok Kumar
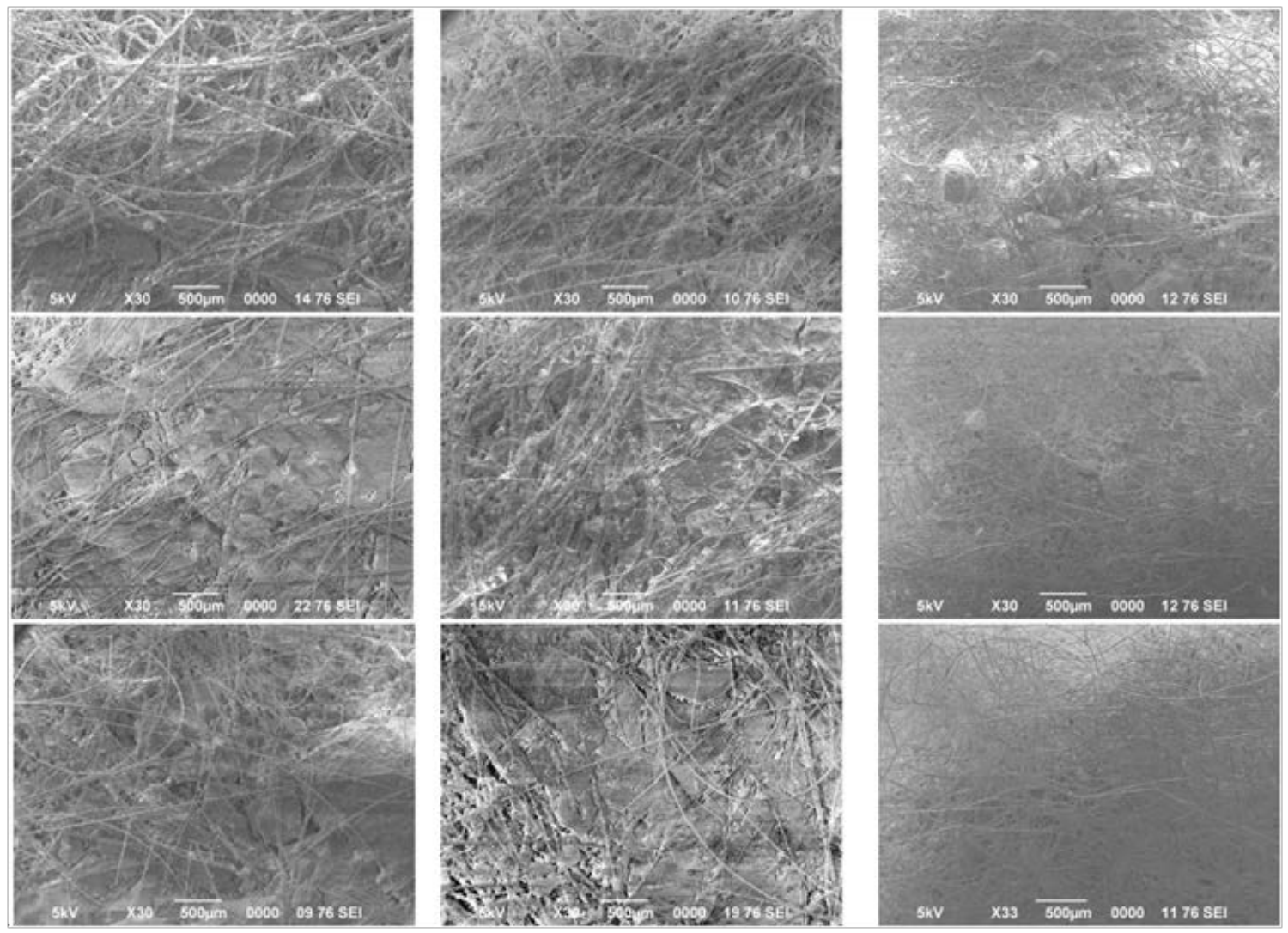
The U.S. Army Engineer Research and Development Center (ERDC) solves the nation's toughest engineering and environmental challenges. ERDC develops innovative solutions in civil and military engineering, geospatial sciences, water resources, and environmental sciences for the Army, the Department of Defense, civilian agencies, and our nation's public good. Find out more at www.erdc.usace.army.mil.

To search for other technical reports published by ERDC, visit the ERDC online library at http://acwc.sdp.sirsi.net/client/default. 
May 2015

\section{Prediction of Long Term Degradation of Insulating Materials}

L. D. Stephenson, Andrew Heffron, Brenda B. Mehnert, Jedediah B. Alvery, Veera Boddu, Elizabeth J. Gao, Debbie J. Lawrence, and Ashok Kumar

Construction Engineering Research Laboratory (CERL)

U.S. Army Engineer Research and Development Center 2902 Newmark Dr.

Champaign, IL 61822-1076

Final Report

Approved for public release; distribution is unlimited.

Prepared for Headquarters, U.S. Army Corps of Engineers

Washington, DC 20314-1000 


\section{Abstract}

Advanced insulation materials provide resistance to heat flow. Properly insulating shelters can reduce heating and cooling costs, as well as improves comfort. However, the long-term performance of insulation materials is relatively unknown. This research investigated the long-term performance of five commercially available insulation materials including nonwoven insulation liner, aerogel blankets, closed cell spray polyurethane foam (ccSPF), extruded polysterene (XPS), and fiberglass batt. Accelerated aging simulation experiments were conducted in an environmental chamber. All materials were subjected to 5 weeks in the chamber and exposed to various temperature and humidity conditions. Thermal conductivity using a heat flow meter apparatus (HFMA) and corresponding Rvalues of each material were calculated. The results indicate that moisture absorption was a major contributor to changes in the thermal properties of the materials. Additional degradation in R-values in ccSPF was caused by loss of blowing agent over time. The results of this research are expected to help formulate an accelerated aging methodology that allows reliable prediction of long-term advanced insulation materials performance.

DISCLAIMER: The contents of this report are not to be used for advertising, publication, or promotional purposes. Citation of trade names does not constitute an official endorsement or approval of the use of such commercial products. All product names and trademarks cited are the property of their respective owners. The findings of this report are not to be construed as an official Department of the Army position unless so designated by other authorized documents.

DESTROY THIS REPORT WHEN NO LONGER NEEDED. DO NOT RETURN IT TO THE ORIGINATOR. 


\section{Contents}
Abstract ii
Illustrations .. $\mathbf{V}$

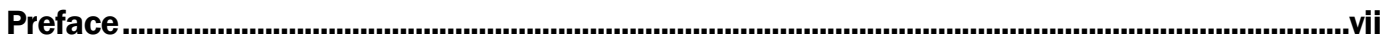

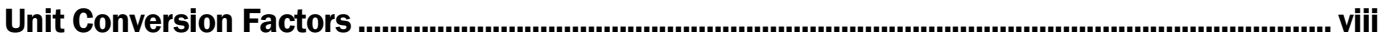

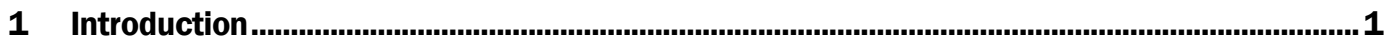

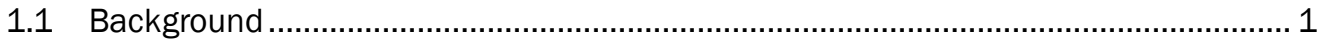

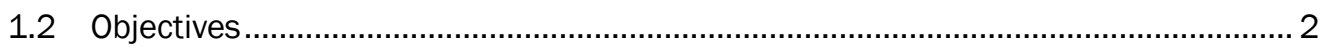

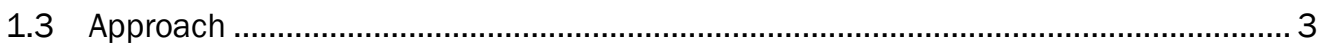

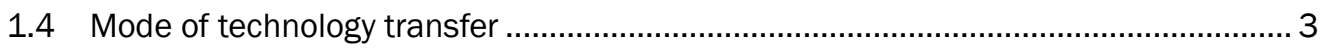

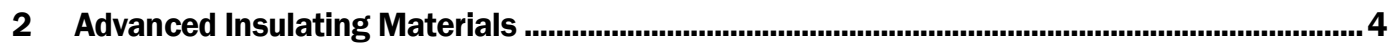

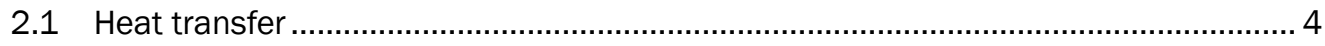

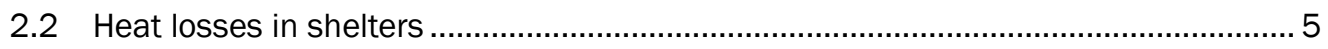

2.2.1 Heat loss through wall, windows, doors, ceilings, floor, etc. ............................................ 5

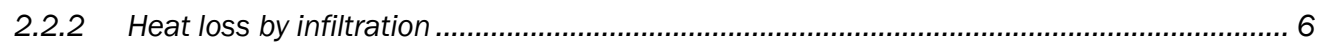

2.3 Properties of selected advanced insulating materials .......................................... 6

2.3.1 Nonwoven composite insulation liner (3M ${ }^{T M}$ Thinsulate $\left.{ }^{T M}\right)$............................................. 7

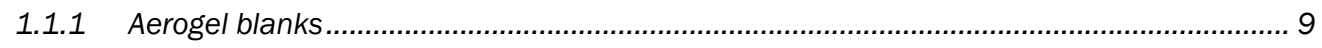

2.3.2 Closed cell spray polyurethane (ccSPF) .................................................................... 10

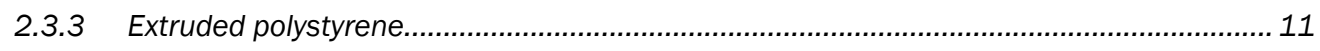

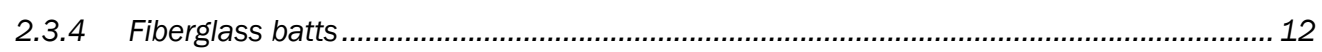

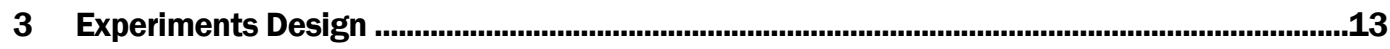

3.1 Time-Temperature-Superposition (TTS) theory .................................................... 13

3.2 Sample preparation ......................................................................................... 16

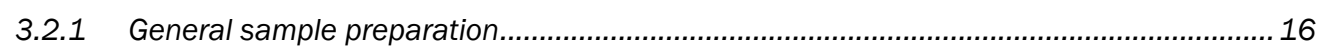

3.2.2 Special preparation of cCSPF sample ........................................................................... 17

3.2.3 Special concern about aerogel blanket .................................................................... 18

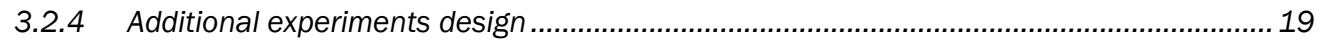

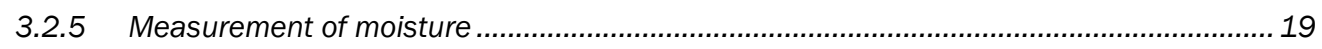

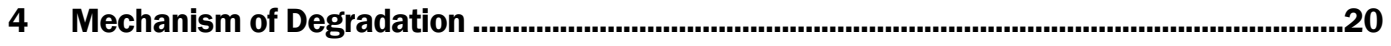

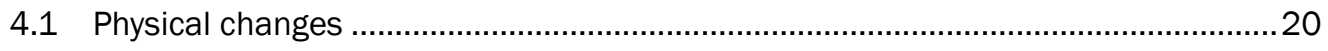

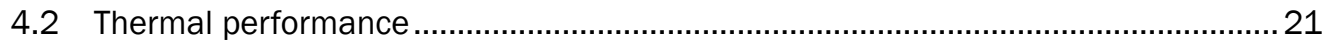

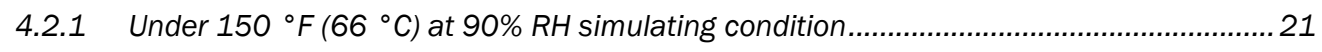

4.2.2 Nonwoven composite insulation liner (3M ${ }^{T M}$ Thinsulate $\left.{ }^{T M}\right)$ results .................................... 23

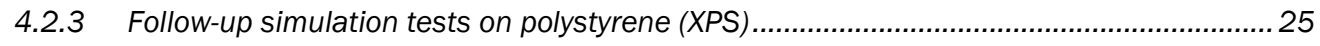

4.2.4 Follow-up aging simulation tests on closed cell spray polyurethane foam (ccSPF) ...........2 27

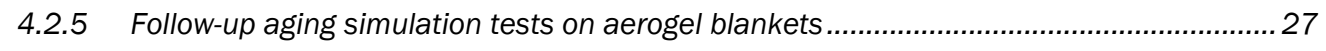




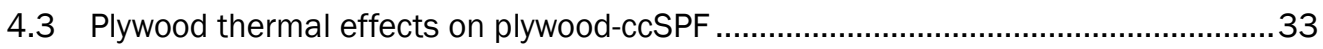

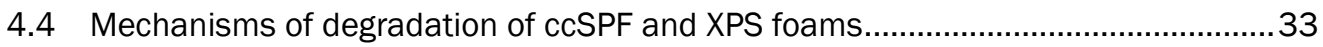

4.5 Fourier Transform Infrared (FTIR) results ......................................................... 38

4.6 Flammability testing of selected advanced insulation materials ..............................48

5 Conclusions and Recommendations ........................................................................................49

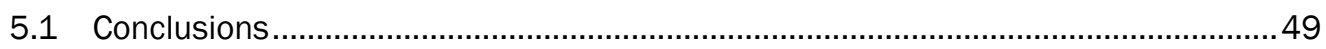

5.2 Recommendations........................................................................................... 49

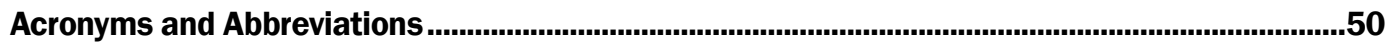

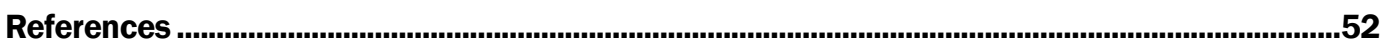

Appendix A: Flammability Testing Report..................................................................................55

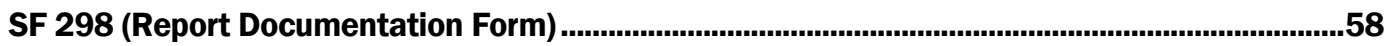




\section{Illustrations}

\section{Figures}

2-1 Schematic of conceptual heat transfer model showing heat loss profile in shelter construction (Modified from Porege and Haines 2001)

2-2 Utilis TM60 shelter with nonwoven composite insulation (Thinsulate ${ }^{\mathrm{TM}}$ ) liner (Camel Manufacturing, Pioneer, TN)

2-3 HDT global airbeam shelter with nonwoven composite insulation (Thinsulate ${ }^{\mathrm{TM}}$ ) liner.

2-4 Nonwoven Insulation liner, (a) manufacturing quilt lines of current prototype liner system, (b) fibrous batting...

2-5 Insulation samples evaluated in this study: (a) fiberglass batt, (b)closed cell spray polyurethane, (c)extruded polystyrene, and (d)aerogel blanket.

2-6 The application of ccSPF: (a) ccSPF with protective coding, (b) ccSPF was used to

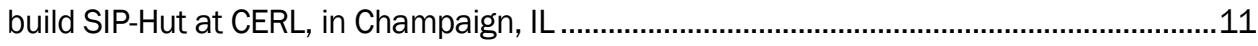

3-1 $L n(C)$ versus time (a), $D_{T}$ versus $1 / T(b)$

3-2 Conceptual TTS plots. In plot at left for moisture concentration M1, equivalent Rvalues at high temperatures occur at earlier times than R-values at lower temperatures. In right plot for moisture concentration M2 (where M2> M1), equivalent R-values occur at earlier times for a given temperature than in $\mathrm{M} 1$ plot on left (Stephenson et al. 2013).

3-3 Cincinnati Sub-Zero Environmental chamber with capabilities to provide controlled temperature and humidity environment for testing insulation samples.

Left: outside closed chamber, Right: inside chamber showing sample racks.

3-4 Laser Comp 801 HFMA for measuring thermal conductivity and determining Rvalues of insulation (Left: outside closed HFMA, Right: Inside of HFMA)

4-1 Observed physical changed in aerogel sample. Clusters of aerogel dust are were circled.

4-2 ccSPF composite samples exposed at (a) left: sample expose to $150^{\circ} \mathrm{F}\left(66^{\circ} \mathrm{C}\right)$ at $30 \% \mathrm{RH}$; right: sample without exposure, (b) sample expose to $150{ }^{\circ} \mathrm{F}\left(66^{\circ} \mathrm{C}\right)$ at $60 \% \mathrm{RH}$, and (c) bottom sample: exposed to $150^{\circ} \mathrm{F}\left(66^{\circ} \mathrm{C}\right)$ at $90 \% \mathrm{RH}$; top sample: unexposed, and is lighter in color

4-3 Blistering occurs on ccSPF samples: (a) typical blistering shown on edges of ccSPF sample, (b) severe blistering shown on top of ccSPF sample

4-4 R-value vs. Time HFMA results of five insulation materials exposed to accelerated testing at $150^{\circ} \mathrm{F}\left(66^{\circ} \mathrm{C}\right)$ at $90 \% \mathrm{RH}$ for up to 35 days

4-5 R-values and moisture concentration versus time for Thinsulate ${ }^{\mathrm{TM}}(\mathrm{TH})$ samples exposed to $150^{\circ} \mathrm{F}\left(66^{\circ} \mathrm{C}\right)$ and two different humidity conditions: Top: R/in. versus time; Bottom: moisture versus time.

4-6 R-values and moisture concentration versus time for ThermalWrap ${ }^{\mathrm{TM}}$ (TW) samples exposed to $150^{\circ} \mathrm{F}\left(66^{\circ} \mathrm{C}\right)$ at two different humidity conditions: Top: $\mathrm{R} / \mathrm{in}$. versus time; Bottom: moisture changes versus time 
4-7 Thermal conductivity and mass change in both types of XPS samples: (a) samples expose at $150^{\circ} \mathrm{F}\left(66^{\circ} \mathrm{C}\right)$ at $90 \% \mathrm{RH}$, (b) samples expose at $150^{\circ} \mathrm{F}$ $\left(66^{\circ} \mathrm{C}\right)$ at $60 \% \mathrm{RH}$.

4-8 Resistivity of ccSPF samples (labeled as PUR): (a) resistivity change of two samples exposed at two different temperature and humidity, (b) percentage changes in resistivity of two samples exposed at two different temperature and humidity

4-9 R-value versus time of aerogel samples AA: (a) R-value change of samples exposed at three different temperature and humidity, (b) percentage changes in R-value of samples exposed at three different temperature and humidity

4-10 R-value versus time of aerogel samples AB: (a) R-value change of samples exposed at three different temperature and humidity, (b) percentage changes in R-value of samples exposed at three different temperature and humidity

4-11 R-value versus time of aerogel samples AC: (a) R-value change of samples exposed at three different temperature and humidity, (b) percentage changes in R-value of samples exposed at three different temperature and humidity 32

4-12 Logarithmic plot of moisture uptake versus time for ccSPF. 36

4-13 Comparison of ambient and accelerated degradation for ccSPF. 37

4-14 Ln (R-Rf)-values versus time for ccSPF. Using exponential fit, in right plot, slope of $150^{\circ} \mathrm{F}\left(66^{\circ} \mathrm{C}\right)$ at $90 \% \mathrm{RH}$ fitted line is 30 times slope of ambient $\left(75^{\circ} \mathrm{F}\left(24^{\circ}\right.\right.$ $\mathrm{C})$ at $60 \% \mathrm{RH})$. This indicates that $150^{\circ} \mathrm{F}\left(66^{\circ} \mathrm{C}\right)$ at $90 \% \mathrm{RH}$ simulates exposure for approximately 30 times longer than insulation exposed for the same time period in the ambient exposure.

4-15 TTS plot of accelerated testing data shown as $\operatorname{Ln}(R)$ versus $\operatorname{Ln}(\mathrm{t})$. Both exposures were at $90 \% \mathrm{RH}$. Shift factor, ат $~ 3.5$

4-16 FTIR transmittance spectra. a. Aerogel blanket AA subjected to environmental conditions of $150^{\circ} \mathrm{F}\left(65.6^{\circ} \mathrm{C}\right)$ at $90 \% \mathrm{RH}$.

4-17 Details of FTIR overlays of all three aerogel blankets at $150^{\circ} \mathrm{F}\left(66^{\circ} \mathrm{C}\right)$ at 90\% RH indicates changes in free moisture

4-18 Details of FTIR overlays of all three aerogel blankets at $150^{\circ} \mathrm{F}\left(66^{\circ} \mathrm{C}\right)$ at $30 \% \mathrm{RH}$ indicates changes in free moisture

4-19 Details of FTIR overlays of $\mathrm{AC}$ at both $90 \% \mathrm{RH}$ and $30 \% \mathrm{RH}$ at $150^{\circ} \mathrm{F}\left(66^{\circ} \mathrm{C}\right)$ indicates structural changes.

4-20 SEM micrographs of AA aged at $150^{\circ} \mathrm{F}\left(66^{\circ} \mathrm{C}\right)$ at $90 \% \mathrm{RH}$ for $(\mathrm{a}) 0$ time, (b) 1 week, (c) 5 weeks

4-21 SEM micrographs of $\mathrm{AB}$ aged at $150^{\circ} \mathrm{F}\left(66^{\circ} \mathrm{C}\right)$ at $90 \% \mathrm{RH}$ for (a) 0 time, (b) 1 week, (c) 5 weeks

4-22 SEM micrographs of $\mathrm{AC}$ aged at $150^{\circ} \mathrm{F}\left(66^{\circ} \mathrm{C}\right)$ at $90 \% \mathrm{RH}$ for (a) 0 time, (b) 1 week, (c) 5 weeks

\section{Tables}

2-1 Properties of five tested insulating materials ..................................................................... 7

2-2 Summary of insulating materials tested ...............................................................................10

4-1 Calculated versus actual removal of plywood thermal effects from ccSPF/plywood composite 


\section{Preface}

This research was conducted for Operational Energy Plans and Programs Office, Office of the Secretary of Defense under Operational Energy Capital Improvement Fund Program "Advanced, Energy Efficient Shelter Systems for Contingency Basing and Other Applications." The project title was "Advanced Materials for Energy Efficient Shelters." The technical monitor was Clinton McAdams, Natick Soldier Research, Development and Engineering Center (NSRDEC).

The work was performed by the Materials and Structures Branch (CF-M) of the Infrastructure Division (CF), U.S. Army Engineer Research and Development Center, Construction Engineering Research Laboratory (ERDCCERL). At the time of publication, Vicki L. Van Blaricum was Chief, CEERD-CF-M; L. Michael Golish was Chief, CEERD-CF; and Kurt Kinnevan, CEERD-CV-T, was the Acting Technical Director for Adaptive and Resilient Installations. The Deputy Director of ERDC-CERL was Dr. Kirankumar Topudurti and the Director was Dr. Ilker Adiguzel.

COL J effrey R. Eckstein was the Commander of ERDC, and Dr. J effery P. Holland was the Director. 


\section{Unit Conversion Factors}

\begin{tabular}{|l|l|l|}
\hline Multiply & By & To Obtain \\
\hline British thermal units (International Table) & $1,055.056$ & Joules \\
\hline cubic feet & 0.02831685 & cubic meters \\
\hline cubic inches & $1.6387064 \mathrm{E}-05$ & cubic meters \\
\hline cubic yards & 0.7645549 & cubic meters \\
\hline degrees Fahrenheit & $($ F-32)/1.8 & degrees Celsius \\
\hline feet & 0.3048 & Meters \\
\hline foot-pounds force & 1.355818 & Joules \\
\hline inches & 0.0254 & Meters \\
\hline square feet & 0.09290304 & square meters \\
\hline square inches & $6.4516 \mathrm{E}-04$ & square meters \\
\hline square miles & $2.589998 \mathrm{E}+06$ & square meters \\
\hline square yards & 0.8361274 & square meters \\
\hline Thermal resistivity (U.S.) & 0.1761102 & Thermal Resistivity (SI) \\
\hline
\end{tabular}




\section{Introduction}

\subsection{Background}

U.S. Department of Defense energy-related costs for fuel used in generators in the field for heating and cooling shelters is about $\$ 1.7$ billion annually (based on $\$ 15 /$ gallon). Much of this fuel is consumed by shelter systems, including tents, which are not energy efficient. Currently battlefield shelter systems often require energy intensive heating and airconditioning units to compensate for air leakage. Shelters that consist of single layer fabric shells and liners require a 5-ton environmental control unit (ECU) to cool each small shelter system, a one-for-one ratio. The Field Deployable ECU (FDECU) that is an Air Force Basic Expeditionary Airfield Resources (BEAR) standard has a power demand of over 15kW at temperatures over $115^{\circ} \mathrm{F}\left(46^{\circ} \mathrm{C}\right)$. A BEAR expeditionary base with a population of 3,300, this equates to approximately 300 ECUs with a peak power demand of $4.5 \mathrm{~mW}$ to cool small shelters. The circumstances are similar for Army Force Provider base camps. The F100 that is the Force Provider standard ECU has a power demand of $17 \mathrm{~kW}$ at peak cooling. For a 600 person Force Provider camp, this equates to approximately 57 ECUs with a peak power demand of $969 \mathrm{~kW}$ to cool tents.

This program was undertaken to demonstrate and transition shelter systems that will reduce required heating and cooling by $50 \%$ while providing improved capabilities and quality of life. The intent of this "Advanced High Performance Insulation" focus area is to address the enduring challenge of developing and evaluating the long-term performance of a thermal insulation for shelter systems that provides a sufficient thermal barrier and minimizes logistics burden, while being able to withstand harsh military environments. Several technology developments have been conducted to leverage materials of high thermal barrier properties.

The majority of Army soft-wall shelters (tents) do not have insulation, other than an additional liner that is heavy, bulky, and difficult to transport and properly apply to the shelters. Polyurethane (PU) external foam insulation is now, but is not practical for expeditionary use since the PU foam component must be transported to the deployment site, properly applied, and once installed, the PU foam cannot be easily removed to allow the shelter to be re-deployed. Moreover, PU foam is difficult to discard since it is considered a hazardous waste. 
Hard-wall shelter designs, in some cases, have no insulation annotated in their designs. In cases where designs include insulation, it is often not applied due to lack of material on-hand. Other pre-fabricated hard-wall shelters do include insulation, but it is minimally applied.

Advanced thermal insulation materials are one of the techniques commonly used to mitigate energy losses in shelters. The science behind this mitigation technique is based on the material properties in the shelter or shelter envelope. Properly installed insulation materials improve the energy efficiency by reducing the heat loss through walls, windows, doors, ceilings, floors, air infiltration, etc. In addition, insulation materials help to reduce heat gain during the summer season and to reduce heat loss during the winter months. Insulation materials help improve the shelter's overall energy efficiency, reduce the energy consumption, and limit the production of carbon dioxide and sulfur dioxide (recognized elements in acid rain) by reducing demand for fossil fuels (thermal insulation materials).

However, insulation materials are prone to degradation over time based on environmental conditions. Long-term degradation can be predicted as well as the mechanism of degradation can be identified based on shortterm accelerated testing in the laboratory. This work was undertaken to evaluate five commercially available insulating materials:

- nonwoven insulation liner (Thinsulate ${ }^{\mathrm{TM}}$ )

- aerogels blankets from three different suppliers

- closed cell spray polyurethane foam (ccSPF)

- extruded polysterene (XPS)

- fiberglass batts as a "control standard."

\subsection{Objectives}

The objective of this study was to evaluate long-term performances of selected advanced insulation materials. The overall objectives of this research were to:

1. Conduct accelerated aging experiments by exposure selected materials to various temperatures and moisture conditions.

2. Evaluate the degradation of thermal properties of selected insulation materials based on the differences in thermal conductivity and R-values.

3. Predict the long-term performance of selected material and their future application.

4. Identify mechanisms of mechanisms of degradation based on science. 


\subsection{Approach}

This work investigated the long-term performance of selected advanced insulation materials. Accelerated aging experiments were conducted to simulate the natural aging of insulation samples subject to 5 weeks thermal cycles by exposure to elevated temperatures at elevated moisture conditions. The accelerated aging experiments were conducted in an environmental chamber. The changes of physical properties were determined. The thermal conductivity and resistivity (reported as R/in) of those materials were measured using a heat flow meter apparatus (HFMA). The mechanisms of degradation were identified.

\subsection{Mode of technology transfer}

It is anticipated that the results of this research will be used to develop an accelerated aging methodology that allows reliable prediction of long-term performance of advanced insulation materials. 


\section{Advanced Insulating Materials}

\subsection{Heat transfer}

It is necessary to understand the mechanism of heat transfer and heat losses in shelters before discussing how insulation materials can reduce heat losses in shelter system. Heat is a form of energy (King 2003; Field and Solie 2007). Heat flow follows thermal gradient from warmer to cooler until the thermal gradient vanishes. Heat transfer or heat flow involves three mechanisms: conduction, convection, and radiation (Lienhard and Lienhard 2011, Porege and Haines 2001). Conduction is the way that heat transfer through the molecular agitation of a substance. Heat transfer through conduction can be expressed as:

$$
\begin{gathered}
H=A C\left(t_{i}-t_{0}\right) \\
C=\frac{K}{X}
\end{gathered}
$$

where:

$$
\begin{aligned}
\mathrm{H} & =\text { heat flow, } \mathrm{W}(\mathrm{Btu} / \mathrm{hr}) \\
\mathrm{A} & =\text { area of exposed surface, } \mathrm{m}^{2}\left(\mathrm{ft}^{2}\right) \\
\mathrm{K} & =\text { thermal conductivity of material, } \mathrm{W} / \mathrm{mK}\left(\mathrm{Btu} \mathrm{in} / \mathrm{hr} \mathrm{ft}^{2}{ }^{\circ} \mathrm{F}\right) \\
\mathrm{C} & =\text { thermal conductance of shelter element, } \mathrm{W} / \mathrm{m}^{2} \mathrm{~K}\left(\mathrm{Btu} / \mathrm{hr} \mathrm{ft}^{2}{ }^{\circ} \mathrm{F}\right) \\
\mathrm{X} & =\text { thickness of material of material, } \mathrm{m}(\mathrm{in}) \\
\mathrm{t}_{\mathrm{i}} & =\text { inside air temperature, }{ }^{\circ} \mathrm{F}\left({ }^{\circ} \mathrm{C}\right) \\
\mathrm{t} & =\text { outside air temperature, }{ }^{\circ} \mathrm{F}\left({ }^{\circ} \mathrm{C}\right) .
\end{aligned}
$$

Convection is the migration of heat by the movement of matter, such as flow of currents within a fluid body. The amount of heat that can be transferred per unit of time through convection is affected by the velocity of moving medium, the surface area, and the temperatures of the cooler side and the hotter side.

The third mechanism of heat transfer is radiation. Heat transfer through radiation travels in a straight line such that the surrounding areas along the heat paths will heat up and absorb energy (Porege and Haines 2001). 


\subsection{Heat losses in shelters}

As mentioned in the above section, heat transfer occurs through three mechanisms and heat flow follows a temperature gradient until the temperature difference vanishes. Due to poorly insulated or non-insulated shelter construction, heat losses in shelters can occur through walls, window, doors, ceiling, floors, and by air infiltration, etc.

\subsubsection{Heat loss through wall, windows, doors, ceilings, floor, etc.}

Heat loss through wall, windows, doors, ceilings, floor, etc. (Figure 2-1) can be described as:

$$
\begin{gathered}
H=A U\left(t_{i}-t_{0}\right) \\
U=1 /\left(1 / f_{i}+{ }^{x} / k_{1}+x_{2} / k_{2}+{ }^{x} / k_{3}+1 / f_{0}\right)
\end{gathered}
$$

where:

$$
\begin{aligned}
\mathrm{H} & =\text { heat flow, } \mathrm{W}(\mathrm{Btu} / \mathrm{hr}) \\
\mathrm{A} & =\text { area of exposed surface, } \mathrm{m}^{2}\left(\mathrm{ft}^{2}\right) \\
\mathrm{U} & =\text { overall coefficient of heat transmission, } \mathrm{W} / \mathrm{m}^{2} \mathrm{~K}\left(\mathrm{Btu} / \mathrm{hr} \mathrm{ft}^{\circ}{ }^{\circ} \mathrm{F}\right) \\
\mathrm{k} & =\text { thermal conductivity of material, } \mathrm{W} / \mathrm{mK}\left(\mathrm{Btu} \mathrm{in} / \mathrm{hr} \mathrm{ft}^{2}{ }^{\circ} \mathrm{F}\right) \\
\mathrm{f}_{\mathrm{i}} & =\text { surface conductance for inside wall, }\left(\mathrm{W} / \mathrm{m}^{2} \mathrm{~K}\right) \\
\mathrm{f} & =\text { surface conductance for outside wall, }\left(\mathrm{W} / \mathrm{m}^{2} \mathrm{~K}\right) \\
\mathrm{x} & =\text { thickness of material, } \mathrm{m}(\mathrm{in}) \\
\mathrm{t}_{\mathrm{i}} & =\text { inside air temperature, }{ }^{\circ} \mathrm{F}\left({ }^{\circ} \mathrm{C}\right) \\
\mathrm{t} & =\text { outside air temperature, }{ }^{\circ} \mathrm{F}\left({ }^{\circ} \mathrm{C}\right) .
\end{aligned}
$$

Figure 2-1. Schematic of conceptual heat transfer model showing heat loss profile in shelter construction (Modified from Porege and Haines 2001).

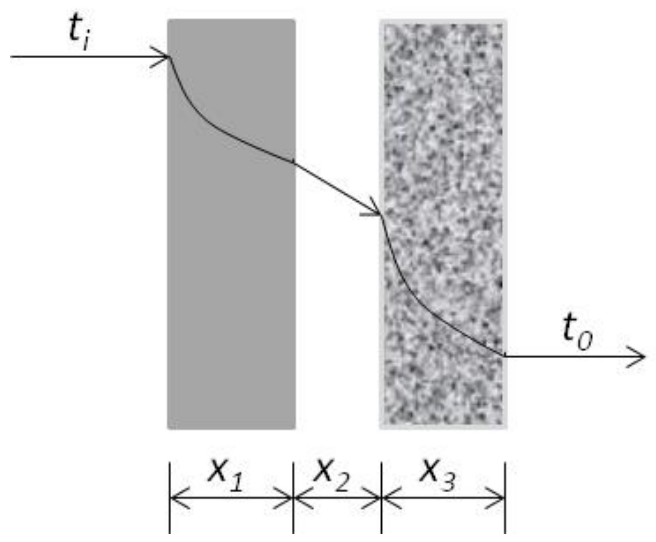




\subsubsection{Heat loss by infiltration}

Heat loss caused by infiltration can be calculated as:

$$
H=\operatorname{sdnV}\left(t_{i}-t_{0}\right)
$$

where:

$$
\begin{aligned}
\mathrm{H} & =\text { heat loss infiltration, } \mathrm{W}(\mathrm{Btu} / \mathrm{hr}) \\
\mathrm{s} & =\text { specific heat capacity of air, }(\mathrm{kJ} / \mathrm{kg} \mathrm{K}) \\
\mathrm{d} & =\text { density of air, }\left(\mathrm{kg} / \mathrm{m}^{3}\right) \\
\mathrm{n} & =\text { number of air shifts or air changes, }(1 / \mathrm{s}) \\
\mathrm{V} & =\text { volume of room, }\left(\mathrm{m}^{3}\right) \\
\mathrm{x} & =\text { thickness of material, } \mathrm{m}(\mathrm{in}) \\
\mathrm{t}_{\mathrm{i}} & =\text { inside air temperature, }{ }^{\circ} \mathrm{F}\left({ }^{\circ} \mathrm{C}\right) \\
\mathrm{t} & =\text { outside air temperature, }{ }^{\circ} \mathrm{F}\left({ }^{\circ} \mathrm{C}\right)
\end{aligned}
$$

Strategies to reduce air infiltration, include weather stripping, weather sealing tapes, and housewrap. Further consideration of air infiltration is beyond the scope of this report, with the exception of one material tested that combined the functions of a housewrap (to mitigate air infiltration) with an insulating material (to mitigate heat transfer by conduction).

To reduce heat loss in shelters, lower costs, and maintain comfort level, it is necessary to apply mitigation techniques to improve the overall energy efficiency in shelters. Insulation materials have been considered as one of the most efficient ways to reducing energy losses in shelter envelopes due to their ability to provide resistance to heat flow (thermal conduction). The more resistance the insulation materials can provide, the less energy is needed for heating, cooling, or operation. As a result, the energy efficiency of a shelter can be improved by using these materials.

\subsection{Properties of selected advanced insulating materials}

This project selected and evaluated five commercially available insulating materials with respect to R-value versus time at elevated temperature and humidity levels:

1. Nonwoven insulation liner

2. Aerogel blankets from different suppliers identified as " $\mathrm{AA}$," " $\mathrm{AB}$," and "AC," respectively

3. Closed cell polyurethane foam (ccSPF)

4. Extruded polystyrene(XPS)

5. Fiberglass batts as controlled standard. 
Table 2-1 lists typical properties and costs of these materials.

\subsubsection{Nonwoven composite insulation liner (3M ${ }^{\mathrm{TM}}$ Thinsulate $^{\mathrm{TM}}$ )}

A nonwoven composite insulation liner that can be used for energy conservation in expedient soft-wall shelter provides improved thermal performance that results in $\sim 30 \%$ less fuel consumption, improved quality of life, and enhanced ease of insulated shelter setup. Figures 2-2 and 2-3 show the shelters with nonwoven composite insulation liner $\left(3 \mathrm{M}^{\mathrm{TM}}\right.$ Thinsulate ${ }^{\mathrm{TM}}$ ).

The insulated liner is fabricated from $3 \mathrm{M}^{\mathrm{TM}}$ Thinsulate ${ }^{\mathrm{TM}}$ comprised of very thin fibers of polypropylene (PP) and polyethylene terephthalate (PETE) (Figure 2-4). Thinsulate ${ }^{\mathrm{TM}}$ is reputed to be more effective due to the increased density of fibers with decreased size of fibers compared with more traditional insulation. The liners are designed to limit the heat loss through opening and unprotected areas and to assist maintaining comfortable temperature ranges inside the shelter. Gaps between fibers not only reduce heat flow, but also allow moisture to escape. These materials are relatively stable at nominal shelter envelopes temperatures. The liner provides an effective R-value of about 4.7 per inch (Camel 2015). In addition, the fiber materials are not susceptible to moisture absorption. Furthermore, the composite insulation material does not require any refrigerant gases to help reduce convection currents within the fabric that may eventually escape as the fabric ages, thereby reducing material's R-value.

Table 2-1. Properties of five tested insulating materials.

\begin{tabular}{|c|c|c|c|c|c|}
\hline \multirow{2}{*}{ Sample } & Conductivity & Heat Flux & Thickness & R per Inch & Typical Cost \\
\cline { 2 - 6 } & $\left(\mathrm{W} / \mathrm{m}^{\circ} \mathrm{K}\right)$ & $\left(\mathrm{W} / \mathrm{m}^{2}\right)$ & $(\mathrm{mm})[\mathrm{in}]$ & $\left(\mathrm{ft}^{2} \mathrm{Fh} / \mathrm{BTU}\right) / \mathrm{in}$ & $\left(\right.$ per $\left.\mathrm{ft}^{2}\right)$ \\
\hline Thinsulate $^{\mathrm{TM}}$ & 0.0307 & 47.9 & $16[0.63]$ & 4.7 & $\$ 0.40$ \\
\hline Aerogel Blanket & 0.0157 & 39.6 & $9.9[0.39]$ & 9.2 & $\$ 4.00$ \\
\hline $\begin{array}{c}\text { closed cell spray } \\
\text { Polyurethane (ccSPF) }\end{array}$ & 0.0252 & 12.2 & $51.8[2.0]$ & 5.7 & $\$ 2.00$ \\
\hline $\begin{array}{c}\text { Extruded Polystyrene } \\
\text { (XPS) }\end{array}$ & 0.0281 & 13.8 & $51.8[2.0]$ & 5.1 & $\$ 1.28$ \\
\hline \begin{tabular}{c} 
Fiberglass Batt \\
\hline
\end{tabular} & 0.0420 & 11.8 & $88.9[3.5]$ & 3.4 & $\$ 0.31$ \\
\hline
\end{tabular}


Figure 2-2. Utilis TM60 shelter with nonwoven composite insulation (Thinsulate ${ }^{\mathrm{TM}}$ ) liner (Camel Manufacturing, Pioneer, TN).

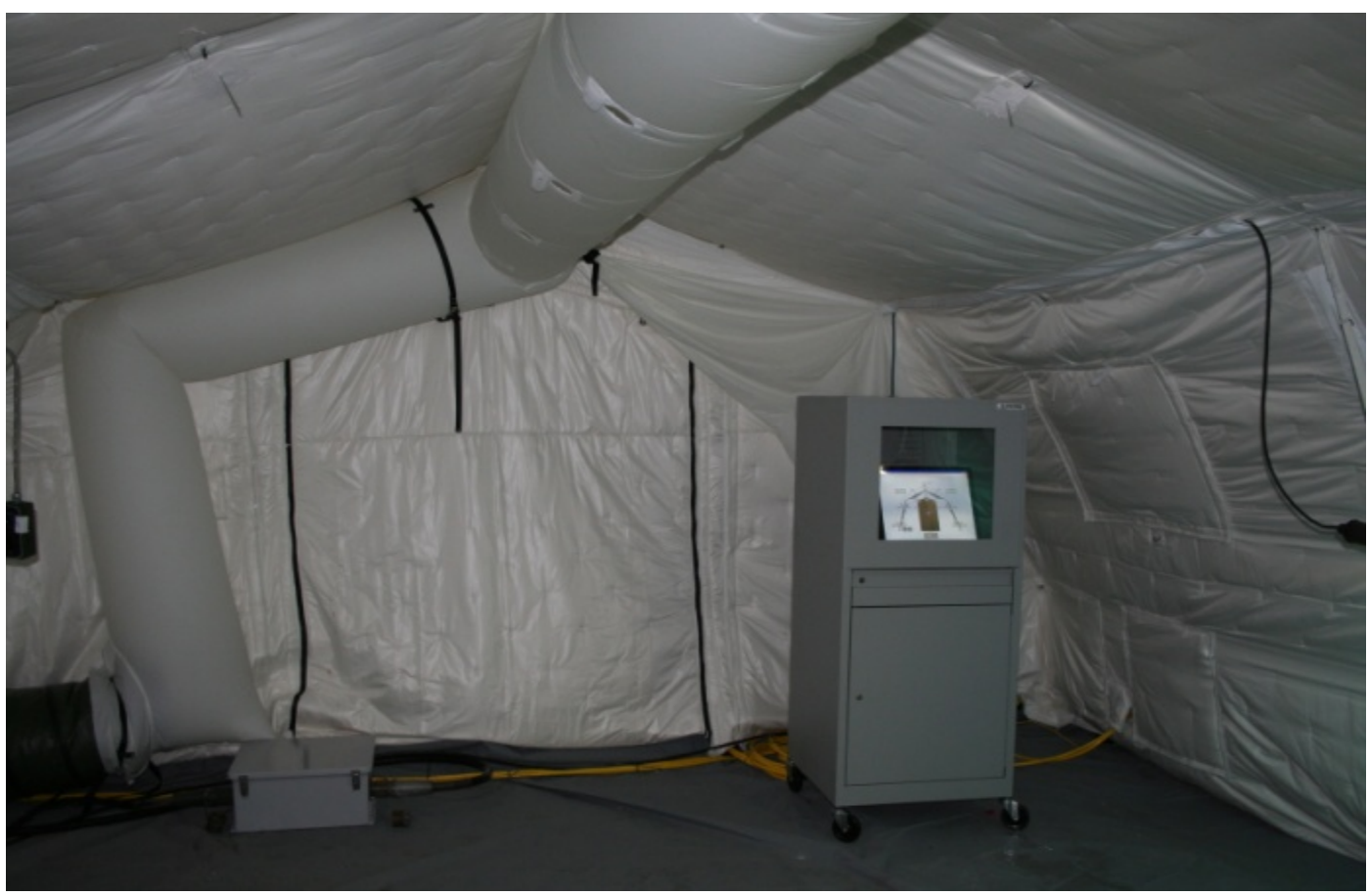

Figure 2-3. HDT global airbeam shelter with nonwoven composite insulation (Thinsulate ${ }^{\mathrm{TM}}$ ) liner.

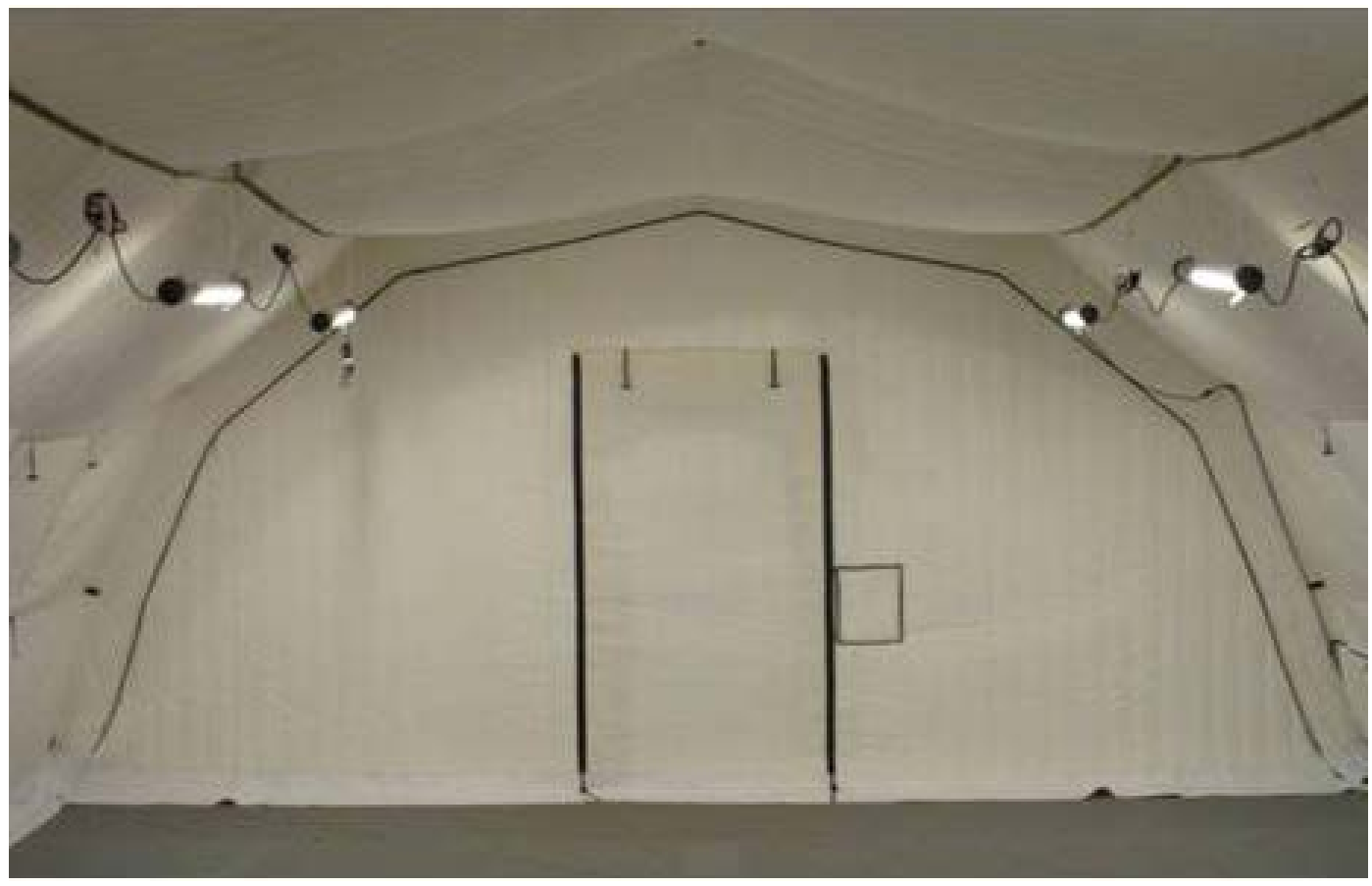


Figure 2-4. Nonwoven Insulation liner, (a) manufacturing quilt lines of current prototype liner system, (b) fibrous batting.

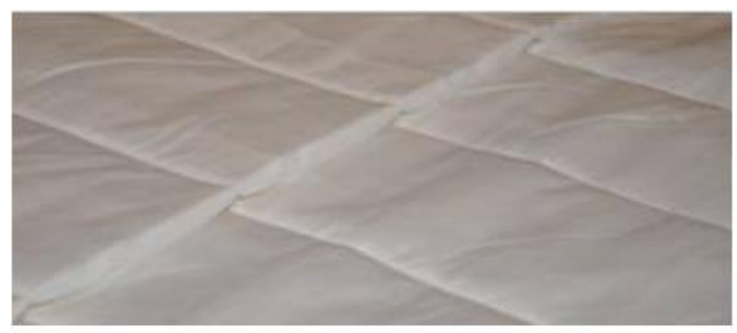

(a)

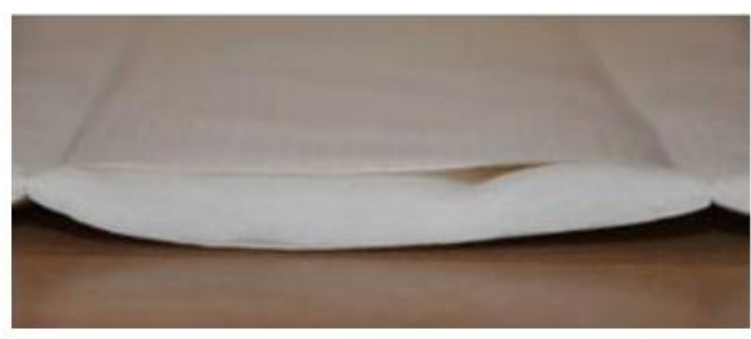

(b)

\subsubsection{Aerogel blanks}

Aerogels are extremely low-density solids with cells on the nano-scale. Air is trapped in the porous silica and occupied 99\% total volume of the material. This unique feature makes aerogel function as a good thermal insulator, which nullifies the three mechanisms of heat transfer including convection, conduction, and radiation. Because air occupies $99 \%$ of total volume, aerogel is a poor thermal conductor. However, aerogel insulation materials are generally reserved for special purpose use because of their relatively high cost. For example, aerogel materials can be used to supplement traditional fiberglass, foam, or cellulose insulation in areas where thermal bridges may be formed or used in places where it is not practical to install thicker insulation, such as retrofit of a room needing additional insulation. In the latter case, the thin aerogel blanket can be installed flat against an existing wall using masonry screws, and then covered by wood paneling, thereby circumventing the need to open existing wall cavities.

A typical method to make aerogel composites involves molding a silica gel around a supporting (xonotlite-type calcium silicate) structure, followed by the drying process, then mixing with a polymer binder (often a type of polyester [e.g., polyethylene terephthalate]) to make the aerogel blanket (Wei et al. 2011, Frank et al. 1998). Three types of aerogel insulation materials were tested in this project. All are made from trimethylsilylated silica gel and all are hydrophobic (Aspen Aerogels 2011, Acoustiblok Inc. 2009, Cabot Corp. 2013). Table 2-2 lists the properties of the aerogel materials. Figure 2-5 (d) shows an aerogel sample. 
Table 2-2. Summary of insulating materials tested.

\begin{tabular}{|l|l|l|l|}
\hline Label & Type of insulation & Other components & Mfg. Process \\
\hline XPA & Polystyrene foam & trans-1,3,3,3-Tetrafluoroprop-1-ene blowing agent & Extruded \\
\hline XPB & Polystyrene foam & 1-Chloro-1,1-difluoroethane and 1,1,1,2-Tetrafluoroethane blowing agent & Extruded \\
\hline ccSPF & Polyurethane foam & 1,1,1,3,3-Pentafluoropropane blowing agent, plywood substrate & Sprayed \\
\hline AA & Aerogel composite & Calcium Silicate dopant, glass and PET fibers & Molded \\
\hline AB & Aerogel composite & Glass and PET fibers & Molded \\
\hline AC & Aerogel composite & Bicomponent fibers with PET core and copolyolefin sheath & Nested and fused \\
\hline
\end{tabular}

Figure 2-5. Insulation samples evaluated in this study: (a) fiberglass batt, (b)closed cell spray polyurethane, (c)extruded polystyrene, and (d)aerogel blanket.

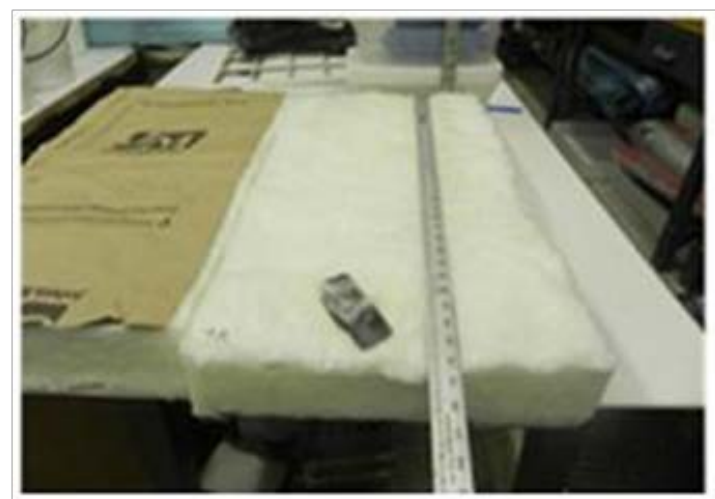

a.

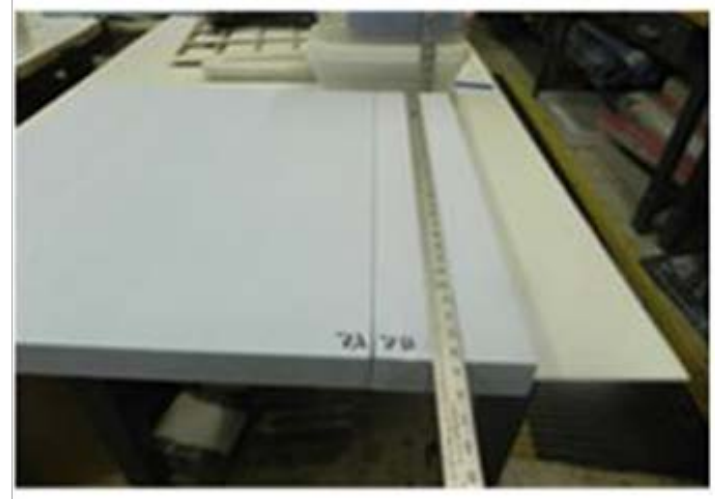

C.

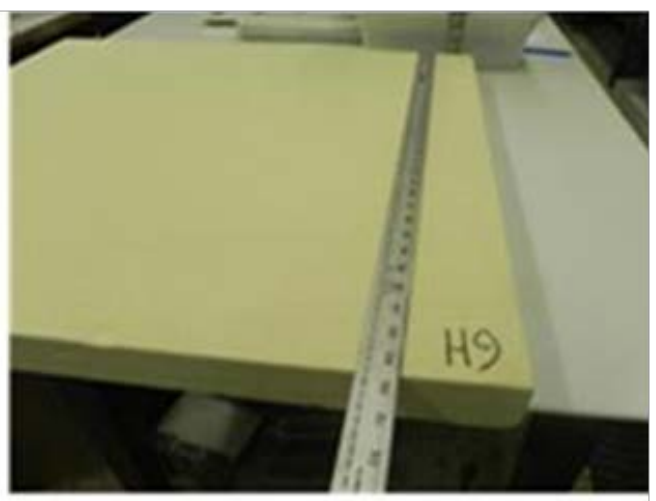

b.

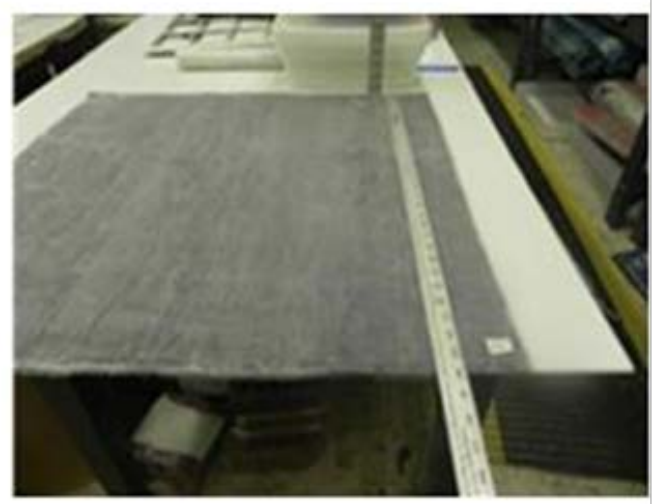

d.

\subsubsection{Closed cell spray polyurethane (ccSPF)}

Spray polyurethane is applied as an expanding multi-component mixture. In general, the closed cells are filled with a blowing agent to improve thermal properties. It can be applied to a variety of surfaces, including the interior cavities of an unfinished wall or ceiling. This material provides additional structural support as well as an improved air barrier due to the materials adheres to the structure (Parasin and Nagy 1991). 
The ccSPF foam can be coated with a variety of high performance protective coatings, for example, acrylic, silicone, or urethane, to provide protection from ultra violet light and weathering in exterior roofing. In addition, cCSPF foam is considered one of the best insulation materials with an aged R-value of 5-7 per inch depending on formulation. This material derives its superior insulation by trapping a gaseous blowing agent in each tiny cell. The blowing agents can be pentane, isopentane, cyclopentane and liquid $\mathrm{CO}_{2}$, or isocyanate and water. A typical application of ccSPF insulation material is in Structurally Insulated Panels-Hut (SIP-Hut) (Figure 2-6).

Figure 2-6. The application of ccSPF: (a) ccSPF with protective coding, (b) ccSPF was used to build SIP-Hut at CERL, in Champaign, IL.

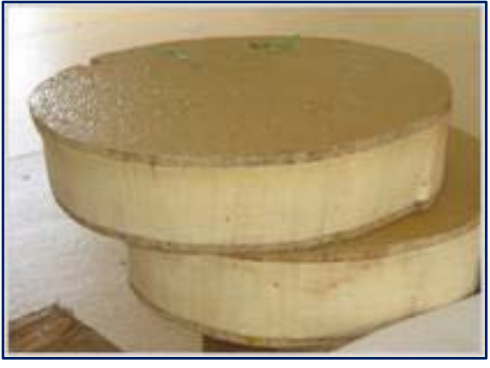

a.

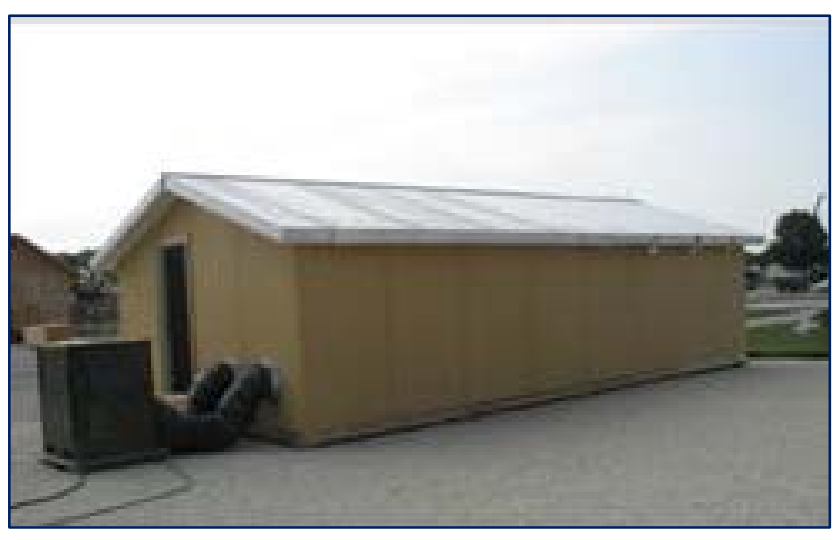

b.

\subsubsection{Extruded polystyrene}

Extruded polystyrene (XPS) is a closed cell foam in which the interior cells are filled with a blowing agent. Frequently, XPS is used as part of an exterior wall panel (Trpevski et al. 2007). The choice of blowing agent has the greatest effect on thermal performance; different blowing agents used to form foams with identical geometries can have entirely different thermal properties. Additionally, long-term performance can vary greatly between blowing agents (Zhu et al. 2009). This project evaluated two versions of XPS foam with nominal thicknesses of 50.8 and $54.0 \mathrm{~mm}$. One version used a trans-1,3,3,3-Tetrafluoroprop-1-ene blowing agent (Honeywell 2014); the other used a combination of 1-Chloro-1,1-difluoroethane and 1,1,1,2-Tetrafluoroethane (Dow 2011). Figure 2-5(c) shows the sample of XPS tested in this project. 


\subsubsection{Fiberglass batts}

Fiberglass insulation (Figure 2-5[a]) has been used extensively in shelter for many years. It is relatively inexpensive, however, according to the U.S. Department of Energy (DOE), in wall applications, ccSPF insulation functions at $105 \%$ of its labeled R-value, while glass fiber batts function at $67 \%$ of their advertised R-value. Typical roofing applications of ccSPF may be installed in less than half the time it would take to install board and membrane systems. The fiberglass tested had a paper coated backing material to prevent moisture from entering the product. The backing material was only on one side of the insulation. 


\section{Experiments Design}

\subsection{Time-Temperature-Superposition (TTS) theory}

A commonly used method of simulating aging properties of polymeric materials is to test samples at an elevated temperature so that the elevated temperature represents selected properties at ambient temperatures, but at a much later time (Cheng and Yang 2006).

The simplified model assumes an Arrhenius-type term for hygrothermal degradation dependents on activation energy $\left(E_{A}\right)$, temperature $(T)$, and moisture concentration $(\mathrm{M})$, and it varies with time (t) (d'Arlas et al. 2007).The simplified model, which incorporates a mechanism of degradation due to diffusion of moisture into the materials is best expressed as an Arrhenius equations that uses "scaled" R-values, i.e., R-values are scaled to a new variable, $\mathrm{c}$, such that $o \leq \mathrm{c} \leq 1$. The maximum value of $\mathrm{R}$ is scaled to 1 , and the fully degraded R-value is scaled to 0 , so that:

$$
C=\left(R_{t}-R_{f}\right) /\left(R_{0}-R_{f}\right)
$$

If the R-value degradation is dependent on the diffusion of moisture, $\mathrm{C}$ versus time can be modeled as:

$$
C=\exp \left[\left(-D_{T}\right) t\right]
$$

where:

$$
\begin{aligned}
\mathrm{C} & =1 \text { for new material } \\
\mathrm{C} & =0 \text { for fully degraded material } \\
\mathrm{D}_{\mathrm{T}} & =\text { diffusion constant at temperature } \mathrm{T} \\
\mathrm{R}_{0} & =\mathrm{R} \text {-value at time } \mathrm{t}=0 \\
\mathrm{R}_{\mathrm{t}} & =\mathrm{R} \text {-value at time " } \mathrm{t} \text { " } \\
\mathrm{R}_{\mathrm{f}} & =\text { fully degraded } \mathrm{R} \text {-value } \\
\mathrm{t} & =\text { time of exposure, (days) } \\
\mathrm{E}_{\mathrm{A}} & =\text { activation energy, (from empirical data fit) } \\
\mathrm{K} & =\text { Boltzmann constant, }\left(1.381 \mathrm{X} 10^{-23} \mathrm{~J} / \mathrm{K}\right) \\
\mathrm{N}_{\mathrm{A}} & =\text { Avogadro's number, }\left(6.022 \times 10^{23} / \mathrm{mole}\right) \\
\mathrm{T} & =\text { temperature, }(\mathrm{K}) .
\end{aligned}
$$


Applying an Arrhenius model of diffusion, it is found that:

$$
D_{T 1} / D_{T 2}=\exp \left[-\left(E_{A} / N_{A} K\right)\left(1 / T_{1}-1 / T_{2}\right)\right]
$$

where:

$$
\begin{aligned}
\mathrm{D}_{\mathrm{T} 1} & =\text { diffusion constant at temperature T1, } \\
\mathrm{D}_{\mathrm{T} 2} & =\text { diffusion constant at temperature T2, } \\
\mathrm{E}_{\mathrm{A}} & =\text { activation energy, (from empirical data fit) } \\
& =\text { Boltzmann constant, }\left(1.381 \mathrm{X} 10^{-23} \mathrm{~J} / \mathrm{K}\right) \\
\mathrm{N} & =\text { Avogadro's number, }\left(6.022 \times 10^{23} / \text { mole }\right) \\
\mathrm{T} & =\text { temperature },(\mathrm{K}) .
\end{aligned}
$$

Plotting $\operatorname{Ln}(\mathrm{C})$ versus time ( $\mathrm{t}$ ) yields a family of lines in which each line represents for each temperature (T) (Figure 3-1[a]). The slope of each line

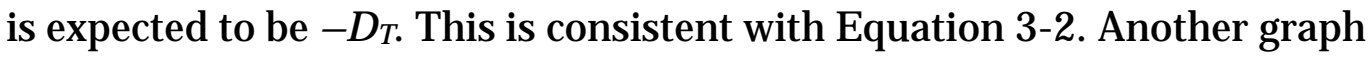
is generated by plotting Ln(DT) against 1/ (T) (Figure 3-1[b]). The slope of the resulting line is given by $\left(-\mathrm{E}_{\mathrm{A}} / \mathrm{N}_{\mathrm{A}} \mathrm{K}\right)$, which is consistent with Equation 3-3. As a result, the activation energy $\left(E_{A}\right)$ for the degradation process can be calculated. Note that the same $C$ value can exist for various favorable combinations of $\mathrm{D}_{\mathrm{T}}$ and $\mathrm{t}$ :

$$
D_{T 1} / D_{T 2}=t_{T 2} / t_{T 1}
$$

where:

$$
\begin{aligned}
\mathrm{t} & =\text { time of exposure, (days) } \\
\mathrm{D}_{\mathrm{T}} & =\text { diffusion constant at temperature } \mathrm{T} .
\end{aligned}
$$

Figure 3-1. $L n(C)$ versus time (a), $D_{T}$ versus $1 / T(\mathrm{~b})$.

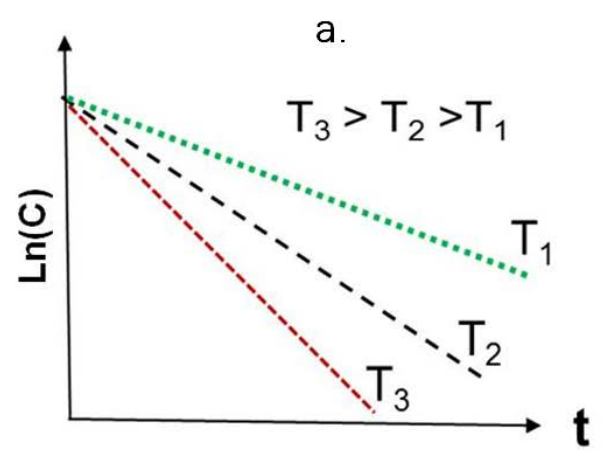

Slopes of each line are $-D_{T 1}$, $-D_{T 2}$, and $-D_{T 3}$, respectively b.

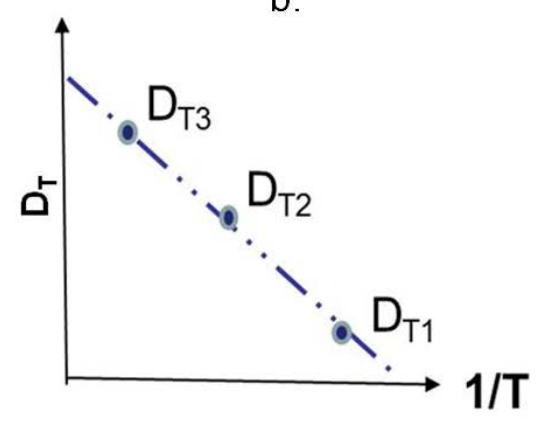

Slope $=-E_{A} / N_{A} K$

In addition, Equations 3-3 and 3-4 taken together indicate that, if $\mathrm{C} \mathrm{re}-$ mains constant so that $\mathrm{C}\left(\mathrm{t}_{1}, \mathrm{~T}_{1}\right)=\mathrm{C}\left(\mathrm{t}_{2}, \mathrm{~T} 2\right)$, then time $(\mathrm{t})$ is a function of 
inverse temperature $(1 / T)$. Also, if $t_{1}>t_{2}$ and $C\left(t_{1}, T_{1}\right)=C\left(t_{2}, T_{2}\right)$, then $T_{2}>$ $\mathrm{T}_{1}$, and these equations provide a way of calibrating the effects of natural aging for a long time ( $\left.\mathrm{t}_{1}\right)$ at ambient temperature $\left(\mathrm{T}_{1}\right)$ to the effects of short-time $\left(\mathrm{t}_{2}\right)$ accelerated aging at a higher temperature $\left(\mathrm{T}_{2}\right)$. Finally, Equation 3-1 and 3-2 taken together indicate that:

$$
R_{t}=R_{f}+\left(R_{0}-R_{f}\right)(C)
$$

where:

$$
\begin{aligned}
C & =1 \text { for new material } \\
C & =0 \text { for fully degraded material } \\
D_{T} & =\text { diffusion constant at temperature } T \\
R_{0} & =R \text {-value at time } t=0 \\
R_{t} & =\text { R-value at time " } t \text { " } \\
R_{f} & =\text { fully degraded R-value. }
\end{aligned}
$$

An alternative expression (Pielichowski et al. 2000), used by McManus and Cunningham (1997) is given for the degradation rate $\left(\mathrm{D}_{\mathrm{T}}\right)$ of materials properties (as a function of time) under these conditions as:

$$
D_{T}=k M(C)^{n} \exp \left[-\left(E_{A} / N_{A} K T\right)\right]
$$

where:

$$
\begin{aligned}
C & =1 \text { for new material } \\
C & =0 \text { for fully degraded material } \\
M & =\text { moisture content, dimensionless } \\
M & =0 \text { when the material is dry, dimensionless } \\
M & =1 \text { when the material is fully saturated } \\
E_{A} & =\text { activation energy, (from empirical data fit) } \\
K & =\text { rate parameter, (to be fitted from test data) } \\
N & =\text { exponent from empirical data fit } \\
T & =\text { temperature, }(K) .
\end{aligned}
$$

Thus, the rate of $\mathrm{R}$-value degradation can be predicted from $\mathrm{D}_{\mathrm{T}}$.

In either case mentioned above, it is expected that the TTS results will show that short exposure degradation of R-values at an elevated temperature is equivalent to long-term degradation at lower temperatures. Also, Rvalue degradation is expected to increase faster at higher moisture concentrations (Figure 3-2). 
Figure 3-2. Conceptual TTS plots. In plot at left for moisture concentration M1, equivalent Rvalues at high temperatures occur at earlier times than R-values at lower temperatures. In right plot for moisture concentration M2 (where M2> M1), equivalent R-values occur at earlier times for a given temperature than in M1 plot on left (Stephenson et al. 2013).

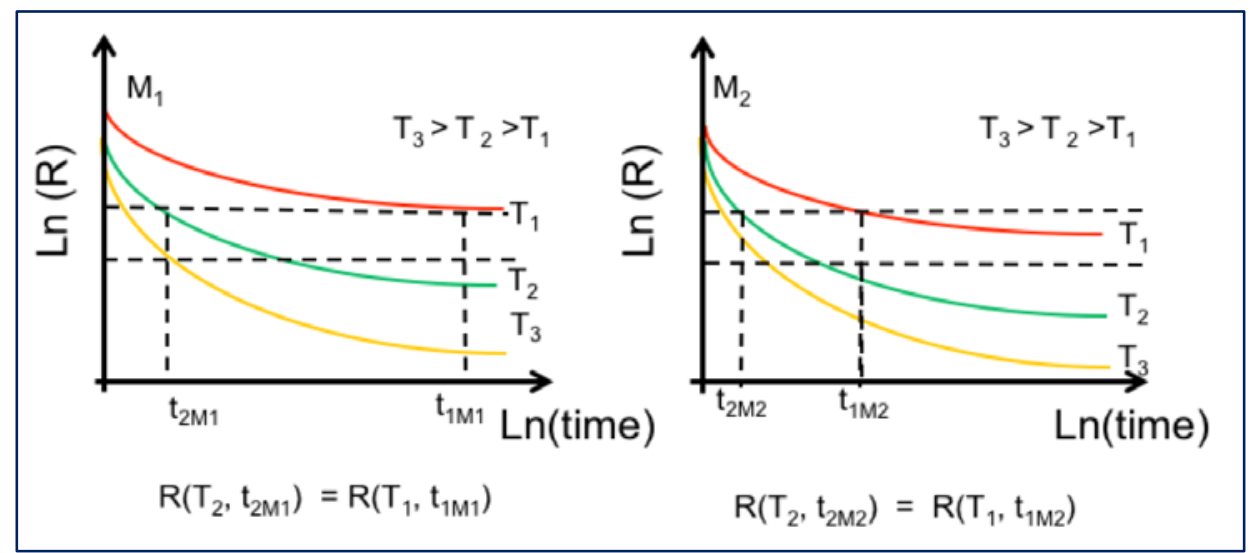

\subsection{Environmental chamber and heat flow meter apparatus}

All samples were placed in the (Cincinnati Sub-Zero Product. Inc., Cincinnati, $\mathrm{OH}$ ) sub-zero environmental chamber (Figure 3-3), where simulated accelerated aging experiments was conducted. This instrument is designed to provide an environment with specific temperature and humidity conditions. In addition, it is designed to operate in a temperature range of - 100 to $375^{\circ} \mathrm{F}\left(-73\right.$ to $\left.190^{\circ} \mathrm{C}\right)$ and in controlled humidity rang of 10 to $98 \% \mathrm{RH}$.

In this research, a Laser Comp FOX801 (LaserComp, Inc., Saugus, MA) HFMA (Figure 3-4) was used to measure the apparent thermal conductivity of selected insulation materials as specified in ASTM C518 (ASTM 2000). The HFMA is designed to measure the steady-state heat flow, and thus provides accurate results.

\subsection{Sample preparation}

\subsubsection{General sample preparation}

The dimensions of all insulation samples were $30 \times 30$ in. with various thicknesses. Baseline R-value measurements for each sample were conducted by using the HFMA (Figure 3-4). All samples were placed in the Sub-zero environmental chamber (Figure 3-3 [right]), subject to 5 weeks testing, and exposed to temperature of $150{ }^{\circ} \mathrm{F}\left(66^{\circ} \mathrm{C}\right)$ at $90 \% \mathrm{RH}$ (relative humidity). All samples were removed at 1 week interval and R-value of each sample was measured by HFMA. Three replicates of each insulation samples were tested. 
Figure 3-3. Cincinnati Sub-Zero Environmental chamber with capabilities to provide controlled temperature and humidity environment for testing insulation samples. Left: outside closed chamber, Right: inside chamber showing sample racks.

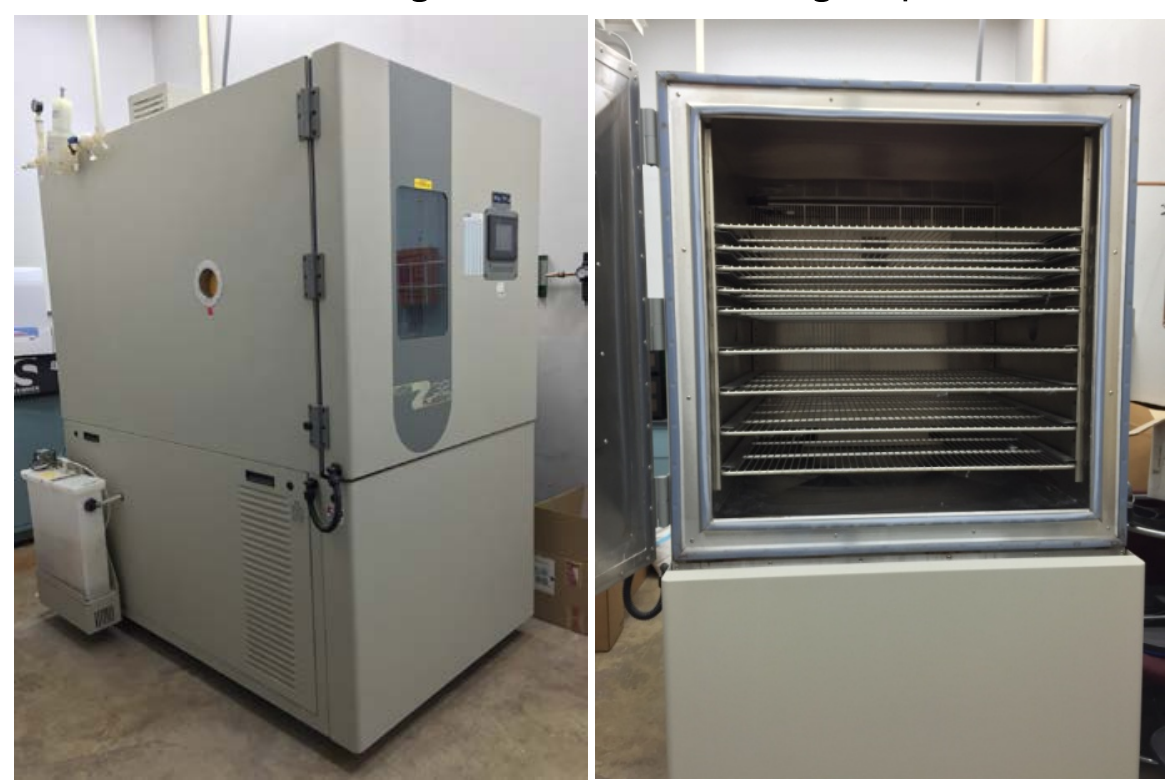

Figure 3-4. Laser Comp 801 HFMA for measuring thermal conductivity and determining Rvalues of insulation (Left: outside closed HFMA, Right: Inside of HFMA).
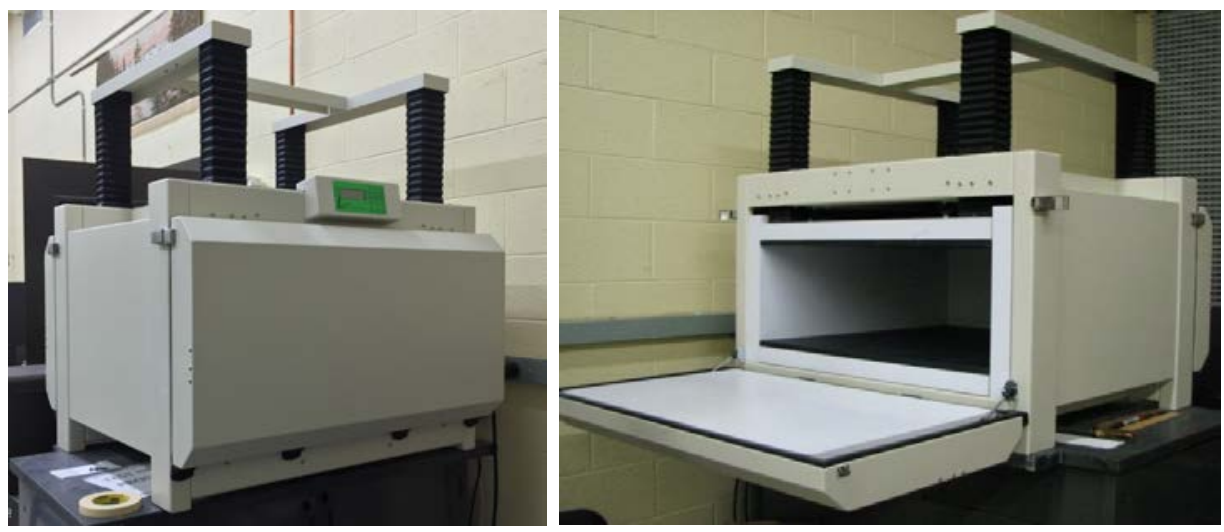

\subsubsection{Special preparation of ccSPF sample}

The initial experimental design was to conduct simulation experiments at $180^{\circ} \mathrm{F}\left(82^{\circ} \mathrm{C}\right)$ in the environmental chamber. However, the free-standing closed cell spray polyurethane foam (cCSPF) warped badly, which prevented getting accurate measurement of R-value of this sample. In addition, the extruded polysterene (XPS) sample expanded, which prevented testing in the HFMA. As a result, the subsequent chamber temperature was set at $150{ }^{\circ} \mathrm{F}\left(66^{\circ} \mathrm{C}\right)$ at $90 \% \mathrm{RH}$ for following experiments.

The ccSPF sample still has the same problem after sample exposed to $150{ }^{\circ} \mathrm{F}\left(66^{\circ} \mathrm{C}\right)$ at $90 \% \mathrm{RH}$ for 2 weeks. It was also difficult to test wrapped 
sample in HFMA. Typically ccSPF is spray onto the wood surface. To make this simulating experiment more representative of actual application of ccSPF and to solve the warping problem, the ccSPF was sprayed onto $30 \mathrm{x}$ 30 in. sections of 0.75 in. thick marine grade plywood. Plywood samples without ccSPF spray were also placed in the environmental chamber and were subjected to the same experimental conditions. The R-value for plywood only sample was measured and then was subtracted from plywoodccSPF samples.

The plywood itself is affected by moisture, which contributes to the overall degradation of the cCSPF/ plywood combination. To distinguish between the effects of cCSPF and plywood, blank samples of plywood were exposed and measured at the same conditions and time intervals. Treating this as a thermal circuit model with the two components in series (Mills 1999), the plywood effects can be mathematically removed using the relationship:

$$
\rho_{f}=\Delta T\left(\frac{1}{q_{c}}-\frac{1}{q_{w}}\right) / t_{f}=\frac{1}{k_{f}}
$$

where:

$$
\begin{aligned}
\rho_{\mathrm{f}} & =\text { the thermal resistivity of the foam (R-value per in) } \\
\Delta \mathrm{T} & =\text { the temperature difference across the HFMA plates } \\
\mathrm{q}_{\mathrm{c}} & =\text { the heat flux through the PUR/ plywood composite } \\
\mathrm{q}_{\mathrm{w}} & =\text { the heat flux through plywood alone } \\
\mathrm{t}_{\mathrm{f}} & =\text { the thickness of the foam } \\
\mathrm{k}_{\mathrm{f}} & =\text { the thermal conductivity of the foam. }
\end{aligned}
$$

To verify the validity of this approach, measurements were taken on a sample of combined ccSPF and plywood (post-environmental chamber) followed by the separation and individual measurements of the two components.

\subsubsection{Special concern about aerogel blanket}

It was observed that aerogel samples released fine particles of silica dust during the measurement of R-value using HFMA. To eliminate wrong measurement of thermal conductivity due to improper handling of samples, six original aerogel samples were placed in and removed from the HFMA multiple times. The thermal conductivities of these samples were measured for each placement/ removal. The results indicated that the handling was not a factor that contributed to the changes of $\mathrm{R}$-value. 


\subsubsection{Additional experiments design}

Based on the initial testing condition, expose to $150{ }^{\circ} \mathrm{F}\left(66^{\circ} \mathrm{C}\right)$ at $90 \% \mathrm{RH}$, multiple simulating conditions were applied to three versions of aerogel blanket insulations (labeled AA, AB, and AC, respectively), two types of extruded polystyrene foam (labeled XPA and XPB, respectively), and one type of closed cell spray polyurethane foam. Samples tested were square, measuring $30 \mathrm{in}$. along each width (for best fit in equipment), and thicknesses were as commercially available. In some cases, a sample consisted of two pieces totaling 30 in. square. Each type of insulation was subjected to tests at multiple environmental conditions. For each environmental condition and each type of insulation, at least three samples were evaluated, except where noted. Aerogels were exposed at $150{ }^{\circ} \mathrm{F}\left(66^{\circ} \mathrm{C}\right)$ at $90 \%$ $\mathrm{RH}, 150^{\circ} \mathrm{F}\left(66^{\circ} \mathrm{C}\right)$ at $30 \% \mathrm{RH}$, and $90^{\circ} \mathrm{F}\left(32^{\circ} \mathrm{C}\right)$ at $90 \% \mathrm{RH}$. Polyurethane foams were exposed at $150{ }^{\circ} \mathrm{F}\left(66^{\circ} \mathrm{C}\right)$ and $90 \% \mathrm{RH}, 150^{\circ} \mathrm{F}$ and $30 \%$ $\mathrm{RH}$ and an individual sample at $150^{\circ} \mathrm{F}\left(66^{\circ} \mathrm{C}\right)$ at $60 \% \mathrm{RH}$. One Sample of each type of polystyrene foam was exposed at $150{ }^{\circ} \mathrm{F}\left(66^{\circ} \mathrm{C}\right)$ at $90 \% \mathrm{RH}$, and one of each at $150{ }^{\circ} \mathrm{F}\left(66^{\circ} \mathrm{C}\right)$ at $60 \% \mathrm{RH}$. Samples were placed in the chamber at time zero and removed at 1-week intervals to take measurements. Samples were kept in the environmental chamber through 5 weeks.

In addition, $3 \mathrm{M}^{\mathrm{TM}}$ Thinsulate ${ }^{\mathrm{TM}}$ and Tyvek $^{\circledR}$ ThermalWrap ${ }^{\circledR} 5.0$ (labeled as $\mathrm{TH}$ and TW, respectively) samples were exposed at $150{ }^{\circ} \mathrm{F}\left(66^{\circ} \mathrm{C}\right)$ at $30 \%$ RH. DuPont ${ }^{\mathrm{TM}}$ Tyvek $^{\circledR}$ ThermaWrapl $^{\mathrm{TM}}$ R5.0 is comprised of a thin layer of polyethylene nonwoven fabric attached to polyester/ polyethylene fiber batt. The total thickness of the insulating building wrap is $1.5 \mathrm{in}$. This material is designed to help block air infiltration and provide exterior insulation, thereby improving energy efficiency and supporting sustainable construction (DuPont ${ }^{\mathrm{TM}}$ 2015).

\subsubsection{Measurement of moisture}

Measurement of moisture content was implicitly estimated by comparing mass measurements to the pre-environmental chamber mass of the same sample. Mass was measured on removal from the chamber and on completion of thermal measurements in the HFMA. Moisture content was calculated as the difference between the baseline mass and the average of the mass on removal from the environmental chamber and the mass before replacement in the chamber. 


\section{Mechanism of Degradation}

\subsection{Physical changes}

Under the $150{ }^{\circ} \mathrm{F}\left(66^{\circ} \mathrm{C}\right)$ at $90 \% \mathrm{RH}$ experimental conditions, no significant physical changes were observed in XPS and fiberglass batt samples. The physical changes were observed in aerogel samples (Figure 4-1). The aerogel dust formed small crystals on the surface of samples. No significant physical changes were observed in other two environmental conditions $\left(150^{\circ} \mathrm{F}\left[66^{\circ} \mathrm{C}\right]\right.$ at $30 \% \mathrm{RH}$ and $90^{\circ} \mathrm{F}\left[32^{\circ} \mathrm{C}\right]$ at $\left.90 \% \mathrm{RH}\right)$.

However, the polyurethane materials showed significant physical changes in all three environmental conditions (Figure 4-2[a, b, c]). The ccSPF sample became darker, changing from light yellow to dark yellow, and deformed after exposure in a degradation-simulating experiment (Figure 4$2[c]$ ). Mild discoloration also occurred during storage. Various volume expansions occurred (Figure 4-2). More extreme expansion occurred during the higher humidity conditions. Blistering occurred in the $150^{\circ} \mathrm{F}\left(66^{\circ} \mathrm{C}\right)$ at $90 \% \mathrm{RH}$ conditions. Expansion and blistering typically occurred within the first week of exposure. Some samples expanded (in length and width, as well as thickness) enough so that the material had to be trimmed to fit in the HFMA for measurements. In those cases, the mass of the trimmed material was measured and taken into account. The sample shown in Figure 4-3(b) was so extreme that no conductivity measurements could be taken beyond the baseline values. Note that samples stored (in the laboratory environment) for longer periods of time before exposure in the environmental chamber were more prone to blistering and expansion.

Figure 4-1. Observed physical changed in aerogel sample. Clusters of aerogel dust are circled.

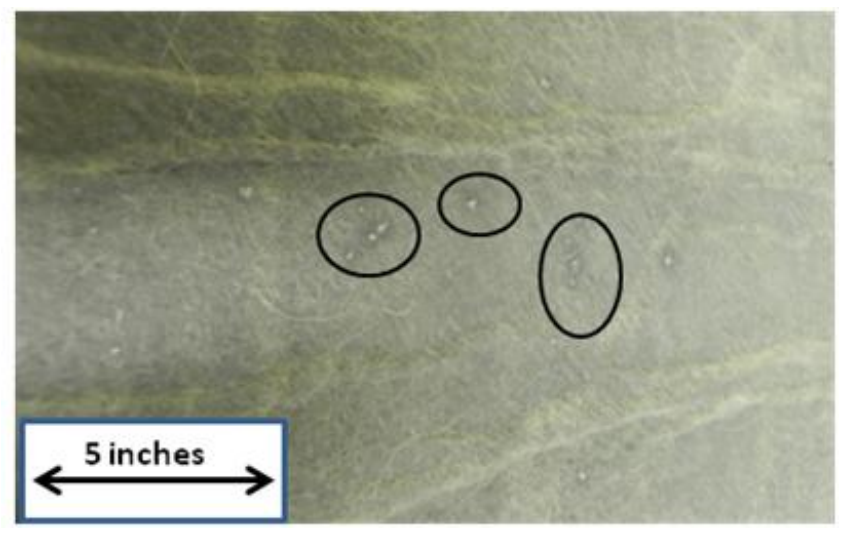


Figure 4-2. ccSPF composite samples exposed at (a) left: sample expose to $150{ }^{\circ} \mathrm{F}\left(66^{\circ} \mathrm{C}\right)$ at $30 \% \mathrm{RH}$; right: sample without exposure, (b) sample expose to $150^{\circ} \mathrm{F}\left(66^{\circ} \mathrm{C}\right)$ at $60 \% \mathrm{RH}$, and (c) bottom sample: exposed to $150^{\circ} \mathrm{F}\left(66^{\circ} \mathrm{C}\right)$ at $90 \% \mathrm{RH}$; top sample: unexposed, and is lighter in color.

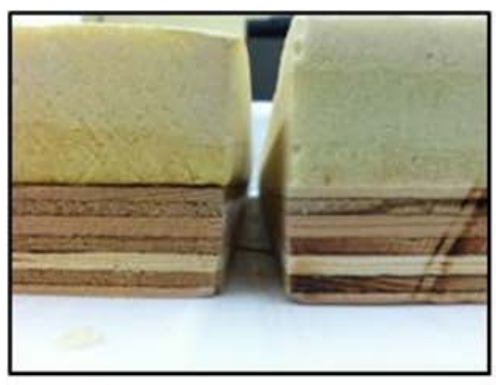

(a)

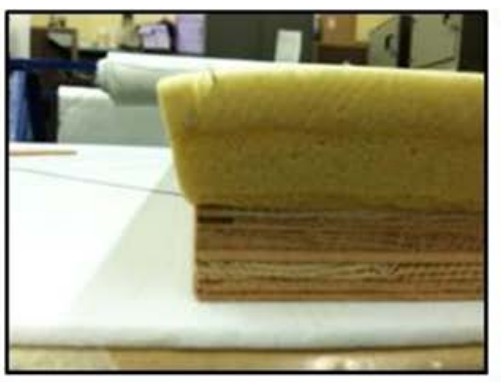

(b)

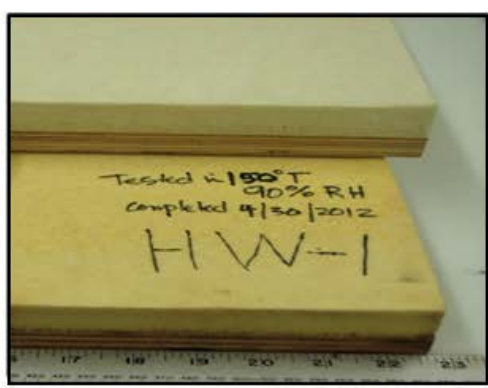

(c)

Figure 4-3. Blistering occurs on ccSPF samples: (a) typical blistering shown on edges of ccSPF sample, (b) severe blistering shown on top of ccSPF sample.

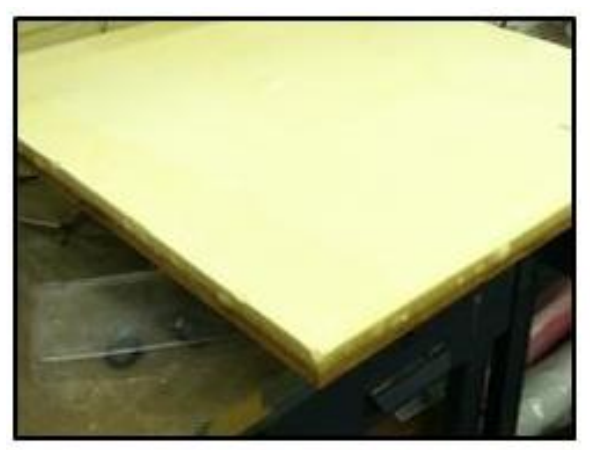

(a)

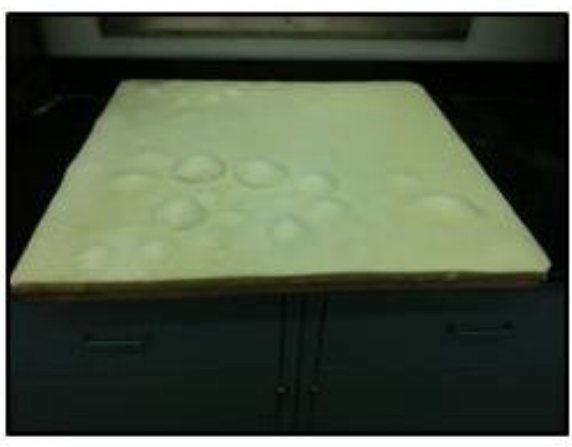

(b)

\subsection{Thermal performance}

\subsubsection{Under $150{ }^{\circ} \mathrm{F}\left(66^{\circ} \mathrm{C}\right)$ at $90 \%$ RH simulating condition}

Figure 4-4 shows the R-values (in R/ in.) for the five types of insulation as a function of time. Since the R-value is the inverse of the thermal conductivity of the sample, the same degradation trends seen in the thermal conductivity of the samples are also seen in the degradation of the R-value of the samples. After 4 weeks of exposure in the chamber, the R-value of Thinsulate ${ }^{\circledR}$ degraded by less than $1 \%$, while the R-value of the polystyrene and the standard fiberglass insulations degraded by less than $3 \%$, and there was not much change between the 1 - and the 4 -week samples. The Rvalue of the aerogel blanket and the polyurethane insulations degraded by roughly 7 and $17 \%$, respectively. The aerogel blanket insulation degraded an additional $8 \%$ between 1 and 4 weeks, while the polyurethane insulation degraded an additional $10.5 \%$ between 1 and 4 weeks. 
These initial testing results indicate that two of the insulation materials (viz., aerogel blankets and polyurethanes) decrease in R-value over time as they are exposed to elevated temperatures and moisture. It was not clear from these early experiments which parameter was more important. However, in follow-up experiments, R-values were further evaluated by exposure to selected temperature and humidity conditions to determine the mechanisms of degradation, and to parse out the individual contributions of moisture and temperature to the degradation.

The plotted data (Figure 4-4) tend to indicate that, although the aerogel blankets and polystyrene samples insulation properties have degraded, by $15 \%$ for the former and $27.5 \%$ for the latter after month of exposure at elevated temperatures and elevated humidity levels, the loss of R-value seems to approach a limit in both cases. The mathematical description of the Rvalues plots over time in each case appears to be consistent with an exponential decay law consistent with an Arrhenius mechanism.

It may seem surprising that the aerogel blanket samples, combined silica aerogels in a matrix of polyethylene terephthalate (PETE), were degraded by the temperature moisture exposure over time, since the aerogels are only silica and air. It is likely that the PETE binder phase degrades and causes a reduction in $\mathrm{R}$-value. It is also possible that alternate binder materials will render aerogel insulation blankets that do not degrade in R-value, as do these samples, with the polyester binder. It is likely that the polymeric binder phase, in this case polyester, degrades and causes a reduction in Rvalue. It is also possible alternate binder materials will render aerogel insulation blankets that do not degrade in R-value, as do these samples, with the polyester binder.

Aerogel tests results above (in Figure 4-4) are from the supplier designated "AA." Additional samples of aerogel blankets were tested from other suppliers, and are designated "AB" and "AC" respectively. Figures 4-9 through 4-11 show the results of these tests, which are discussed later. 
Figure 4-4. R-value vs. Time HFMA results of five insulation materials exposed to accelerated testing at $150^{\circ} \mathrm{F}\left(66^{\circ} \mathrm{C}\right)$ at $90 \% \mathrm{RH}$ for up to 35 days.

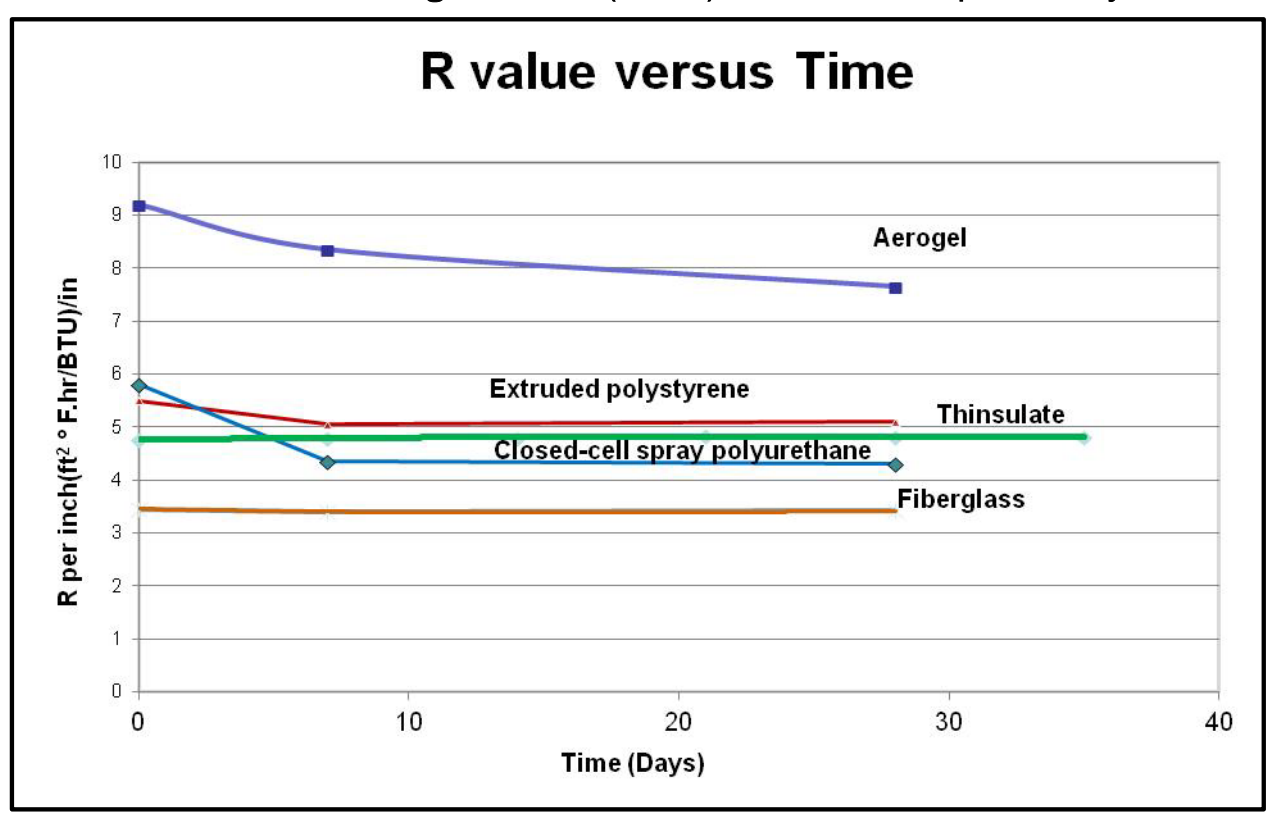

These results have laid the foundation for further experiments to simulate long-term aging. For the present case, under very high humidity conditions ( $\mathrm{RH} \sim 90 \%$ ), an analysis of these data indicates that: (1) for aerogel blankets with polyester binder, $\mathrm{R}_{0}=9.2, \mathrm{R}_{\mathrm{f}}=7.5, \mathrm{E}_{\mathrm{A}}=177 \mathrm{~J} / \mathrm{mole}$, and (2) for closed cell polyurethane foam, $R_{0}=5.8, R_{f}=4, E_{A}=221 \mathrm{~J} / \mathrm{mole}$. Further experiments will be necessary to calibrate the equations that use a materials degradation analysis called "TTS Theory" as mentioned early in this chapter.

\subsubsection{Nonwoven composite insulation liner (3M $\mathrm{M}^{\mathrm{TM}}$ Thinsulate $\left.^{\mathrm{TM}}\right)$ results}

Both Thinsulate $^{\mathrm{TM}}$ and ThermalWrap ${ }^{\mathrm{TM}}$ R5.0 samples (labeled as TH and $\mathrm{TM}$, respectively) experienced less than $1 \%$ changes in $\mathrm{R}$-values by the end of 5 weeks of exposure at $150{ }^{\circ} \mathrm{F}\left(66^{\circ} \mathrm{C}\right)$ at $90 \% \mathrm{RH}$ and at $150{ }^{\circ} \mathrm{F}\left(66^{\circ} \mathrm{C}\right)$ at 30\% RH (Figures 4-5 [top] and 4-6 [top]). The mass changes in both materials were not significant, but did indicate a very slight release of moisture (Figures 4-5 [bottom] and 4-6 [bottom]).

These results indicated that thermal conductivity of Thinsulate ${ }^{\mathrm{TM}}$ change very little when samples expose to extreme environmental conditions. In addition, the thermal performances of this material are similar to the ThermalWrap $^{\mathrm{TM}}$ R5.0. Furthermore, Thinsulate ${ }^{\mathrm{TM}}$ does not absorb water at the extreme conditions. 
Figure 4-5. R-values and moisture concentration versus time for Thinsulate ${ }^{\mathrm{TM}}$

(TH) samples exposed to $150^{\circ} \mathrm{F}\left(66^{\circ} \mathrm{C}\right)$ and two different humidity

conditions: Top: $\mathrm{R} / \mathrm{in}$. versus time; Bottom: moisture versus time.

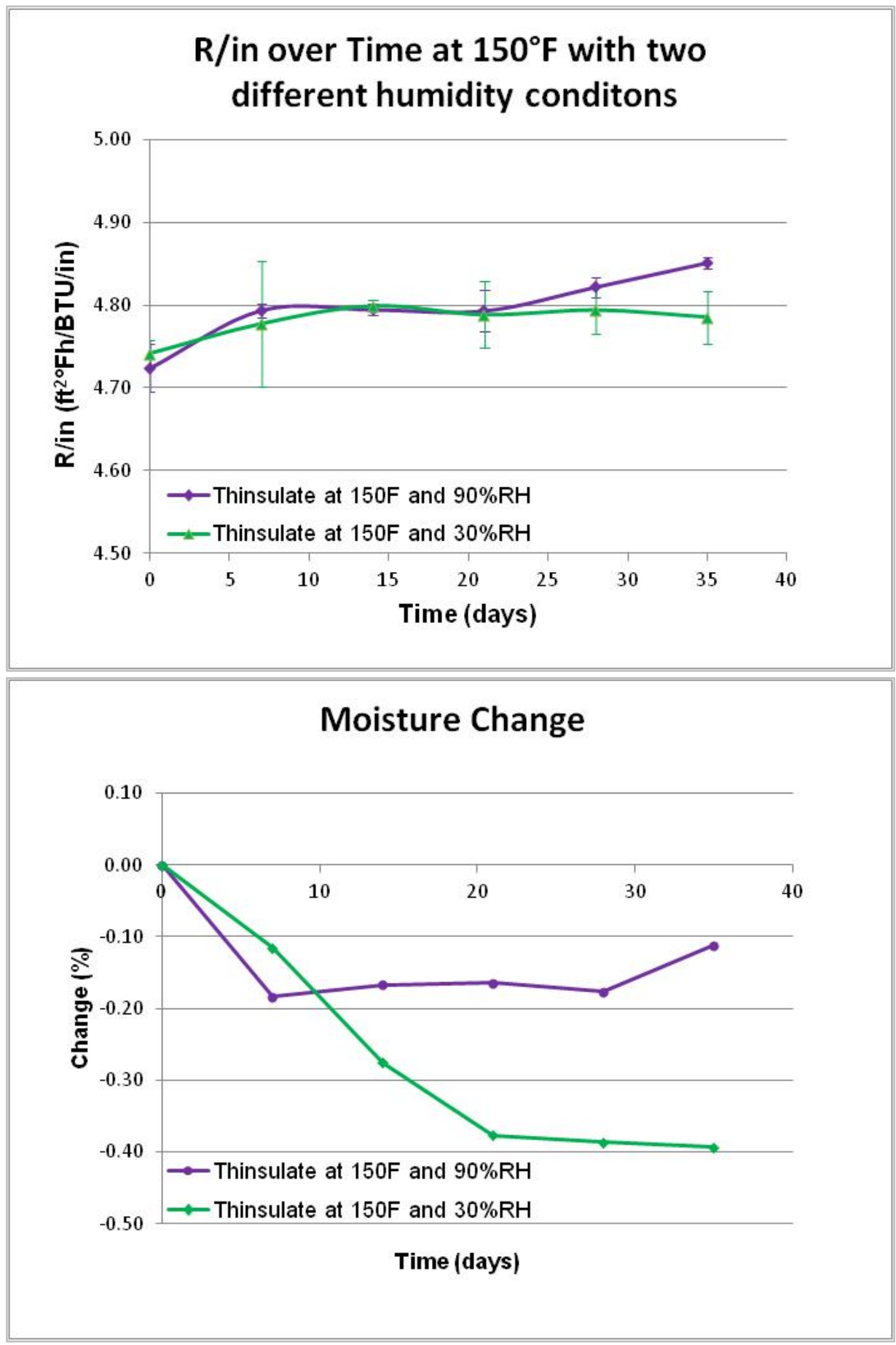


Figure 4-6. R-values and moisture concentration versus time for ThermalWrap ${ }^{\mathrm{TM}}$ (TW) samples exposed to $150^{\circ} \mathrm{F}\left(66^{\circ} \mathrm{C}\right)$ at two different humidity conditions: Top: $\mathrm{R} / \mathrm{in}$. versus time; Bottom: moisture changes versus time.

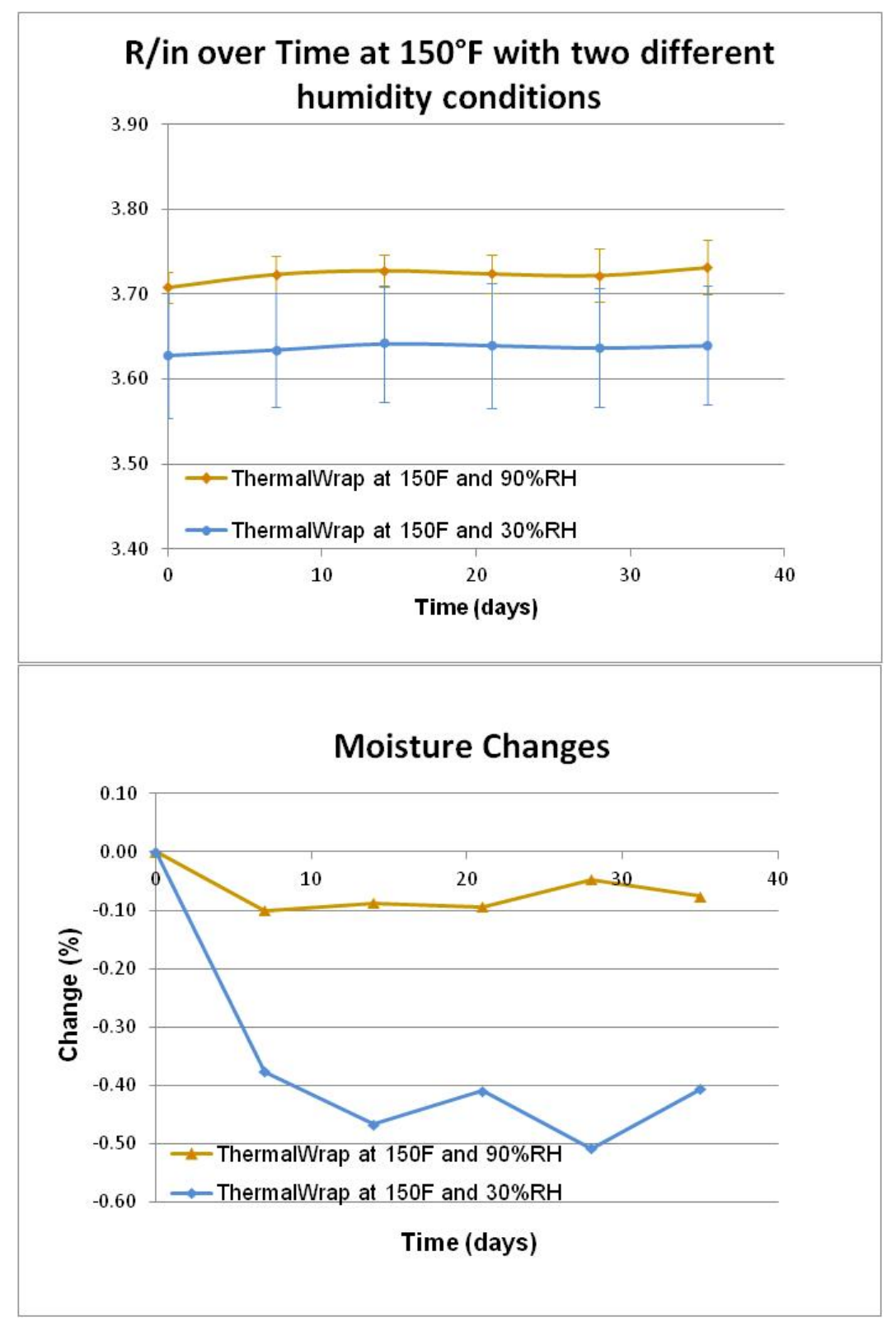

\subsubsection{Follow-up simulation tests on polystyrene (XPS)}

Both types of XPS materials (viz. XPA and XPB) experienced less than 1\% change in thermal conductivity by the end of 5 weeks of exposure at $150{ }^{\circ} \mathrm{F}$ $\left(66^{\circ} \mathrm{C}\right.$ ) at $90 \% \mathrm{RH}$, which is insignificant compared to the relative error inherent in the HFMA measurements. Both types showed small decreases in mass during that time. The XPB had a $0.4 \%$ decrease in conductivity with a $1.4 \%$ loss in mass and XPA had a $1 \%$ decrease in conductivity with a $0.5 \%$ loss in mass (Figure $4-7)$. At $150^{\circ} \mathrm{F}\left(66^{\circ} \mathrm{C}\right)$ at $60 \% \mathrm{RH}$ simulated 
condition, both types of XPS again experienced little change in thermal conductivity. At the end of 5 weeks, XPA had a $2 \%$ decrease in conductivity with a $0.7 \%$ loss in mass and XPB had a $0.6 \%$ decrease in conductivity with a $0.5 \%$ loss in mass. Due to limited space in the environmental chamber and also to the fact that very little change occurred under the more extreme conditions, it was determined not to conduct further testing of XPS at the milder environmental conditions.

Figure 4-7. Thermal conductivity and mass change in both types of XPS samples: (a) samples expose at $150^{\circ} \mathrm{F}\left(66^{\circ} \mathrm{C}\right)$ at $90 \% \mathrm{RH}$, (b) samples expose at $150{ }^{\circ} \mathrm{F}\left(66^{\circ} \mathrm{C}\right)$ at $60 \% \mathrm{RH}$.
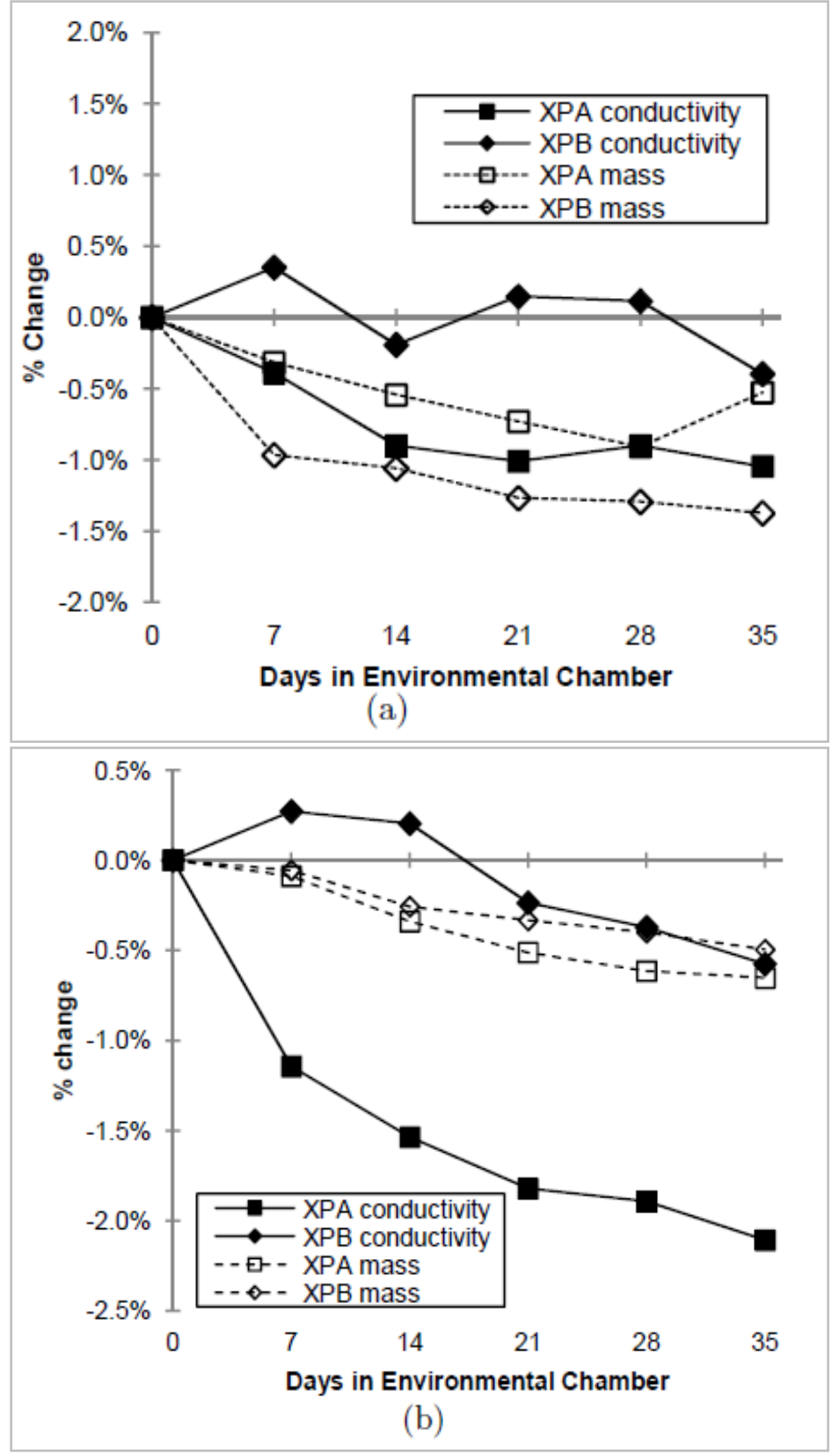


\subsubsection{Follow-up aging simulation tests on closed cell spray polyurethane foam (ccSPF)}

All ccSPF (or PUR) samples were received at the same time and stored until baseline measurements were individually taken before aging tests. The effects of accelerated aging some samples at $150{ }^{\circ} \mathrm{F}\left(66^{\circ} \mathrm{C}\right)$ and other samples at $90 \% \mathrm{RH}$ and at $150{ }^{\circ} \mathrm{F}\left(66^{\circ} \mathrm{C}\right)$ at $30 \% \mathrm{RH}$ were compared with natural aging in the ambient. Both samples, after being subjected to accelerated aging were then allowed to age naturally under ambient conditions for several months and measured again. The high humidity (90\% RH) samples showed some amount of resistivity recovery, while the low humidity $(30 \% \mathrm{RH})$ samples continued to degrade. The low humidity samples initially increased slightly in resistivity during exposure, after which it proceeded to degrade. On the other hand, the resistivity of the high humidity samples initially decreased significantly during exposure, and then recovered somewhat after removal of samples from the environmental chamber.

The ccSPF samples consistently degraded when samples exposed at $150^{\circ} \mathrm{F}$ $\left(66^{\circ} \mathrm{C}\right)$ at $90 \% \mathrm{RH}$ conditions. By the end of 5 weeks of exposure, samples suffered nearly $10 \%$ loss in resistivity (Figure 4-8). Samples exposed at $150{ }^{\circ} \mathrm{F}\left(66^{\circ} \mathrm{C}\right)$ at $30 \% \mathrm{RH}$ condition showed an initial increase in resistivity of about $5 \%$ during the first week, and then decreased during the remaining 4 weeks. These results are further discussed in Section 4.4.

\subsubsection{Follow-up aging simulation tests on aerogel blankets}

As noted earlier, the aerogel samples tested were from three different manufacturers, and are designated AA, AB, and AC. Also, earlier supplies of the AA brand were noticeably darker than those tested in follow-up simulations (The manufacturer suggested that this was due to the presence of more graphite in the earlier samples, and this seems to have an effect on the degradation properties of the AA product). All three aerogels contain fibers made with PETE, which is known to be hygroscopic (J abarin and Lofgren 1986). Hydrolysis is a great factor in the deterioration of PETE and McMahon has studied the rate of hydrolysis as a function of temperature and RH (McMahon et al. 1959). However, in AB, the fibers are encompassed by the hydrophobic aerogel, so there would be little uptake in moisture. In $\mathrm{AC}$, since the fibers are more loosely nested with the aerogel particles, the possibility of hygroscopy and hydrolysis is greater, which could explain the significant expansion observed and decreased thermal performance. The AC aerogel showed the greatest variation in $\mathrm{R} /$ in. from 6.5 to 7.2. 
Figure 4-8. Resistivity of ccSPF samples (labeled as PUR): (a) resistivity change of two samples exposed at two different temperature and humidity, (b) percentage changes in resistivity of two samples exposed at two different temperature and humidity.

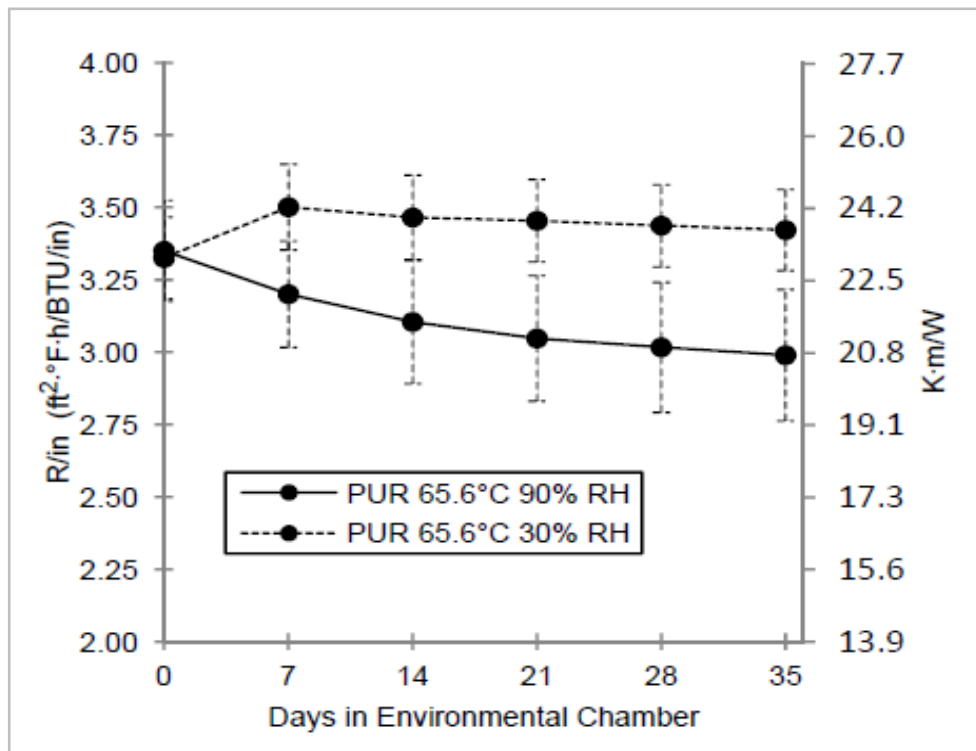

(a)

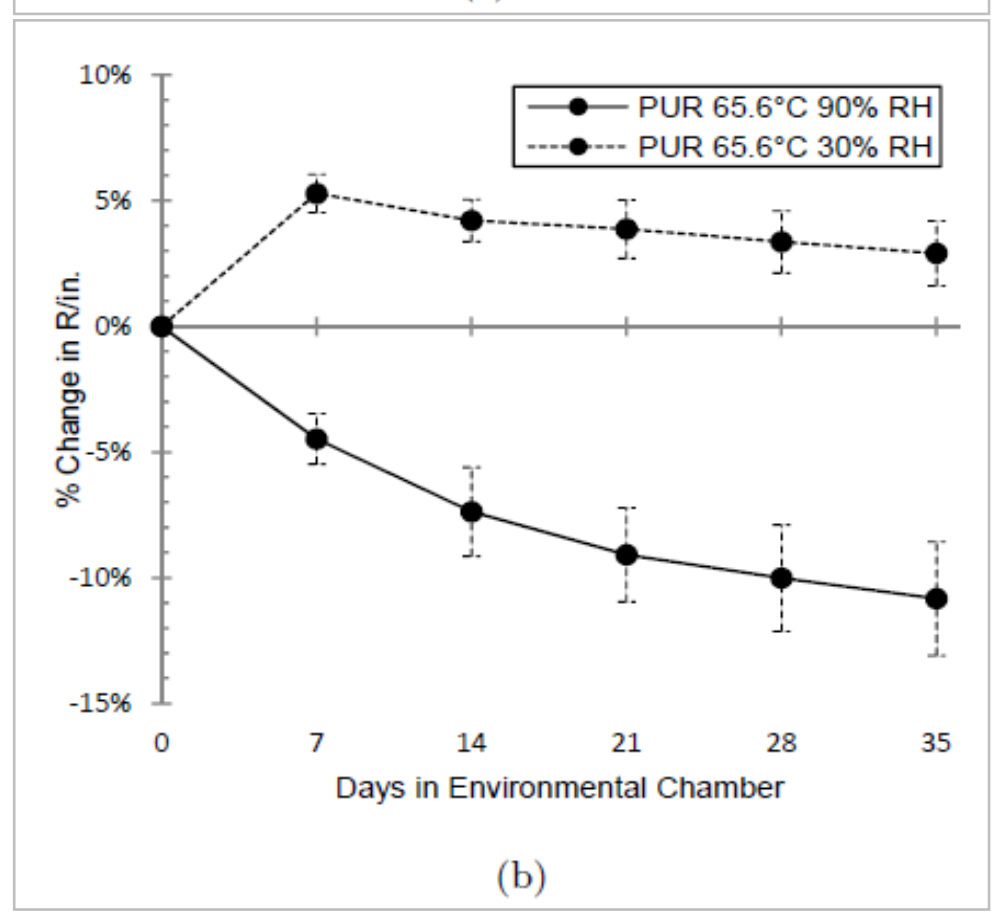

Figures 4-9, 4-10, and 4-11 show the results of accelerated aging exposure. Despite a lack of any noticeable chemical or physical change apparent in $\mathrm{AA}$ and $\mathrm{AB}$, these insulation materials tend to decrease in thermal performance when exposed to elevated temperature and humidity conditions. The greatest change occurs at $150^{\circ} \mathrm{F}\left(66^{\circ} \mathrm{C}\right)$ at $90 \% \mathrm{RH}$ followed by $90{ }^{\circ} \mathrm{F}$ $\left(32{ }^{\circ} \mathrm{C}\right)$ at $90 \% \mathrm{RH}$. Relatively little change occurs at $150^{\circ} \mathrm{F}\left(66^{\circ} \mathrm{C}\right)$ at 
$30 \% \mathrm{RH}$. Clearly the RH level plays a more important role than the temperature. This indicates that the primary cause of degradation of thermal performance is a diffusion of higher thermal conductivity air into the nanonporous aerogel structure. This is confirmed by HFMA measurements that were taken of a few samples several weeks after being placed back into ambient conditions. The aerogel samples that were removed from $150{ }^{\circ} \mathrm{F}\left(66^{\circ} \mathrm{C}\right)$ at $30 \% \mathrm{RH}$ tended to further degrade (ambient conditions were typically between $40-50 \% \mathrm{RH}$ ), while samples that were removed from $150{ }^{\circ} \mathrm{F}\left(66^{\circ} \mathrm{C}\right)$ at $90 \% \mathrm{RH}$ tended to recover slightly.

The apparent changes that occur in AC aerogels appear to be driven more by heat than humidity. Its physical expansion (e.g., increase in thickness) is evidence of some amount of moisture sorption into the fibers. The added heat likely increases the rate of hydrolysis and causes permanent change. There is an abrupt initial decrease in R-value; however, it does not experience significant change during the remaining aging. This may indicate that the change occurs initially, but then reaches some sort of equilibrium.

Note that $\mathrm{AC}$, similar to $\mathrm{AA}$ and $\mathrm{AB}$, should be affected by diffusion of air (which could cause the aerogel to have a higher thermal conductivity due to enhanced convection of entrained air). This may be more difficult to see because of the chemical change occurring and because the diffusion likely happens much quicker. By nesting aerogel particles inside the batting, rather than forming a monolith around them, significantly more aerogel surface is exposed to ambient air. This causes an increase in diffusion, allowing $\mathrm{AC}$ to reach equilibrium much quicker than $\mathrm{AA}$ and $\mathrm{AB}$. The samples of $\mathrm{AC}$ that were measured after several weeks back in ambient did not show a consistent pattern, which could indicate a much quicker diffusion processes.

AA aerogels samples tested in these follow-on aging simulations showed degradations in R-value of less than $5 \%$, which was a considerable improvement over the samples from the same manufacturer tested earlier. Aerogel samples from AB and AC suppliers also exhibited 5-6\% degradation in R-value. Even when subjected to the most extreme temperature/ $\mathrm{RH}$ conditions, the aerogels from manufacturer $\mathrm{AB}$ exhibited higher $\mathrm{R} / \mathrm{in}$. values than $\mathrm{AA}$ or $\mathrm{AC}$ under the most benign conditions. 
Figure 4-9. R-value versus time of aerogel samples AA: (a) R-value change of samples exposed at three different temperature and humidity, (b) percentage changes in Rvalue of samples exposed at three different temperature and humidity.

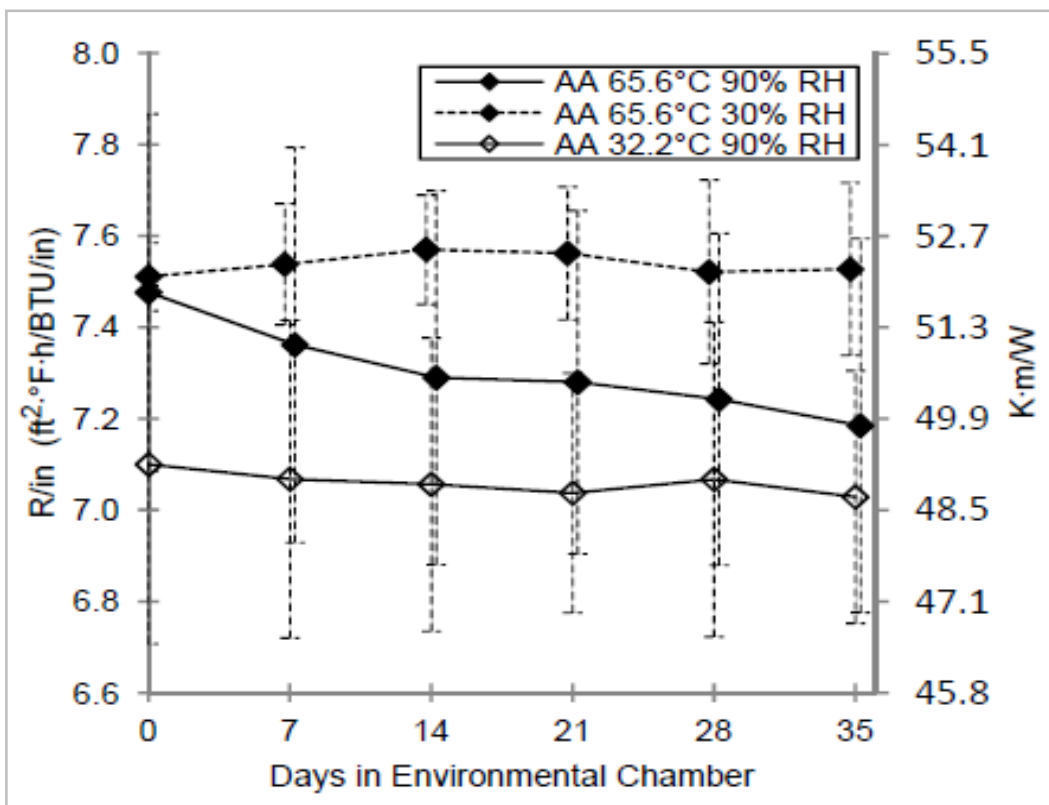

(a)

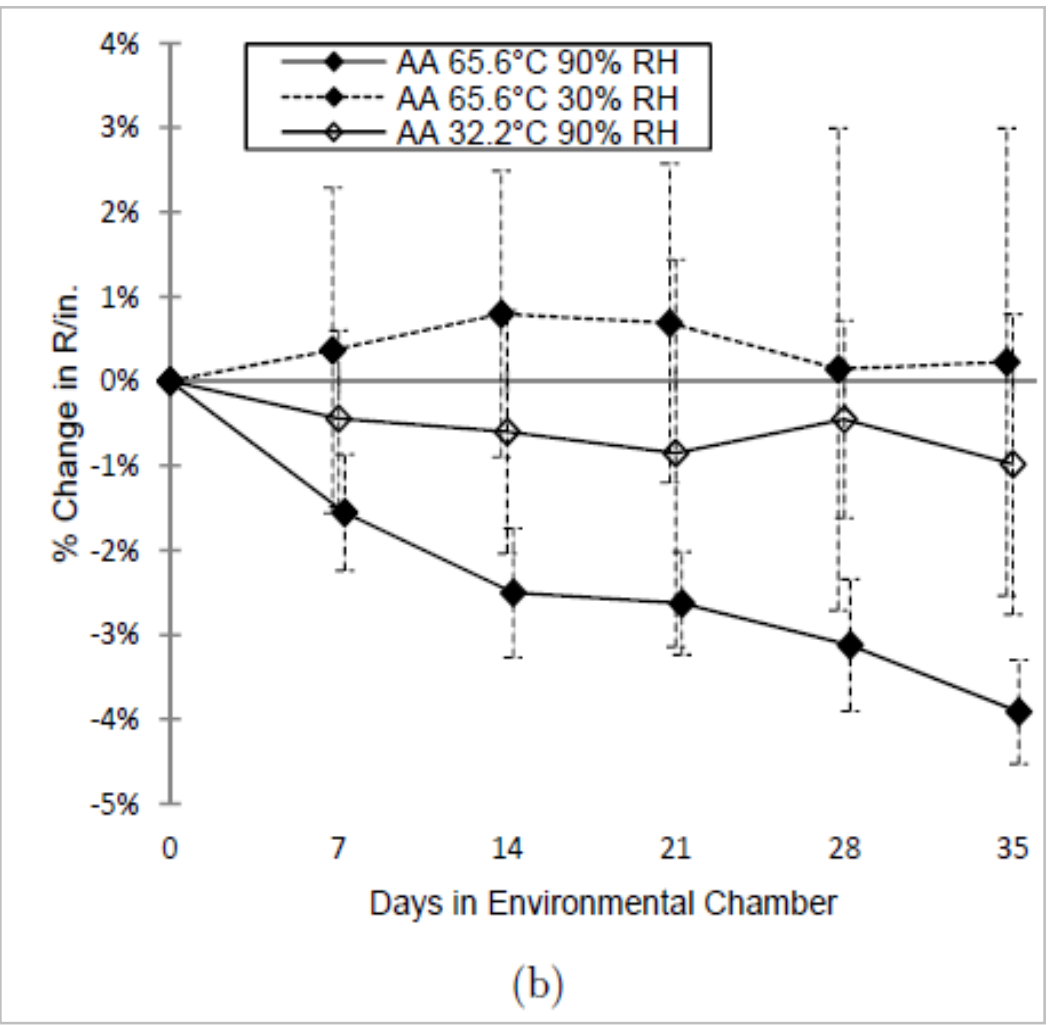


Figure 4-10. R-value versus time of aerogel samples AB: (a) R-value change of samples exposed at three different temperature and humidity, (b) percentage changes in R-value of samples exposed at three different temperature and humidity.

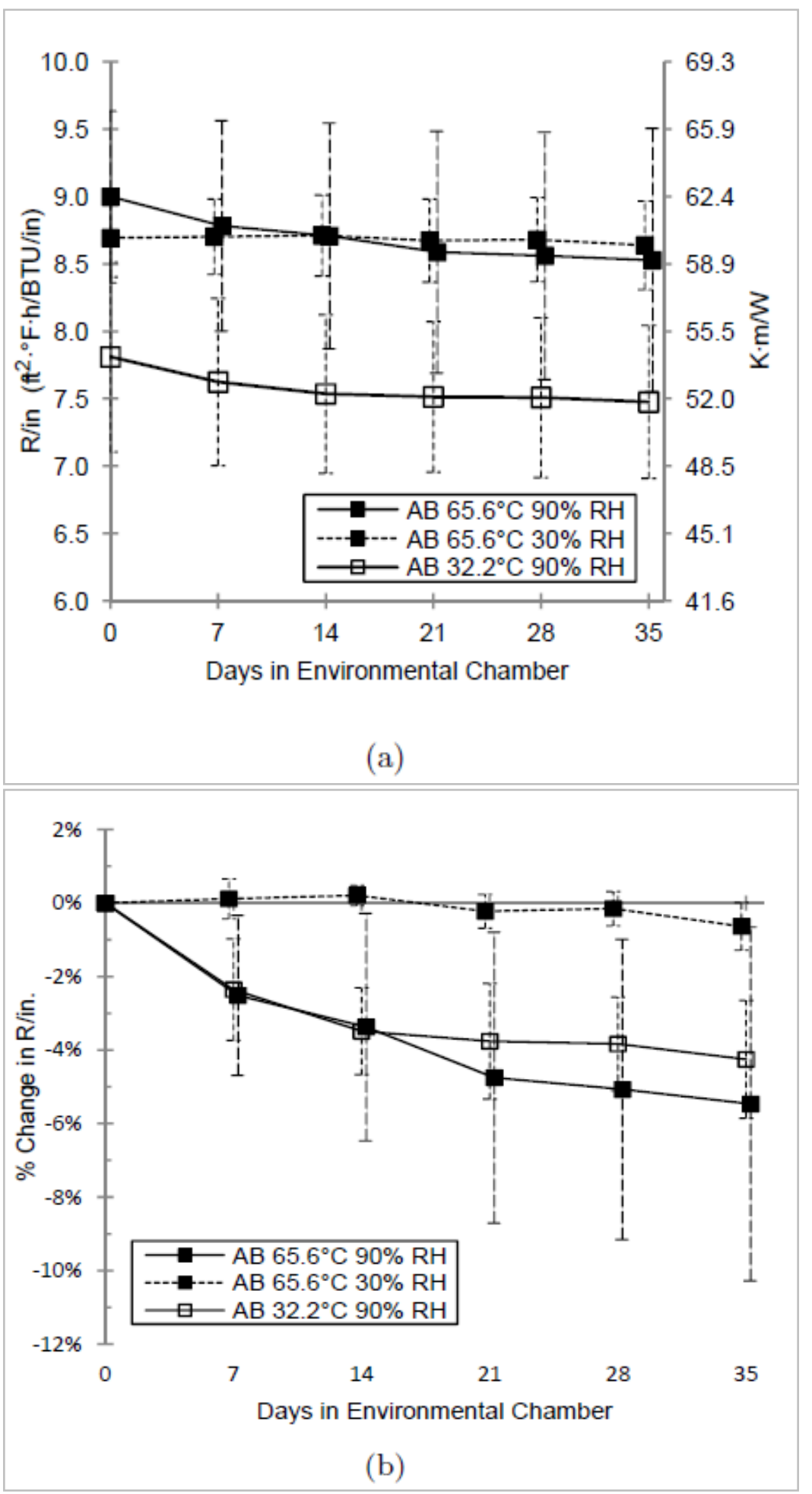


Figure 4-11. R-value versus time of aerogel samples AC: (a) R-value change of samples exposed at three different temperature and humidity, (b) percentage changes in R-value of samples exposed at three different temperature and humidity.

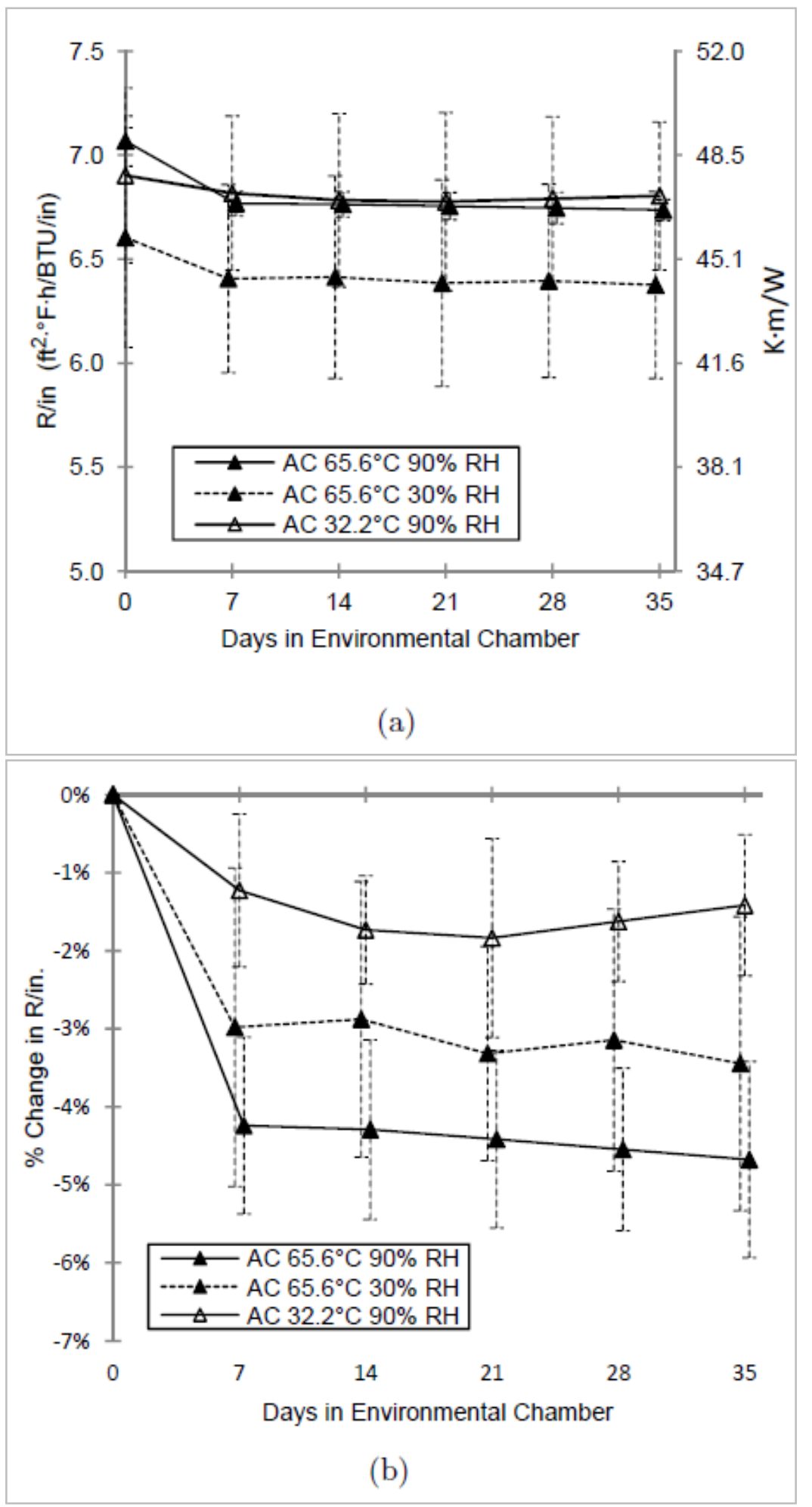




\subsection{Plywood thermal effects on plywood-ccSPF}

The thermal resistivity for the foam was compared with results from physically removing the foam from the plywood (Table 4-1). Further comparisons were made using calculations with several other samples of blank plywood, resulting in an average calculated resistivity of 4.13 $\mathrm{ft}^{2} \cdot{ }^{\circ} \mathrm{F} \cdot \mathrm{hr} / \mathrm{Btu} \cdot \mathrm{in} .(0.596 \mathrm{~K} \cdot \mathrm{m} / \mathrm{W})$, with a standard deviation of 0.09 $\mathrm{ft}^{2} \cdot{ }^{\circ} \mathrm{F} \cdot \mathrm{hr} / \mathrm{Btu} \cdot \mathrm{in} .(0.013 \mathrm{~K} \cdot \mathrm{m} / \mathrm{W})$. This approach appears to give good results for R-values of cCSPF; however, due to much greater variation in the mass of the plywood samples, the amount of individual moisture content could be mathematically estimated. Considering these results, data presented here represent samples of combined ccSPF and plywood. Note that all of the resistivity values of ccSPF itself are calculated to be approximately $40 \%$ higher than the combined ccSPF and plywood values.

Table 4-1. Calculated versus actual removal of plywood thermal effects from ccSPF/plywood composite.

\begin{tabular}{|l|c|c|}
\hline \multicolumn{1}{|c|}{ Material } & $\begin{array}{c}\text { R-value/in. calculations, } \\
\mathrm{ft}^{2}{ }^{\circ} \text { F } \mathrm{hr} / \text { Btu-in. }\end{array}$ & Resistivity (K·m/W) \\
\hline Combined ccSPF & 2.98 & 0.430 \\
\hline Plywood after removal & 1.43 & 0.206 \\
\hline ccSPF, plywood physically removed & 4.17 & 0.601 \\
\hline ccSPF. plywood mathematically removed & 4.13 & 0.596 \\
\hline
\end{tabular}

\subsection{Mechanisms of degradation of ccSPF and XPS foams}

Since the ccSPF samples are adhered to plywood substrates, it is difficult to separate the effects of temperature and humidity between the plywood and the ccSPF. In dryer conditions, ccSPF foam initially increases in R-value, and then proceeds to degrade in $\mathrm{R}$-value. This may be a result of the initial drying of the plywood, followed by the foam degradation. In contrast, at the higher humidity condition the sample initially degrades very rapidly. Once it is removed from the high humidity, some amount of recovery is evident. This may be due to the plywood first taking in water due to the high humidity and then drying out once it is removed from the high humidity.

It is clear from other studies that the blowing agent used has a significant effect on the performance of foam insulations, due to both its gaseous conductivity and its rate of effusion from the foam cells. The overall decrease in R-value observed at both conditions is likely a result of both the loss of blowing agent and the infusion of gases of higher thermal conductivity, such as water vapor. In addition, some sorption of moisture into the 
cell walls may also contribute to the increase in thermal conductivity. Figure 4-3 shows the blistering observed at the edges of the samples aged in the environmental chamber at high humidity, which indicates that moisture is absorbed through the plywood into the foam. The addition of water will increase the thermal conductivity of the foam cell support structures, and thus will decrease the overall R-value in the foam. It was shown that the moisture levels of ccSPF saturated to 12 wt.\% within 40 days (Figure 412). This corresponds to 5 volume \% water loading. Rule of mixture calculations indicate that the degradation in R-value cannot simply be due to the presence of water alone, as it would take a volume loading of $35 \%$ to produce the reduction in R-value by the observed $27 \%$. It is obvious, however, that infiltration of water is an important mechanism that damages the cCSPF insulation, perhaps by displacing the blowing agent and physically damaging the cells of the foam. Polystyrene foams, on the other hand, are hydrophobic, and thus will not experience sorption of moisture.

The small changes in mass found under dry conditions (30\% humidity) are likely due to changes in the composition of gases trapped inside the cells. All of the samples had been stored in laboratory (at $75^{\circ} \mathrm{F}\left[24^{\circ} \mathrm{C}\right]$ at $50 \% \mathrm{RH}$ ) for several months before exposure in the environmental chamber. During that time, some blowing agent gases had possibly already diffused out and some humid air diffused in. This is likely the cause of the lower initial $\mathrm{R} /$ in. values of the ccSPF samples tested in these follow-up accelerated aging simulations. Also, since the polystyrene material is hydrophobic, the higher temperature of the environmental chamber would serve to drive out more humid air than would diffuse in, while no moisture would be absorbed into the structure. This is likely the cause of slight increase in R-value for ccSPF foam samples exposed to dry conditions. In addition, loss of blowing agent over time may also account for long-term degradation of ccSPF sample exposed to ambient environments.

In an attempt to calibrate the effects of short-term high temperature/ high humidity environments $\left(150^{\circ} \mathrm{F}\left[66^{\circ} \mathrm{C}\right]\right.$ at $90 \% \mathrm{RH}$ ) to the effects of aging at ambient environments, a plot was developed that shows the degradation in R-value of ccSPF for sample that had been stored in the laboratory for various times compared to ccSPF samples that had been exposed to high temperature and high humidity (Figure 4-13). In this plot, each " $\mathrm{x}$ " marker represents a different ccSPF sample from the same lot, measured at various times after the lot was received. A linear trend line is included. Triangle markers show accelerated degradation in $150^{\circ} \mathrm{F}\left(66^{\circ} \mathrm{C}\right)$ at $90 \% \mathrm{RH}$ 
conditions, while circle markers show the same for $150^{\circ} \mathrm{F}\left(66^{\circ} \mathrm{C}\right)$ at $30 \%$ RH conditions. Solid lines between markers indicate time between measurements in the environmental conditions. Dashed lines between the markers indicate time for which the post-exposed samples were again allowed to age in ambient conditions.

It was observed that ccSPF samples showed an increase in R-value when samples were first exposed to ambient laboratory environments for 175 days, followed by exposure to $150^{\circ} \mathrm{F}\left(66^{\circ} \mathrm{C}\right)$ at $30 \% \mathrm{RH}$. When these same samples were again exposed to long-term natural aging in the ambient conditions of the laboratory $\left(75^{\circ} \mathrm{F}\left[24^{\circ} \mathrm{C}\right]\right.$ at $\left.60 \% \mathrm{RH}\right)$, the R-value curve tended to approach the original long-term natural aging curve. When the samples that were subjected to accelerated aging (exposure to $150^{\circ} \mathrm{F}$ at $90 \% \mathrm{RH}$ ) for 46 days, were again subjected to natural aging they recovered some of the lost R-values and the R-values vs. Time curve tended to approach the original long-term natural aging curve. A logarithmic plot was developed by extrapolation of the curve that shows long-term aging for ccSPF samples stored in the ambient environment and comparison to the R-values at $150{ }^{\circ} \mathrm{F}\left(66^{\circ} \mathrm{C}\right)$ at $90 \% \mathrm{RH}$ for 46 days (Figure $\left.4-14\right)$.

The ratio of the respective rates of $\mathrm{R}$-value degradation can be estimated by taking the ratio of the slopes of the curves marked "Long-term degradation in ambient" and "Short-term accelerated testing degradation in environmental chamber" versus time (t). The equation describing each curve takes the form of $\ln \left(R_{t}-R_{f}\right)=\left(R_{0}-R_{f}\right)-a t$, where $a=s l o p e, R_{t}=R_{0}$ at $t=0$, and $R_{f}=$ steady-state $R$-value as $t \rightarrow \infty$. Analysis of the data indicates that $\mathrm{R}_{\mathrm{f}}=3.5$, and that the slope ratio is about 30 . The results indicate that 1 year accelerated aging is approximately equivalent to 30 years natural aging inside shelter system (i.e., in $75^{\circ} \mathrm{F}\left[24^{\circ} \mathrm{C}\right]$ at $50-60 \%$ humidity).

Finally, in accordance with the conceptual TTS plot in Section 3.1 and Figure 3-2, the current data was plotted as $\operatorname{Ln}(\mathrm{R})$ against $\operatorname{Ln}(\mathrm{t})$, and yields two distinct curves, one for natural aging at $75^{\circ} \mathrm{F}\left(24^{\circ} \mathrm{C}\right)$ at $50-60 \% \mathrm{RH}$, and one for accelerated aging at $150^{\circ} \mathrm{F}\left(66^{\circ} \mathrm{C}\right)$ at $90 \% \mathrm{RH}$. (See Figure $\left.4-15\right)$. The resulting shift factor, $\mathrm{a}_{\mathrm{r}}$ is $\sim 3.5$, and is the natural logarithm of the ratio of the acceleration time factor. Thus, the acceleration time factor is given by $\exp (3.5) \sim 30$. This result is consistent with the previous conclusion based on the analysis of the slope ratio of the two curves shown in Figure 4-14. 
These observations are again consistent with the hypothesis that damage and R-value degradation of the ccSPF result from moisture uptake. In addition, loss of blowing agent over time is mainly responsible for long-term aging and degradation of ccSPF. In the case of accelerated aging at high temperatures and high humidities, the diffusion of water into the ccSPF likely helps to drive out some of the blowing agent.

Similar research by Zarr and Nguyen at the National Institute of Standards and Technology supports these conclusions (Zarr and Nguyen 1994). They exposed polyisocyanurate (PIR) foam samples, which contained a chlorofluorocarbon (CFC) blowing agent, in an environmental chambers for up to 1 year. Their results showed that the elevated temperatures and humidities greatly facilitated the loss of the blowing agent, thus raising thermal conductivity (with concomitant decrease in resistivity).

Figure 4-12. Logarithmic plot of moisture uptake versus time for ccSPF.

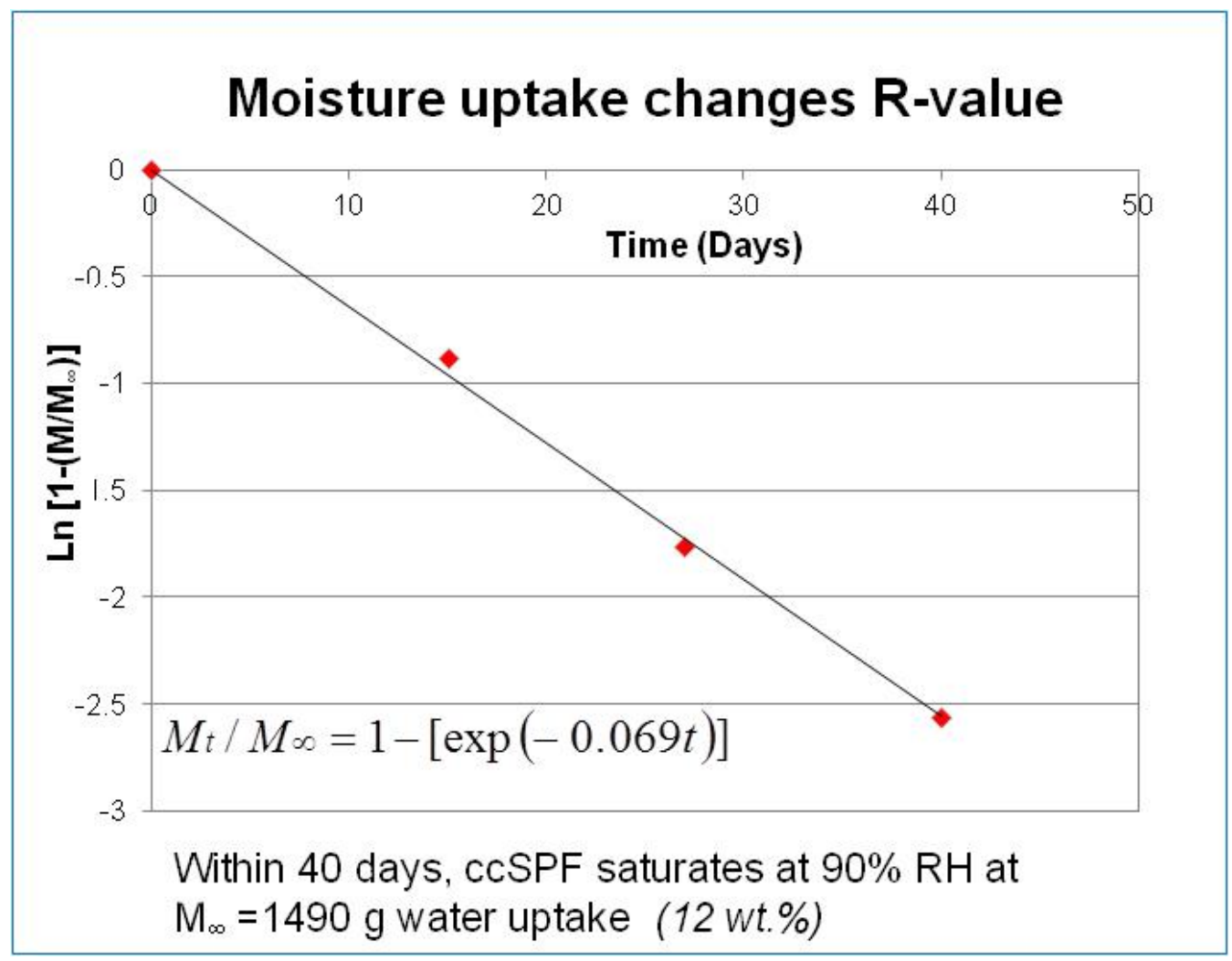


Figure 4-13. Comparison of ambient and accelerated degradation for ccSPF

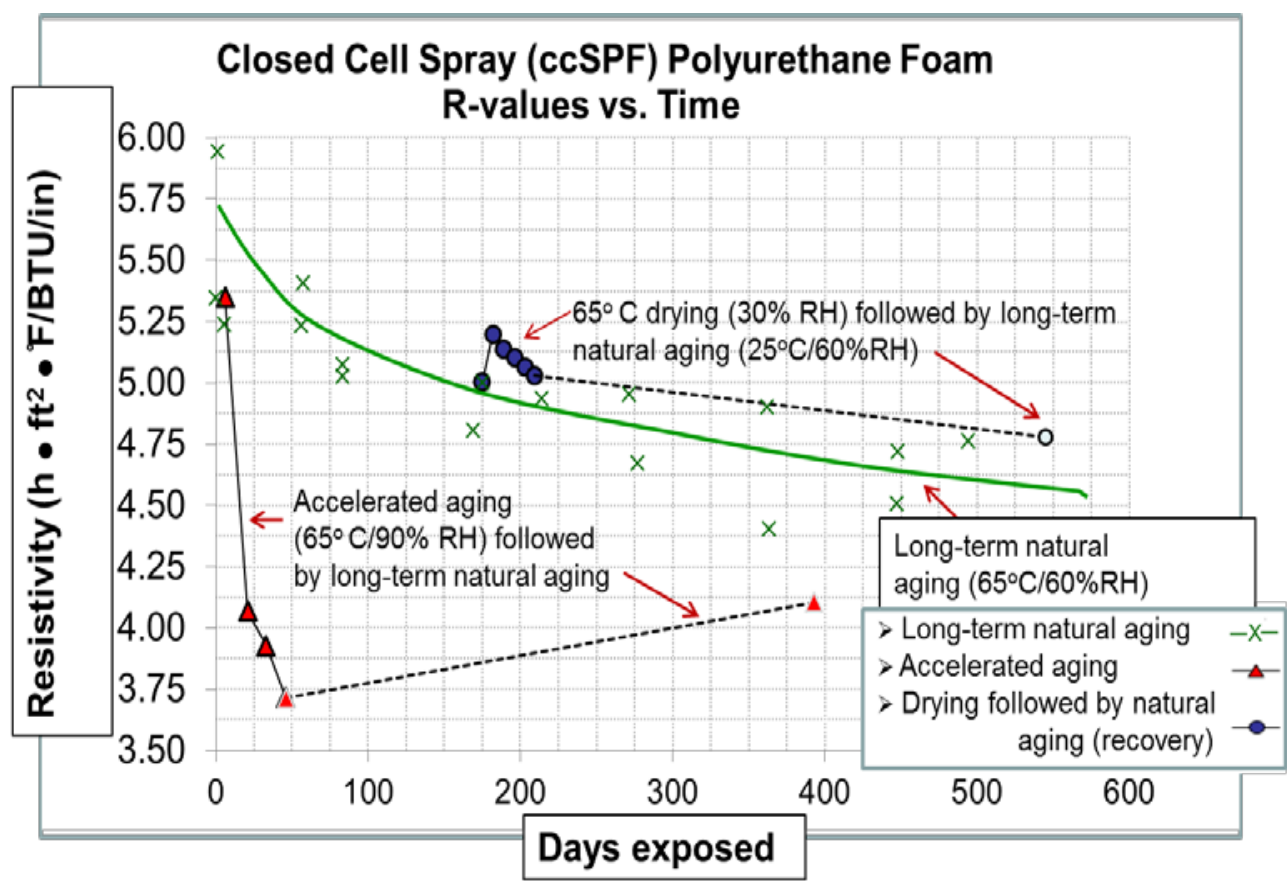

Figure 4-14. Ln ( $\left.R-R_{f}\right)$-values versus time for ccSPF. Using exponential fit, in right plot, slope of $1500^{\circ} \mathrm{F}\left(66^{\circ} \mathrm{C}\right)$ at $90 \% \mathrm{RH}$ fitted line is 30 times slope of ambient $\left(75^{\circ} \mathrm{F}\left[24^{\circ} \mathrm{C}\right]\right.$ at $60 \%$ $\mathrm{RH})$. This indicates that $150^{\circ} \mathrm{F}\left(66^{\circ} \mathrm{C}\right)$ at $90 \% \mathrm{RH}$ simulates exposure for approximately 30 times longer than insulation exposed for the same time period in the ambient exposure.

\section{LN $\left(R_{T}-R_{F}\right)$ VS. TIME}

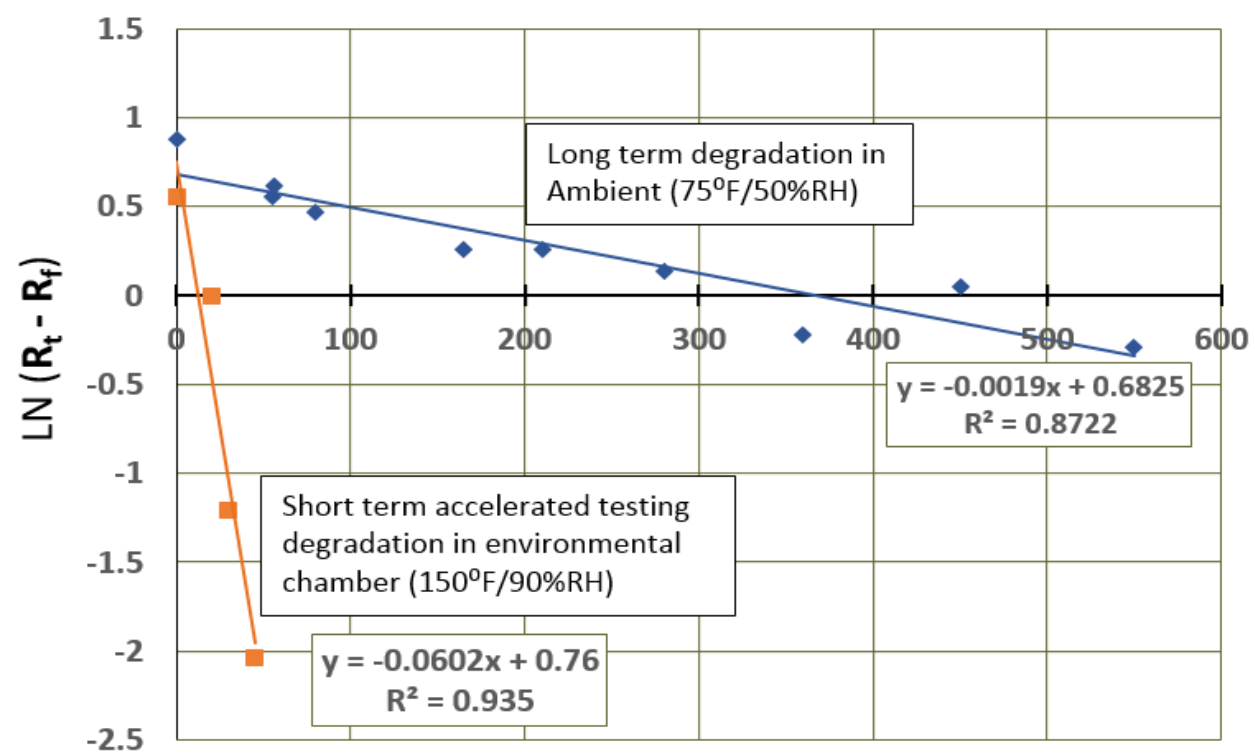

Time (Days) 
Figure 4-15. TTS plot of accelerated testing data shown as $\operatorname{Ln}(R)$ versus $\operatorname{Ln}(t)$. Both exposures were at $90 \%$ RH. Shift factor, aт $~ 3.5$.

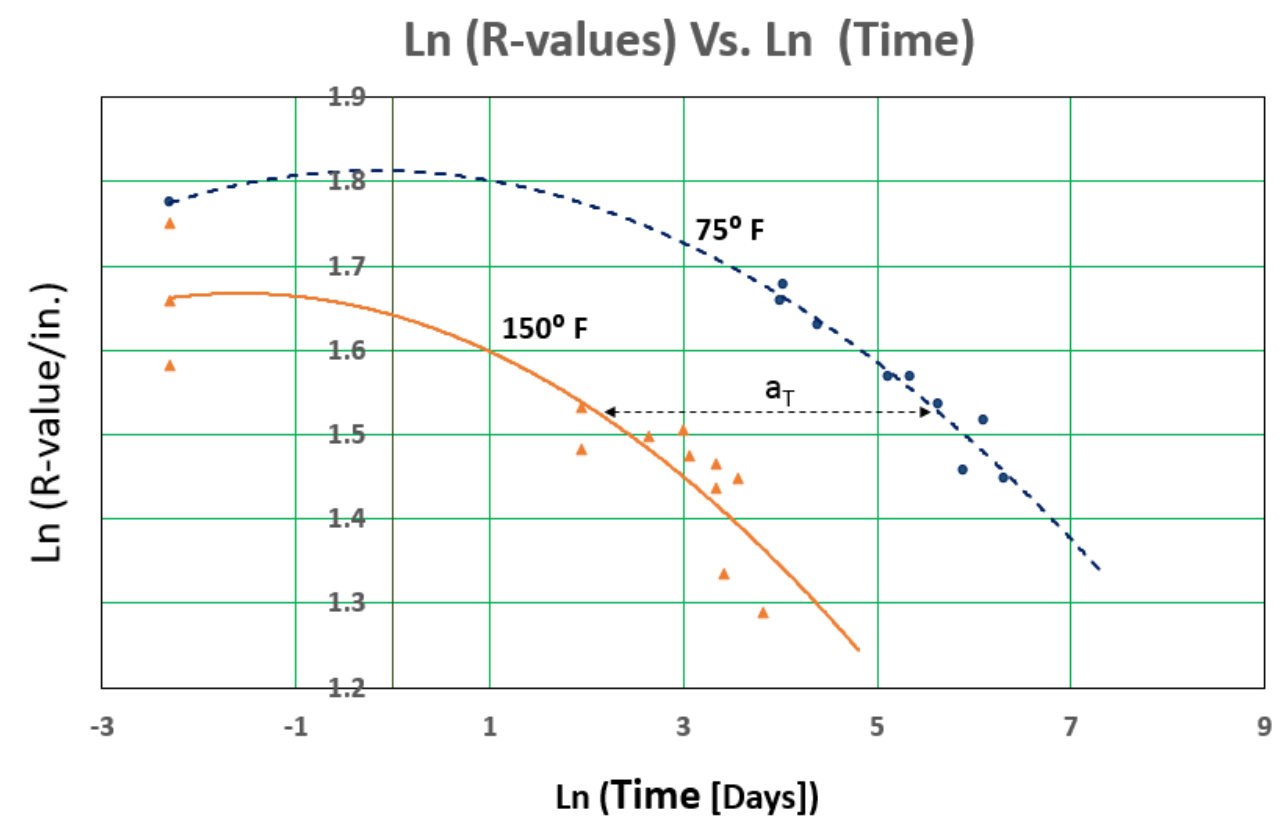

\subsection{Fourier Transform Infrared (FTIR) results}

FTIR spectral analysis of the three Areogel composites were conducted using an FTIR 4100 (J asco Analytical Instruments, Inc., Tokyo, J apan). Based on the information in the material safety data sheets pertaining to $A A, A B$, and AC (Table 2-2), aerogel composites are, in general, continuous filament polymer and glass fibers coated with amorphous silica, calcium silicate, synthetic graphite, and the binding polymers such as poly (ethylene terephthalate) (PET) or polyolefin sheath. The main objective of the FTIR analysis is to study the chemical stability and interactions (degradation and/ or transformation) with major environmental components such as moisture over an extended period of 5 weeks. Several small (1 $12-\mathrm{cm})$ samples (swathes) of each type of the aerogel blankets were exposed to a temperature of $150{ }^{\circ} \mathrm{F}\left(66^{\circ} \mathrm{C}\right)$ and varying relative humidity between $90 \% \mathrm{RH}$ and $30 \% \mathrm{RH}$ for a period of 5 weeks. FTIR spectra and scanning electron micrographs were obtained of each type of sample that was removed from the environmental chamber at 1 and 5 weeks. These FTIR spectra and the SEM (Scanning Electron Micrographs) micrographs were compared with baseline samples (which were not subjected to any exposure).

The FTIR transmittance spectra of the aerogel blankets subjected to the different environmental conditions are included in Figure 4-16(a-f). To fa- 
cilitate the functional group analysis several peaks are identified with the frequency number in the spectra. Figures 4-17 and 4-18 include an overlay of IR spectra of the three aerogel composites at two different humidity conditions in the IR frequency range of 3500-3950 $\mathrm{cm}^{-1}$. Also, Figure 4-19 shows the spectra for the IR frequency range of $1300-2000 \mathrm{~cm}^{-1}$.

For all three materials, the transmission peaked in the range of $3800 \mathrm{~cm}^{-1}$ to $3500 \mathrm{~cm}^{-1}$, indicating there was free water and a hydroxyl group in the baseline spectrum that disappeared after exposure to $150^{\circ} \mathrm{F}\left(66^{\circ} \mathrm{C}\right)$ at $30 \% \mathrm{RH}$. Similar behavior was also apparent at $150^{\circ} \mathrm{F}\left(66^{\circ} \mathrm{C}\right)$ at $90 \% \mathrm{RH}$ conditions (Figures 4-17 and 4-18). At $150{ }^{\circ} \mathrm{F}\left(66^{\circ} \mathrm{C}\right)$ at $90 \% \mathrm{RH}$, the FTIR spectra for AA show the peak $3616 \mathrm{~cm}^{-1}$ in baseline and 1-week samples. However, after 5 weeks, the AA also chemically released a hydroxyl group, shown by the absence of the peak $3616 \mathrm{~cm}^{-1}$.

The AC FTIR spectrum shows that some sort of chemical changes took placed after environmental chamber treatment (Figure 4-19). The characteristic broad peaks around 1738-1712 $\mathrm{cm}^{-1}$ are due to carbonyl $(\mathrm{C}=\mathrm{O})$ groups coming from the polymers. The peaks at $3433 \mathrm{~cm}^{-1}$ are overtones of the $\mathrm{C}=\mathrm{O}$, while the peaks around $1738-1712 \mathrm{~cm}^{-1}$ are $\mathrm{C}=\mathrm{O}$ stretching modes. Some of these peaks around $1720 \mathrm{~cm}^{-1}$ show as a group of multiple peaks due to peak shifts due to hydrogen bonding and or stearic interactions of other moieties in the composites. The broad peak at $\sim 1075 \mathrm{~cm}^{-1}$ is $\mathrm{Si}-\mathrm{O}-\mathrm{Si}$ stretching mode. Several other peaks between $790-950 \mathrm{~cm}^{-1}$ are also attributed to $\mathrm{Si}-\mathrm{OH}$, Si-O stretching and bending modes respectively. The strong peaks around $2350 \mathrm{~cm}^{-1}$ are attributed to Si-C stretching. The broad peak around 3550-3700 $\mathrm{cm}^{-1}$ are in general due to the hydroxyl $(\mathrm{OH})$ groups and free water. The strong peaks around 2875-2885 $\mathrm{cm}^{-1}$ are due to $-\mathrm{CH}_{3}$ stretching. These methyl groups are mainly the contributions from the polymer binders and fibers. The peaks around 790 and $845 \mathrm{~cm}^{-1}$ are the methyl groups of the silicate compounds.

The peak intensity of several of these compounds change with the moisture exposure and duration. Significantly, the peaks flatten out indicating chemical transformation, mostly the variation in degree of hydrogen bonding and rearrangement of methyl compounds, abstraction of water, and release of some environmentally benign compounds. Though off-gas analysis is not conducted during this study, one could expect a slow release of $\mathrm{CO}_{2}$, methanol, and moisture during the aging process. 
Figure 4-16. FTIR transmittance spectra.

a.

Aerogel blanket AA subjected to environmental conditions of $150^{\circ} \mathrm{F}\left(66^{\circ} \mathrm{C}\right)$ at $90 \% \mathrm{RH}$.

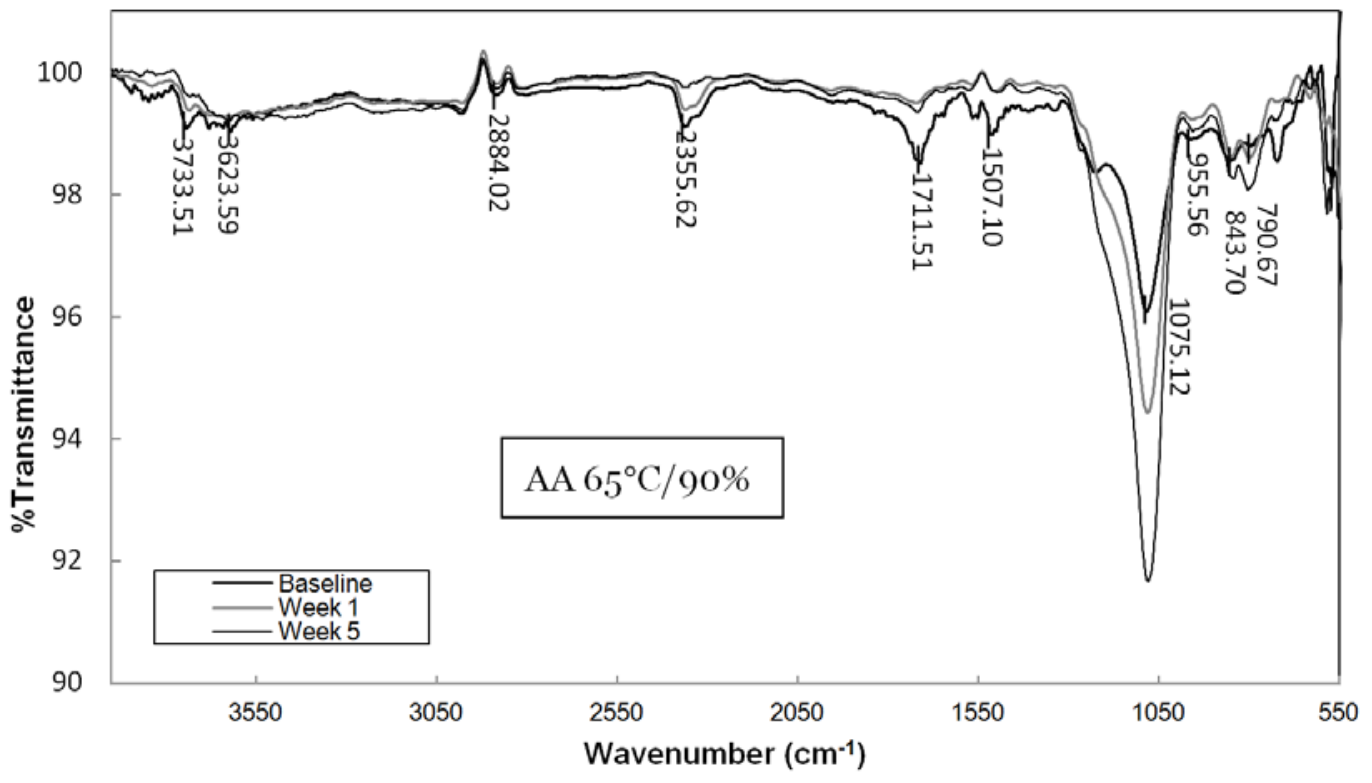

b.

Aerogel blanket AA subjected to environmental conditions of $150^{\circ} \mathrm{F}\left(66^{\circ} \mathrm{C}\right)$ at $30 \% \mathrm{RH}$.

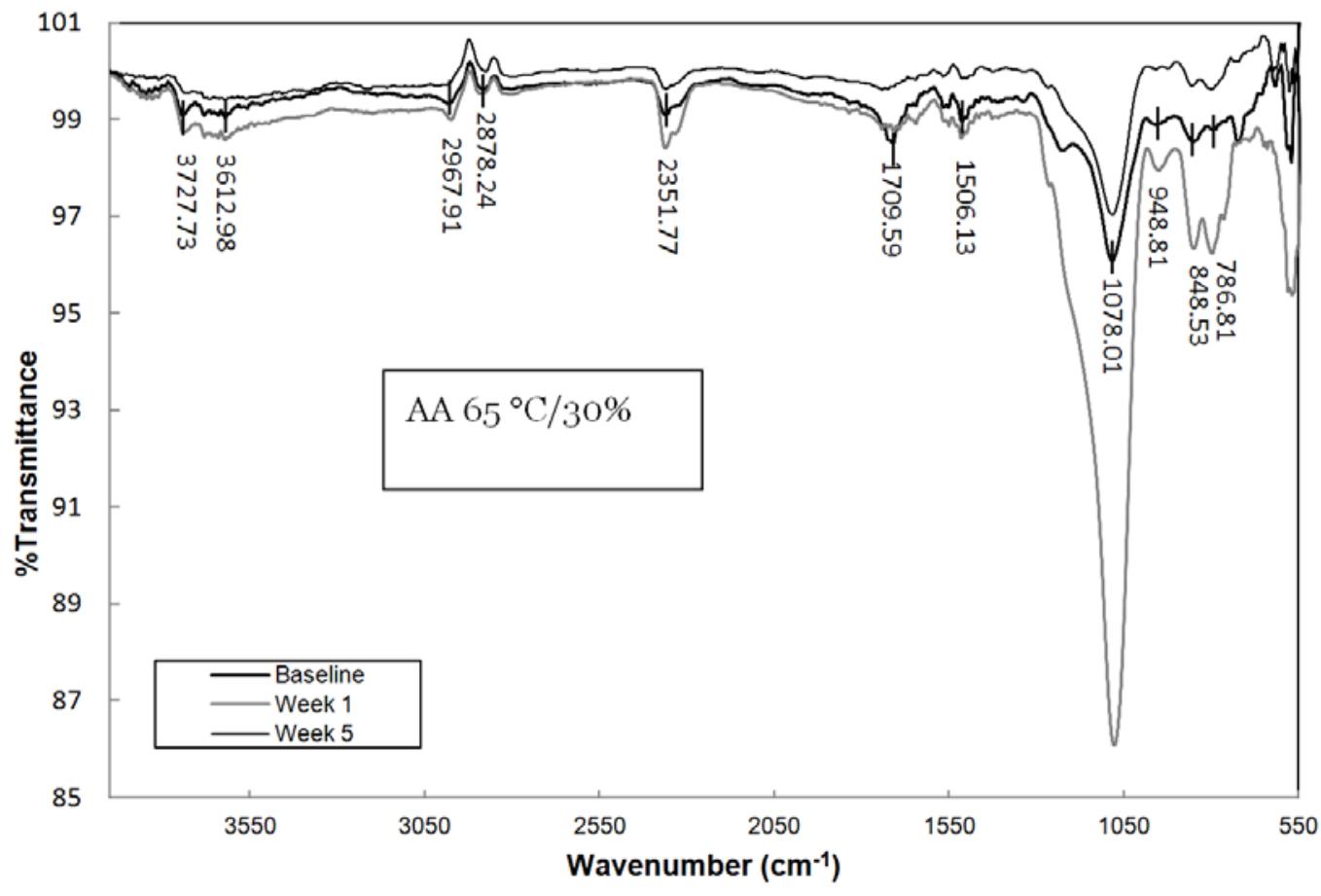


Figure 4-16 (Cont'd).

c.

Aerogel blanket AB subjected to environmental conditions of $150^{\circ} \mathrm{F}\left(66^{\circ} \mathrm{C}\right)$ at $90 \% \mathrm{RH}$.

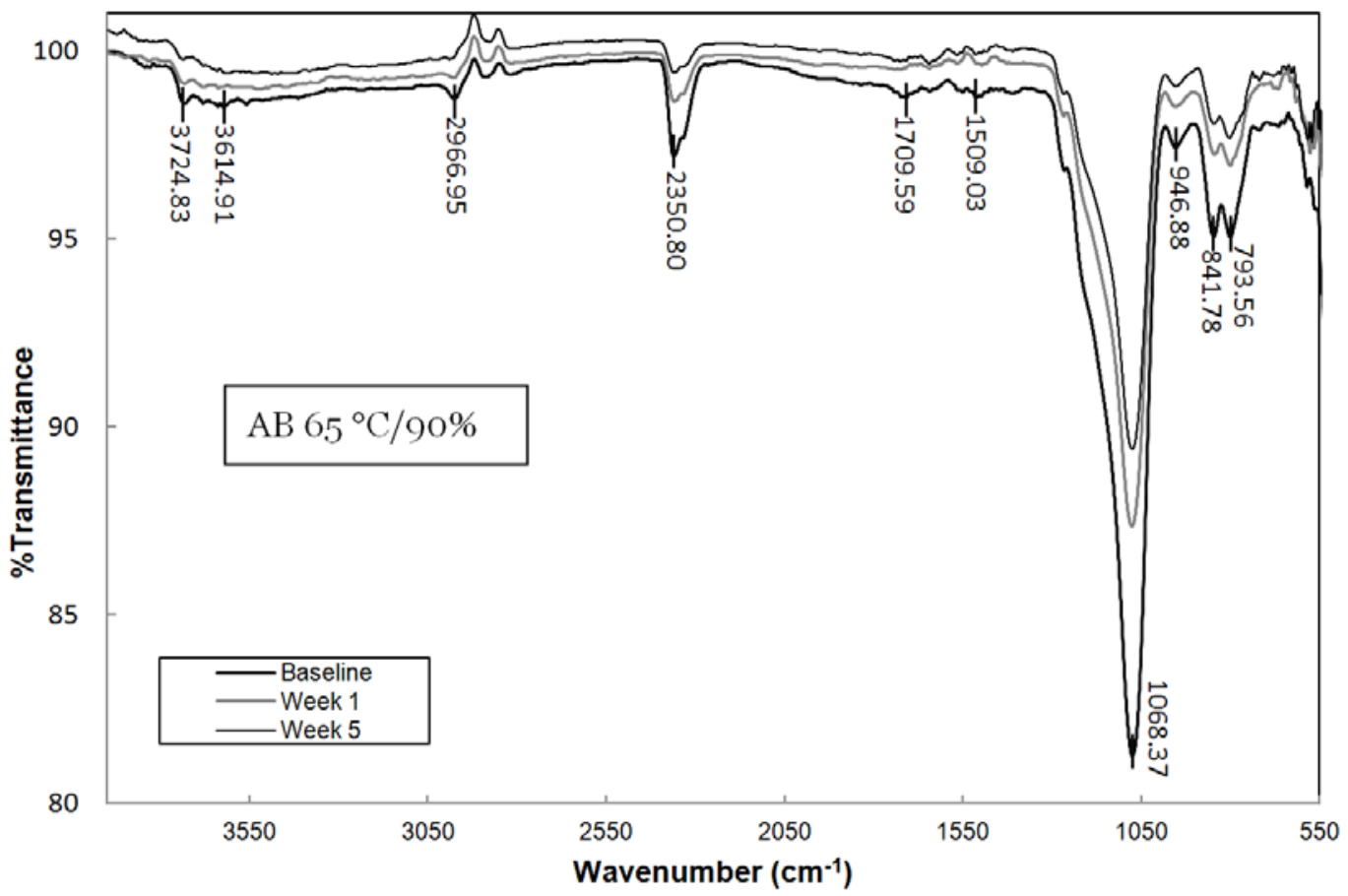

d.

Aerogel blanket $\mathrm{AB}$ subjected to environmental conditions of $150^{\circ} \mathrm{F}\left(66^{\circ} \mathrm{C}\right)$ at $30 \% \mathrm{RH}$.

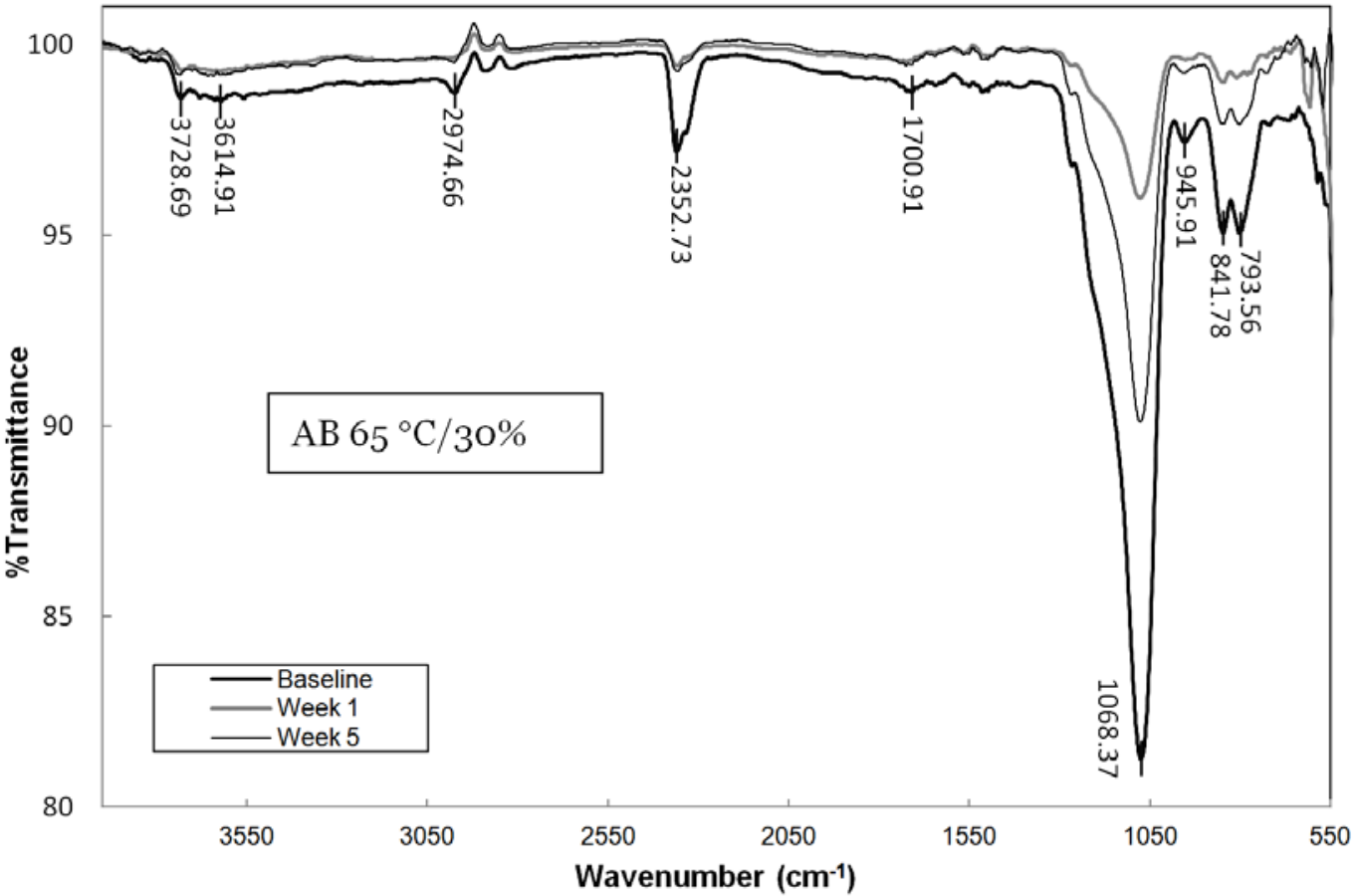


Figure 4-16 (Cont'd).

e.

Aerogel blanket AC subjected to environmental conditions of $150^{\circ} \mathrm{F}\left(66^{\circ} \mathrm{C}\right)$ at $90 \% \mathrm{RH}$.

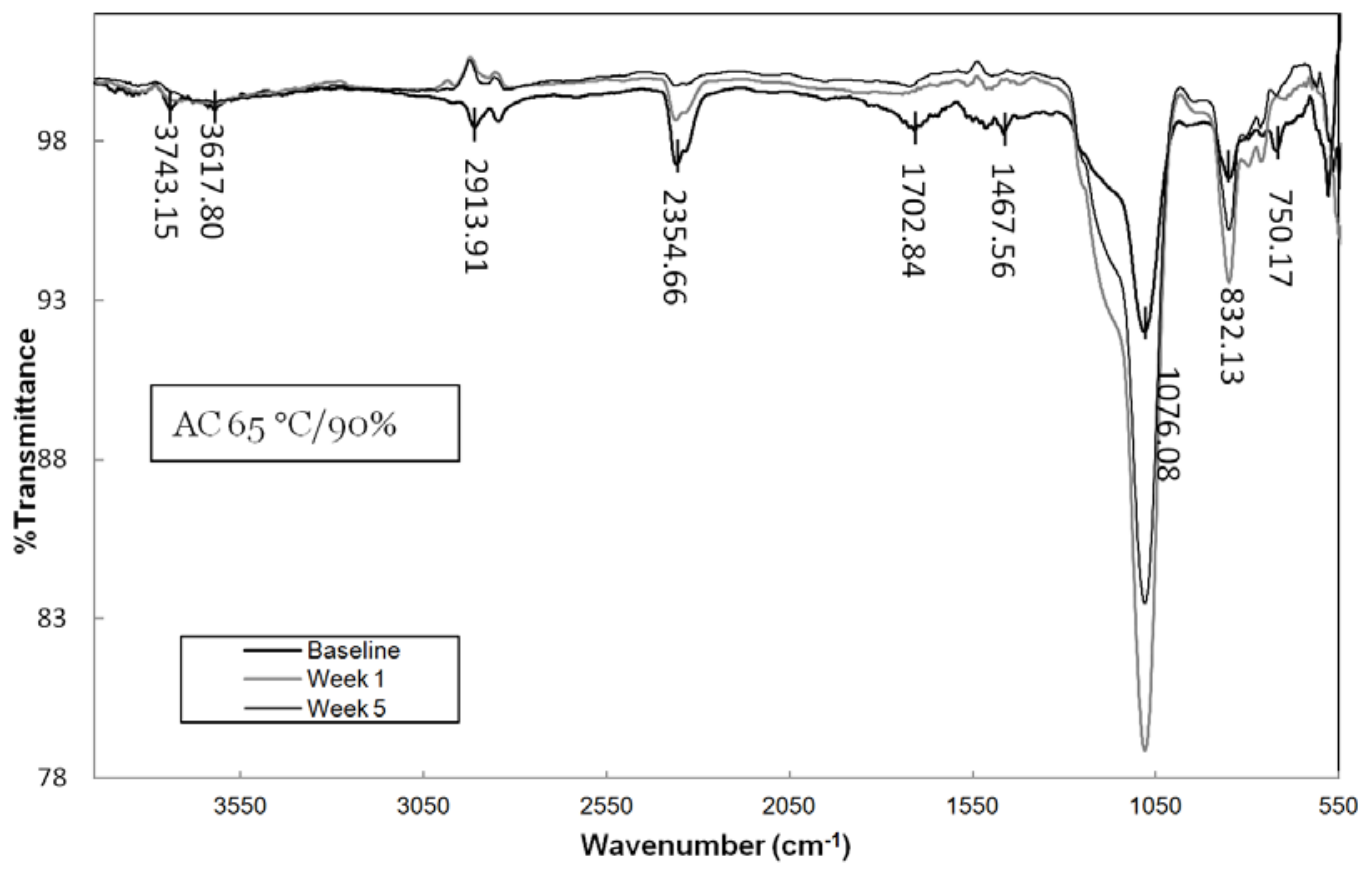

f.

Aerogel blanket AC subjected to environmental conditions of $150^{\circ} \mathrm{F}\left(66^{\circ} \mathrm{C}\right)$ at $30 \% \mathrm{RH}$.

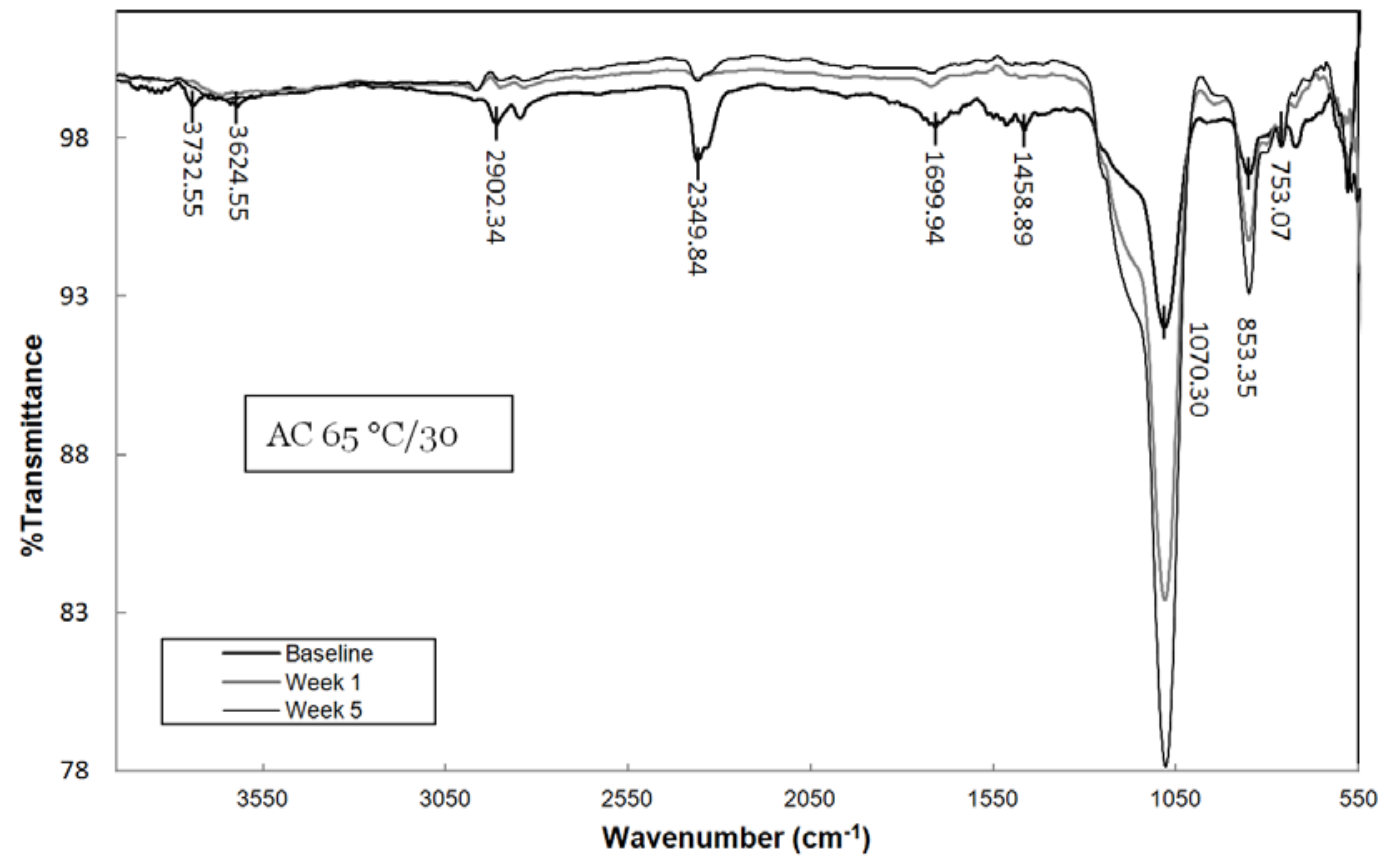


Figure 4-17. Details of FTIR overlays of all three aerogel blankets at $150^{\circ} \mathrm{F}$ $\left(66^{\circ} \mathrm{C}\right)$ at $90 \% \mathrm{RH}$ indicates changes in free moisture.

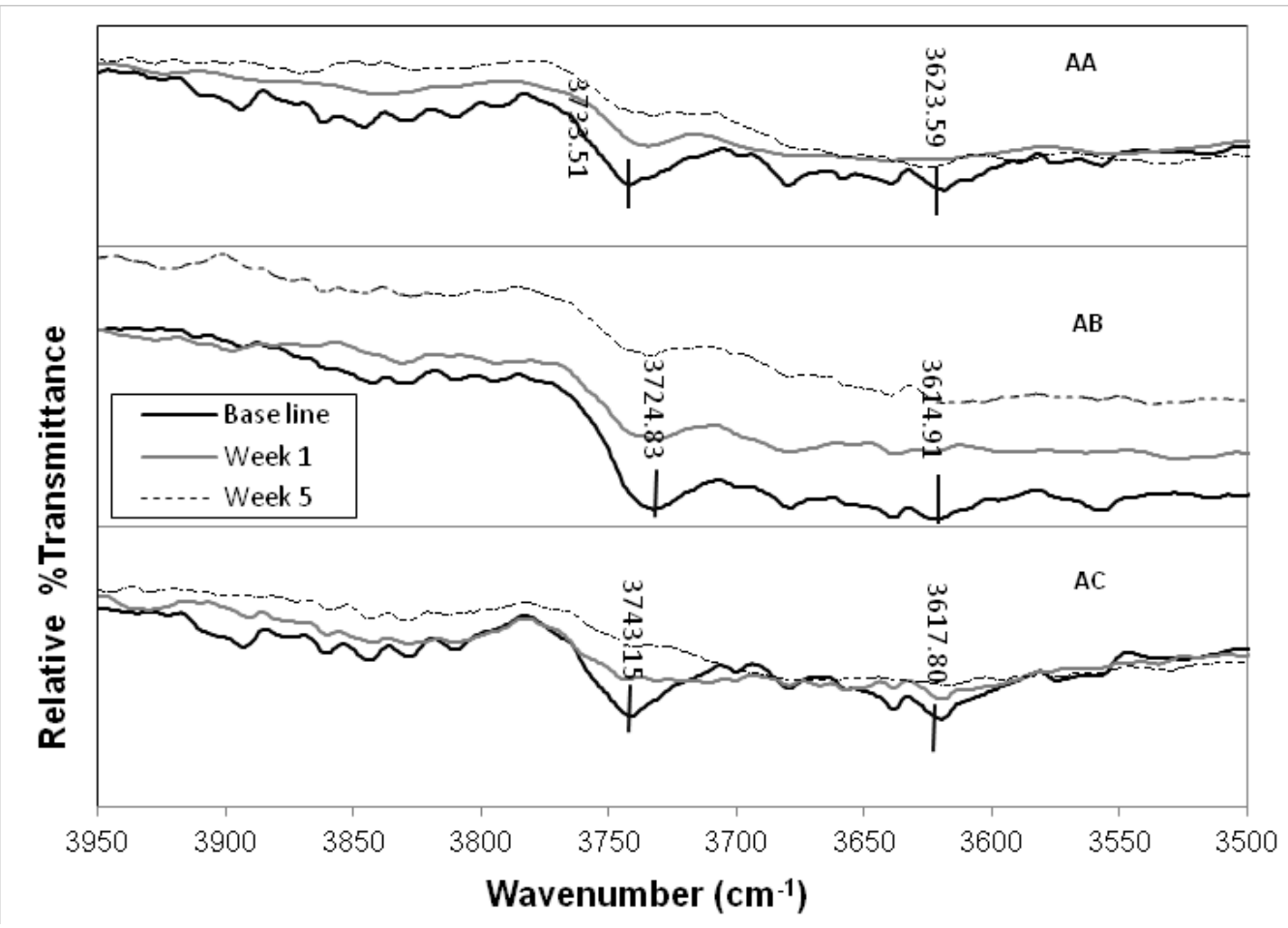

Figure 4-18. Details of FTIR overlays of all three aerogel blankets at $150^{\circ} \mathrm{F}$ $\left(66^{\circ} \mathrm{C}\right)$ at $30 \% \mathrm{RH}$ indicates changes in free moisture.

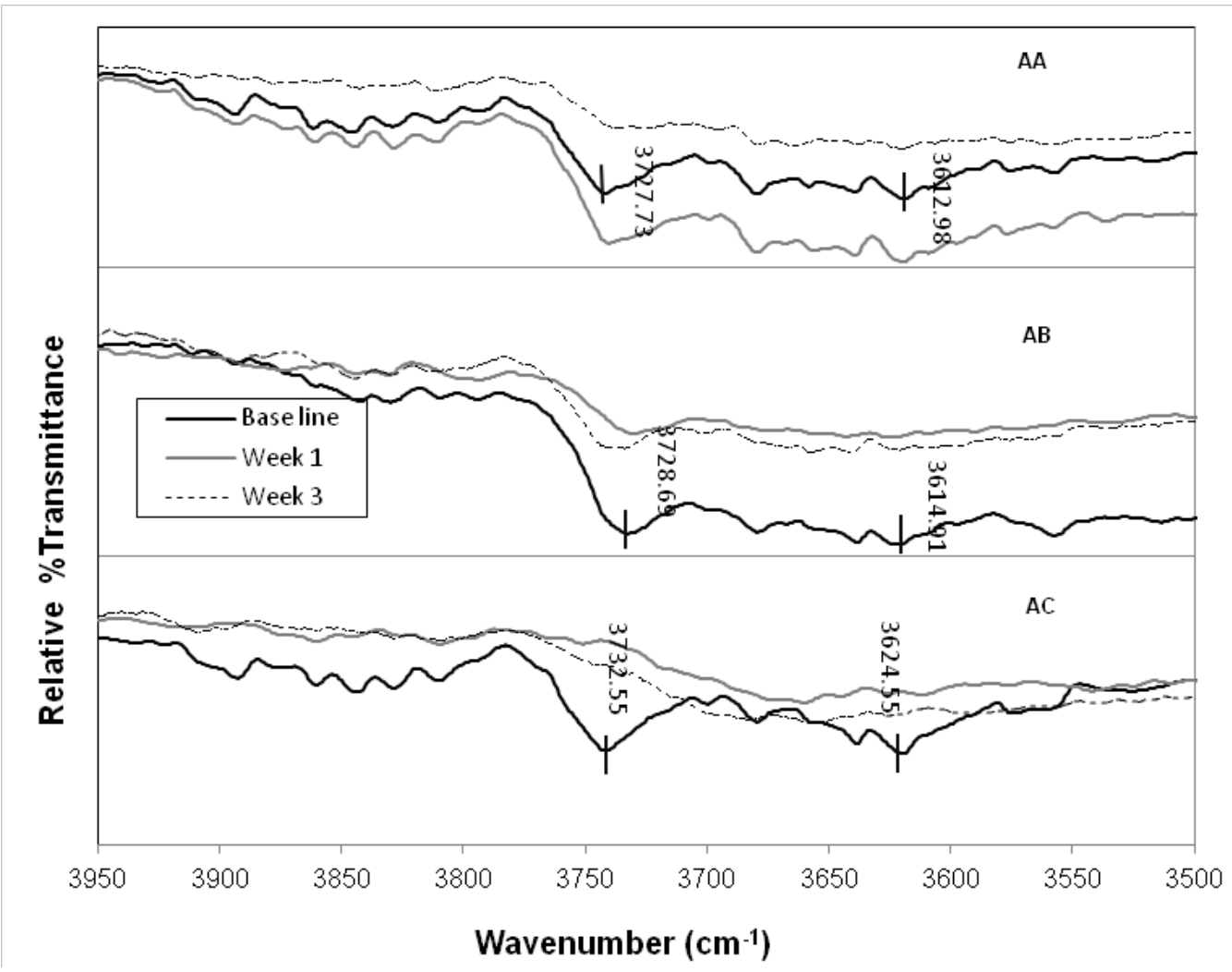


Figure 4-19. Details of FTIR overlays of AC at both $90 \% \mathrm{RH}$ and $30 \% \mathrm{RH}$ at $150^{\circ} \mathrm{F}\left(66^{\circ} \mathrm{C}\right)$ indicates structural changes.

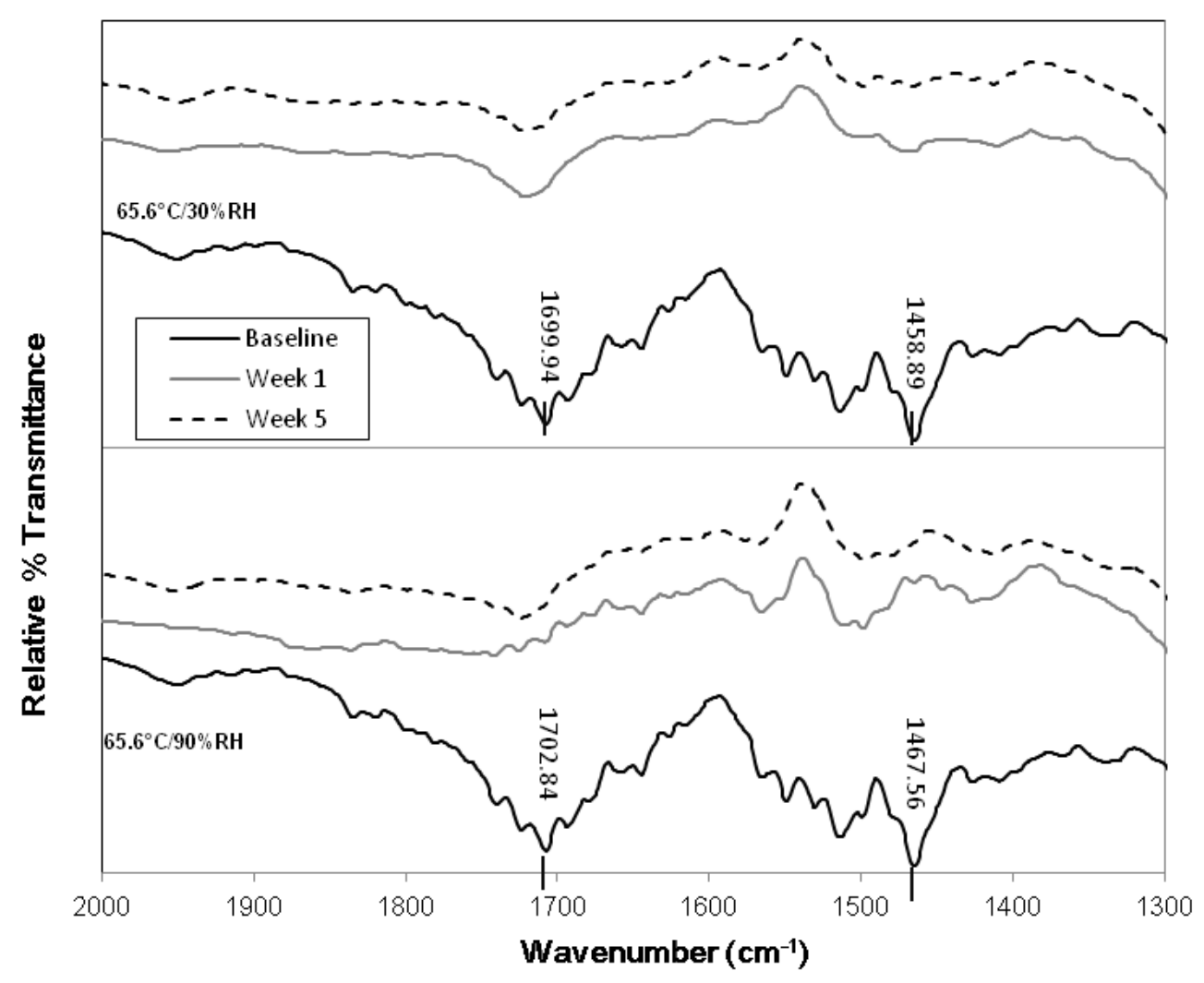

SEMs were taken with JEOL J SM 6390 Scanning Electron Microscope (J EOL USA Inc., Peabody, MA) to observe possible physical changes in the blankets. The SEMs reveal that the polymer, amorphous silicon, and other components are evenly distributed on the fibers in all the three $\mathrm{AA}, \mathrm{AB}$, and AC aerogel composites (Figures 4-20[a], 4-21[a], and 4-22[a]). However, a slow but certainly separation and segregation of the amorphous and/ or particulated material can be observed (Figures 4-20[b], 4-21[b], and 4-22[b]) after a weeklong exposure to the hot and humid conditions. The micrographs obtained after 5 weeks (Figures 4-20[c], 4-21[c], and 422[c]) show further segregation and stratification of the amorphous silica and polymer materials. This segregation and stratification explains the initial decrease and stabilization of the R-value of these aerogel composites. 
Figure 4-20. SEM micrographs of AA aged at $150^{\circ} \mathrm{F}\left(66^{\circ} \mathrm{C}\right)$ at $90 \%$ RH for (a) 0 time, (b) 1 week, (c) 5 weeks.

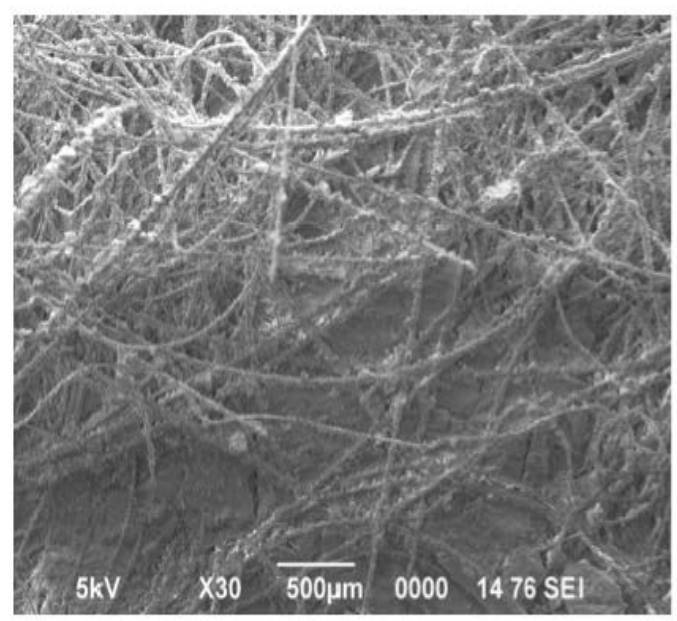

(a)

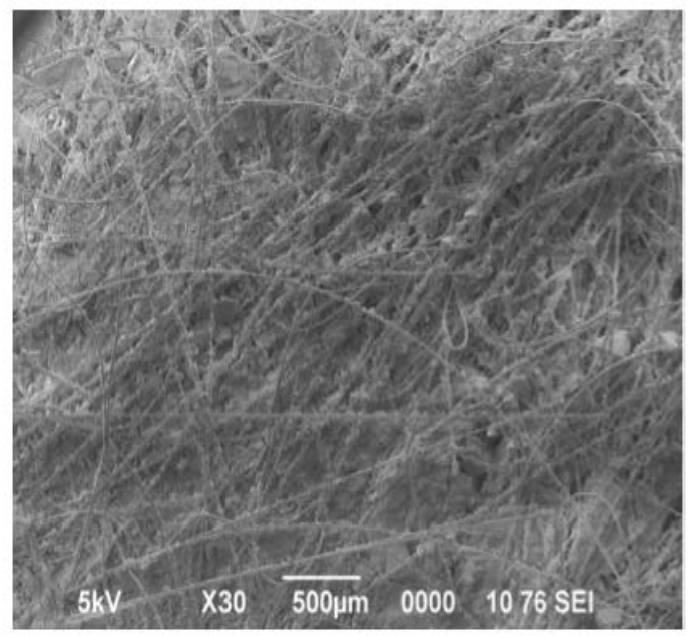

(b)

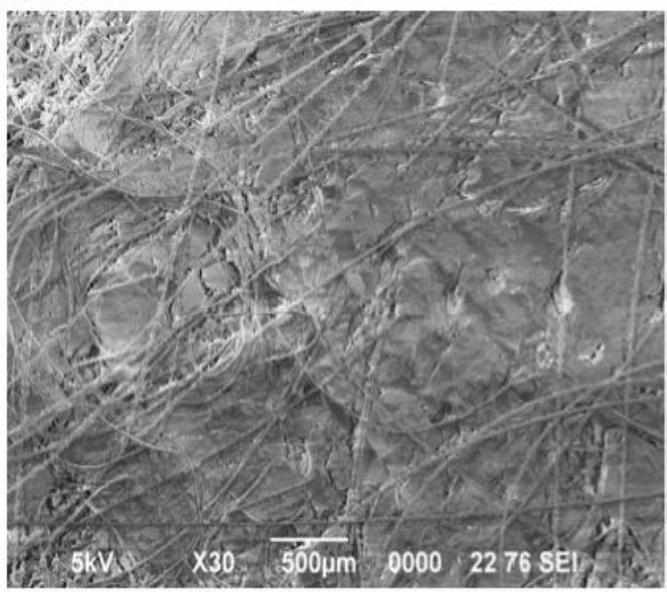

(c) 
Figure 4-21. SEM micrographs of $A B$ aged at $150^{\circ} \mathrm{F}\left(66^{\circ} \mathrm{C}\right)$ at $90 \%$ RH for (a) 0 time, (b) 1 week, (c) 5 weeks

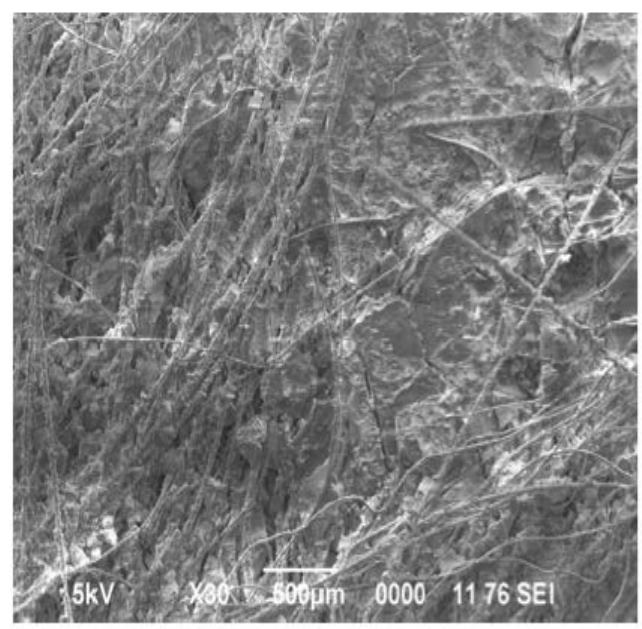

(a)

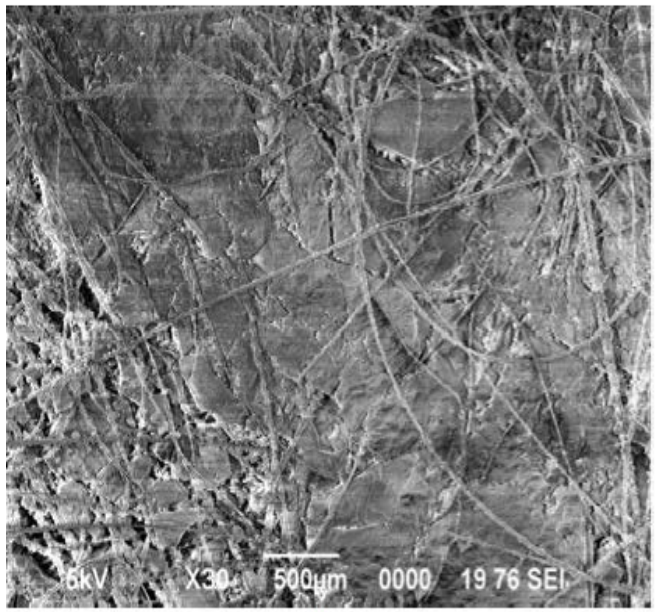

(b)

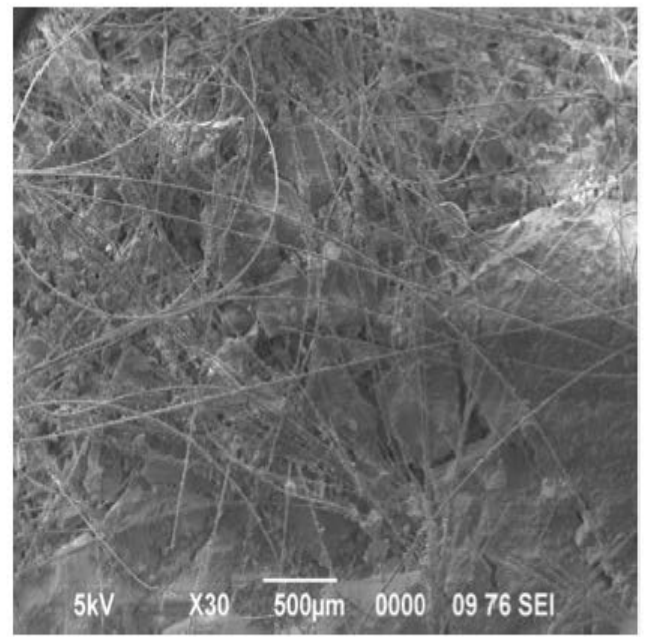

(c) 
Figure 4-22. SEM micrographs of $A C$ aged at $150^{\circ} \mathrm{F}\left(66^{\circ} \mathrm{C}\right)$ at $90 \%$ RH for (a) 0 time, (b) 1 week, (c) 5 weeks

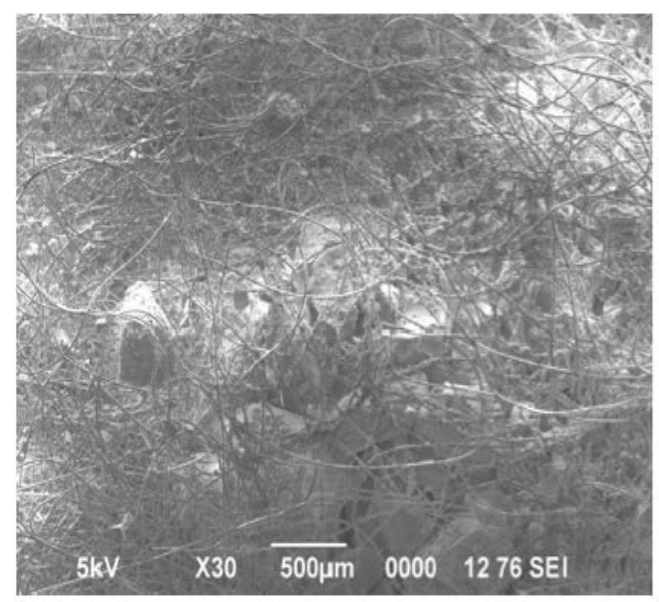

(a)

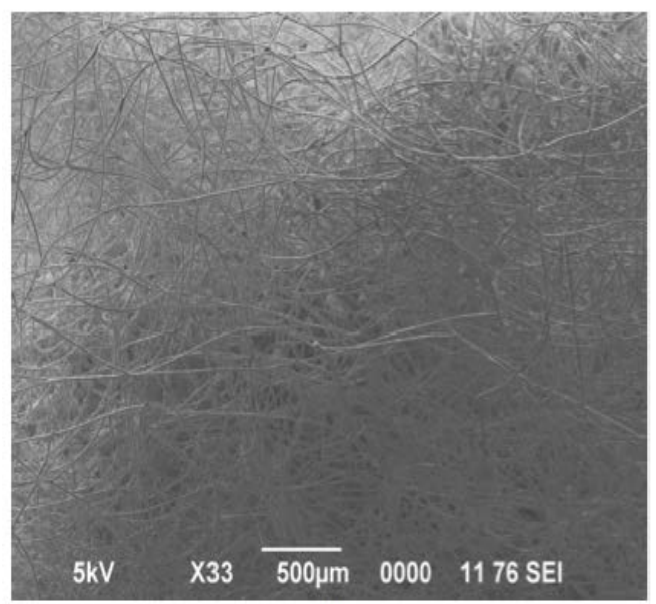

(b)

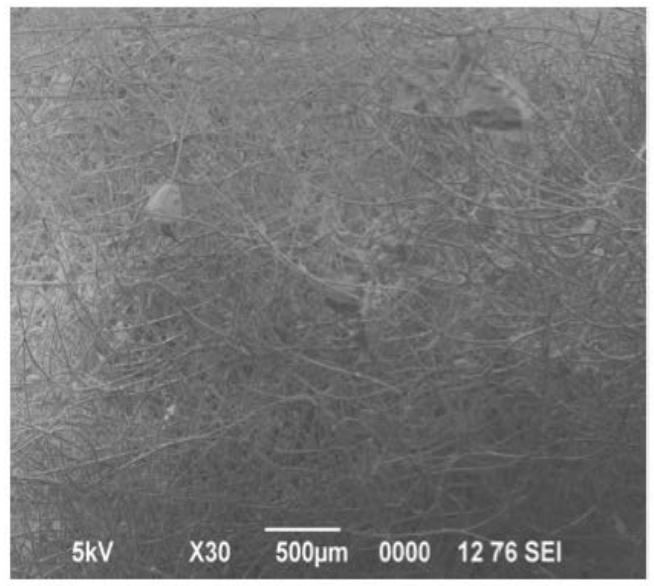

(c) 


\subsection{Flammability testing of selected advanced insulation materials}

Flammability has been considered the most important property of a material when assessing fire hazards. The flammable test of three insulation materials were conducted at U.S. Army Natick Solider Research, Development and Engineering Center (Natick, MA), following ASTM Standard D6413. Three materials sent for testing were: (1) the 2-in. thick blue polystyrene form (XPS), (2) 2-in. thick purple polystyrene form (XPS), and (3) the 1/4-in. thick tan foam. The two 2-in. thick polystyrene foams were shaved down and tested. Appendix A includes the results, which indicate that these two materials had flaming melt drip and excessive smoke. The thin polyurethane foam looked good on the initial test so a complete test was conducted for this sample. 


\section{Conclusions and Recommendations}

\subsection{Conclusions}

This work concludes that Thinsulate ${ }^{\mathrm{TM}}$ and DuPont ${ }^{\mathrm{TM}}$ ThermalWrap $^{\mathrm{TM}}$ R5.0 were slightly affected by simulation in more extreme conditions. The $\mathrm{R}$-value of Thinsulate ${ }^{\mathrm{TM}}$ decreased less than $1 \%$ compared to its initial state. Similar behavior was observed in fiberglass and extruded polystyrene insulations. These two materials were only slightly affected by aging, retaining over $97 \%$ of their initial R-values. On the other hand, some of the aerogel blankets and closed cell polyurethane samples degraded by as much as $15 \%$ and $27.5 \%$, respectively. Even though they lost significant Rvalue, the aerogel blankets still had the highest R-value after aging under high humidity conditions at elevated temperatures. It appears that the reduction in R-values for closed cell polyurethanes and aerogel blankets follows an exponential decay law. The significant decrease in R-value for the closed cell spray polyurethane foam is apparently due to exchange of higher and lower thermal conductivity gases in and out of the material, i.e., diffusion of air into the foams and blowing agent out of the foams.

\subsection{Recommendations}

It is recommended that the technology described in this report be used as the basis to formulate a methodology for evaluation and predication of long-term performance of selected insulation materials at elevated temperatures and humidity conditions. The selection of insulation materials should be chosen from materials that do not absorb water, for example, nonwoven composite insulate liner $\left(3 \mathrm{M}^{\mathrm{TM}}\right.$ Thinsulate $\left.^{\mathrm{TM}}\right)$, fiberglass, polystyrene, and specific brands of aerogel as tested in this project. 


\section{Acronyms and Abbreviations}

\begin{tabular}{|c|c|}
\hline Term & Definition \\
\hline ANSI & American National Standards Institute \\
\hline ASTM & American Society for Testing and Materials \\
\hline BEAR & Basic Expeditionary Airfield Resources \\
\hline BTU & British Thermal Unit \\
\hline CEERD & $\begin{array}{l}\text { US Army Corps of Engineers, Engineer Research and Development } \\
\text { Center }\end{array}$ \\
\hline CERL & Construction Engineering Research Laboratory \\
\hline CFC & Chlorofluorocarbon \\
\hline CRREL & Cold Regions Research and Engineering Laboratory \\
\hline DOE & U.S. Department of Energy \\
\hline ECU & Environmental Control Unit \\
\hline ERDC & Engineer Research and Development Center \\
\hline ERDC-CERL & $\begin{array}{l}\text { Engineer Research and Development Center, Construction Engineering } \\
\text { Research Laboratory }\end{array}$ \\
\hline FDECU & Field Deployable ECU \\
\hline FTIR & Fourier Transform Infrared \\
\hline HFMA & Heat Flow Meter Apparatus \\
\hline IR & infrared \\
\hline LLNL & Lawrence Livermore National Laboratory \\
\hline MSDS & Material Safety Data Sheet \\
\hline NSRDEC & $\begin{array}{l}\text { US Army Natick Soldier Research, Development and Engineering } \\
\text { Center }\end{array}$ \\
\hline OMB & Office of Management and Budget \\
\hline PETE & Polyethylene Terephthalate \\
\hline PIR & Polyisocyanurate \\
\hline PP & Polypropylene \\
\hline PU & polyurethane \\
\hline $\mathrm{RH}$ & Relative Humidity \\
\hline SAR & Same As Report \\
\hline SEM & Scanning Electron Microscope \\
\hline SF & Standard Form \\
\hline SI & Systeme Internationale \\
\hline SIP & Structurally Insulated Panel \\
\hline TH & Thinsulate $^{\mathrm{TM}}$ \\
\hline TR & Technical Report \\
\hline TTS & Time-Temperature-Superposition \\
\hline TW & Thermoplastic Insulation \\
\hline URL & Universal Resource Locator \\
\hline
\end{tabular}


Term

XPA

$X P B$

XPS
Definition

Polystyrene Foam

Polystyrene Foam

Extruded Polystyrene 


\section{References}

American Society for Testing and Materials (ASTM). 2000. "Standard test method for steady state thermal transmission properties by means of the heat flow meter apparatus." ASTM Standard C 518. Annual Book of ASTM Standards 04.06:173184.

Acoustiblok Inc. 2009. Thermablok Thermal Acoustic Isolation Strips. Safety Data Sheet, http://www.thermablok.com/pdf/Thermablok_msds_20090318.pdf

Aspen Aerogels. 2011. Spaceloft ${ }^{\circledR}$ Silica Aerogel Materials. Safety Data Sheet, http://www.aerogel.com/_resources/common/userfiles/file/Data\%20Sheets/Spaceloft_MSDS . $\mathrm{pdf}$

Cabot Corp. 2013. Aerogel Thermal Wrap. Safety Data Sheet, http://www.google.com/url?sa=t\&rct=j\&q=\&esrc=s\&source=web\&cd=7\&cad=rja\&uact=8\&ved =0CD4QFjAG\&url=http\%3A\%2F\%2Fcabot.cz\%2F \%2Fmedia\%2Fsample\%2520sharepoint\%252 Olibraries\%2Fmsds\%2Fen\%2Ftw600-euren.pdf\&ei=WRVIVIvGloz90QTr74DwBA\&usg=AFQjCNFZnsJ9M96YZ6W5KZfknU8Lbei$\underline{0 Q \& b v m=b v .79400599, \text { d.cGU }}$

Camel Manufacturing. 2015. Products: Extreme Weather Liner. Website, http://www.camelmfg.com/products-ewl.php

Cheng, Rongshi, and Hu Yang. 2005. "Application of time-temperature superposition principle to polymer transition kinetics." J . Appl. Polym. Sci. 99(4):1767- 1772. doi:10.1002/app.22706.

dArlas, B, LFernandez-dArlas, P. .MRueda, K. Stefani, de la Caba, A. Mondragon, and E. Ceiza. 2007. "Kinetic and thermodynamic studies of the formation of a polyurethane based on 1,6-hexamethylene diisocyanate and poly(carbonate-coester)diol." Thermochimica acta 459(1):94-103.

DuPont $^{\mathrm{TM}}$. website, http://www.dupont.com/products-and-services/construction-materials/shelter-envelopesystems/brands/water-barrier-systems/products/tyvek-thermawrap.html

Dow Chemical Company. 2011. STYROFOAM ${ }^{\mathrm{TM}} 2.00$ x 24 Inch Panel Core 20 $\mathrm{XNERGY}^{\mathrm{TM}}$. Material Safety Data Sheet, http://www.dryvit.com/fileshare/doc/us/msds/msds_191.pdf

Field, H. L., and J . B. Solie. 2007. Introduction to Agricultural Engineering Technology. Springer Press. Doi 10.1007/ 978-0-387-36915-0_22. pp 286-292

Frank, D., A. Zimmermann, and F. Thonnessen. 1998. Fiber Web/ Aerogel Composite Material Comprising Bicomponent Fibers, Production Thereof and Use Thereof. U.S. Patent 5786059.

Honeywell. 2013. Enovate ${ }^{\circledR}$ 245fa. Material Safety Data Sheet. 
Honeywell. 2014. Solstice ${ }^{\mathrm{TM}}$ Liquid Blowing Agent. Material Safety Data Sheet.

Jabarin S. A., and E. A. Lofgren. 1986. "Effects of water absorption on physical properties and degree of molecular orientation of poly (ethylene terephthalate)." Polymer Engineering \& Science. 26:620-625.

Kistler, S. S. 1931. “Coherent expanded aerogels and jellies.” Nature. 127:741. doi: 10.1038/127741a0.

King, R. H. 2003. “Thermal Insulation Materials.” Encyclopedia of Applied Physics. DOI: 10.1002/3527600434.eap505

Lawrence Livermore National Laboratory (LLNL). 2013. "Estimated U.S. Energy Use in 2012: 95.1Quads." Energy Flow. Web page, https://flowcharts.IInl.gov/energy.html\#2012

Lienhard J ohn H., IV, and J ohn H. Lienhard, V. 2011. Heat Transfer Textbook. $4^{\text {th }}$ ed. Dover Publications, http://app.knovel.com/hotlink/toc/id:kpHTE0007/heat-transfer-textbook/heat-transfertextbook

Marrucho, I. M., F. Santos, N. S. Oliveira, and R. Dohrn. 2005. "Aging of rigid polyurethane foams: Thermal conductivity of $\mathrm{N} 2$ and cyclopentane gas mixtures.”J ournal of Cellular Plastics. 41(3):207-224.

Mcmahon, W., H. A. Birdsall, G. R. J ohnson, and C. T. Camilli. 1959. “Degradation studies of polyethylene terephthalate." J ournal of Chemical and Engineering Data. 4(1)57-79, http://pubs.acs.org/doi/pdf/10.1021/je60001a009

McManus, H. L., and R. A. Cunningham. 1997. "Materials and mechanics analyses of durability tests for high-temperature polymer matrix composites." Fracture Mechanics 1302:1-17

Mills, A. F. 1999. "Modes of heat transfer." Heat Transfer, 2d ed. Upper Saddle River, NJ : Prentice Hall, pp 7-11.

Parasin, A. V., and N. J . Nagy. 1991. Effect of Spray-Applied Polyurethane Foam Insulation on the Racking Load of a Plywood Sheathed Wood Frame Wall. Technical Note 91.1. Vancouver, BC: Council of Forest Industries of B.C., Canada.

Pielichowski, K, P. Czub, and J . Pielichowski. 2000. "The kinetics of cure of epoxides and related sulphur compounds studied by dynamic DSC." Polymer 41(12):43814388.

Porges, F., and R. W. Haines. 2001. HVAC Engineer's Handbook. Oxford: ButterworthHeinemann.

Stephenson, L. D., A. Heffron, B. Mehnert, and D. Lawrence. 2013. “Laboratory testing predicts long-term degradation of insulating materials." Materials Performance. 52(11):37-41.

Trpevski, S. 2007. "Technical improvement of housing envelopes in the F.Y.R. of Macedonia." Research in Architectural Engineering Series. 5:83-94. 
Wei, G., Y. Liu, X. Zhang, F. Yu, and X. Du. 2011. "Thermal conductivities study on silica aerogel and its composite insulation materials." International J ournal of Heat Mass Transfer. 54:2355-2366.

Zarr, R. R., and T. Nguyen. 1994. "Effects of humidity and elevated temperature on the density and thermal conductivity of a rigid polyisocyanurate foam co-blown with $\mathrm{CCl}_{3} \mathrm{~F}$ and $\mathrm{CO}_{2}$." J ournal of Thermal Insulation and Building Envelopes. 17:330350 .

Zhu, Z., J . H. Zong, C. B. Park, and M. Choudhary. 2009. "Effect of loss of blowing agents on thermal insulation properties of polystyrene foams." J ournal of Heat Transfer. 131(5):1-8, http://heattransfer.asmedigitalcollection.asme.org/article.aspx?articleid=1449554 


\title{
Appendix A: Flammability Testing Report
}

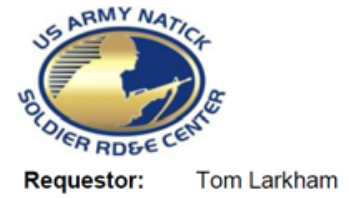

\author{
THE TEXTILE PERFORMANCE EVALUATION FACILITY \\ WARFIGHTER DIRECTORATE \\ NATICK SOLDIER CENTER \\ KANSAS ST., NATICK, MA 01760
}

Requestor:

Larkham

Date: $4 / 25 / 2014$

Nomenclature: Shelter insulations tan, purple and blue.

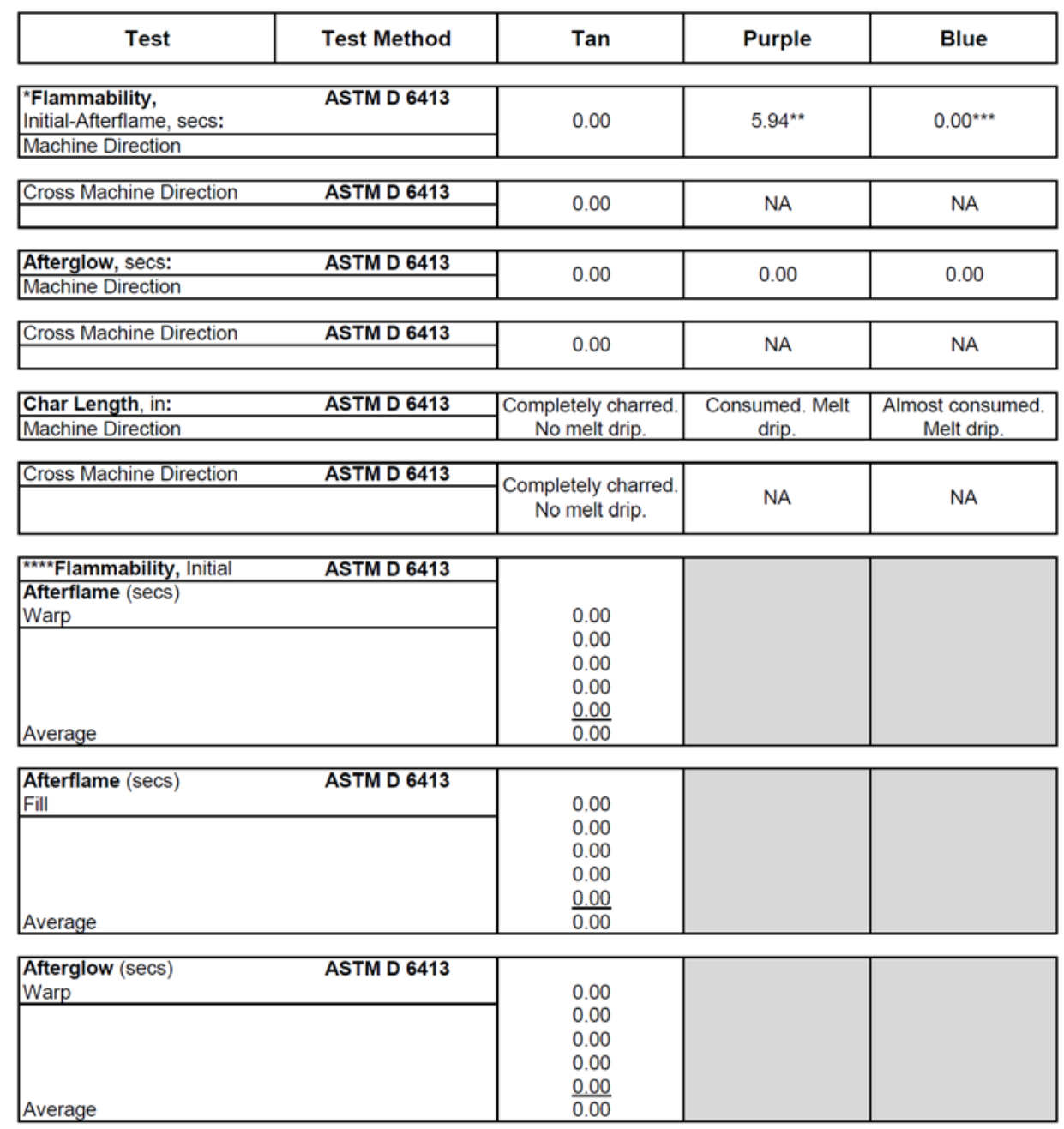




\begin{tabular}{|c|c|c|c|c|}
\hline Test & Test Method & Tan & Purple & Blue \\
\hline $\begin{array}{l}\text { Afterglow (secs) } \\
\text { Fill }\end{array}$ & ASTM D 6413 & \multirow{2}{*}{$\begin{array}{l}0.00 \\
0.00 \\
0.00 \\
0.00 \\
\underline{0.00} \\
0.00\end{array}$} & & \\
\hline Average & & & & \\
\hline
\end{tabular}

\begin{tabular}{|l|l|l|l|}
\hline Char Length (in.) & 8.20 & & \\
Warp & 4.50 & & \\
& 4.70 & & \\
& & & \\
Average & $\underline{5.40}$ & & \\
\hline
\end{tabular}

\begin{tabular}{|l|l|l|l|}
\hline Char Length (in.) & & \\
Fill & 8.20 & & \\
& & 5.20 & \\
& 5.70 & & \\
Average & $\frac{9.20}{6.78}$ & & \\
\hline
\end{tabular}

* Sample size was modified to $(\mathrm{L} \times \mathrm{H}) 3^{\prime \prime} \times 2$ " instead of a standard $3 "$ x 12" .

${ }^{\star \star}$ The specimen was completely consumed and exhibited flaming melt drip.

***Almost completely consumed and exhibited flaming melt drip.

${ }^{* * * *}$ The specimen size was the standard $3 " x 12 "$ and the sample did not exhibit melt drip.

EVALUATOR: Mark Arruda

REVIEWER-1: Amy Bicica

REVIEWER-2: Nancy Hibbert
TEAM LEADER: Luisa DeMorais

Date: $4 / 25 / 2014$

Date: $4 / 25 / 2014$ 
Job\# $7 C$

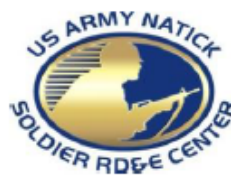

THE TEXTILE PERFORMANCE EVALUATION FACILITY

WARFIGHTER DIRECTORATE

NATICK SOLDIER CENTER

KANSAS ST., NATICK, MA 01760

Requestor: Tom Larkham

Date: $4 / 25 / 2014$

Nomenclature: Tyvek thermawrap insulation(White).

Manufacturer: Dupont

\begin{tabular}{|c|c|c|}
\hline Test & Test Method & Results \\
\hline \begin{tabular}{|l} 
Flammability, \\
Initial-Afterflame, secs: \\
Machine Direction \\
\end{tabular} & ASTM D 6413 & $38.72^{*}$ \\
\hline \begin{tabular}{|l|} 
Afterglow, secs: \\
Machine Direction
\end{tabular} & ASTM D 6413 & 0.00 \\
\hline \begin{tabular}{|l|} 
Char Length, in: \\
Machine Direction \\
\end{tabular} & ASTM D 6413 & 3.70 \\
\hline
\end{tabular}

* The specimen exhibited flaming melt drip.

EVALUATOR: Mark Arruda

REVIEWER-1: Amy Bicica

REVIEWER-2: Nancy Hibbert
TEAM LEADER: Luisa DeMorais

Date: $4 / 25 / 2014$

Date: $4 / 25 / 2014$

Page 1 of 1 


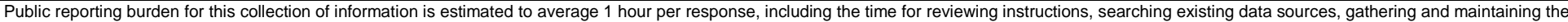

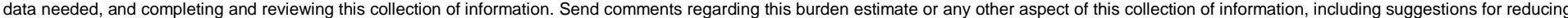

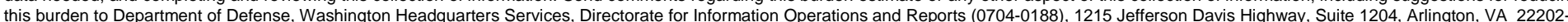

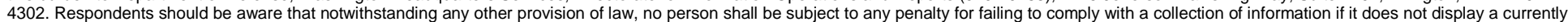
valid OMB control number. PLEASE DO NOT RETURN YOUR FORM TO THE ABOVE ADDRESS.
1. REPORT DATE (DD-MM-YYYY)
2. REPORT TYPE
Final
18-05-2015

\section{TITLE AND SUBTITLE}

Prediction of Long Term Degradation of Insulating Materials

\section{AUTHOR(S)}

L. D. Stephenson, Andrew Heffron, Brenda B. Mehnert, J edediah B. Alvey, Veera Boddu, Elizabeth J . Gao, Deborah J. Lawrence, and Ashok Kumar

3. DATES COVERED (From - To)

\section{5a. CONTRACT NUMBER}

5b. GRANT NUMBER

5c. PROGRAM ELEMENT

\section{5d. PROJECT NUMBER}

5e. TASK NUMBER

5f. WORK UNIT NUMBER

7. PERFORMING ORGANIZATION NAME(S) AND ADDRESS(ES)

U.S. Army Engineer Research and Development Center (ERDC)

Construction Engineering Research Laboratory (CERL)

PO Box 9005,

Champaign, IL 61826-9005

8. PERFORMING ORGANIZATION REPORT NUMBER

ERDC/ CERL TR-15-8

\section{SPONSORING I MONITORING AGENCY NAME(S) AND ADDRESS(ES)}

U.S. Army Engineer Research and Development Center (ERDC)

Construction Engineering Research Laboratory (CERL)

PO Box 9005

Champaign, IL 618216-9005

11. SPONSOR/MONITOR'S REPORT NUMBER(S)

\section{DISTRIBUTION / AVAILABILITY STATEMENT}

Approved for public release; distribution is unlimited.

\section{SUPPLEMENTARY NOTES}

\section{ABSTRACT}

Advanced insulation materials provide resistance to heat flow. Properly insulating shelters can reduce heating and cooling costs, as well as im-proves comfort. However, the long-term performance of insulation materials is relatively unknown. This research investigated the long-term performance of five commercially available insulation materials including nonwoven insulation liner, aerogel blankets, closed cell spray polyurethane foam (ccSPF), extruded polysterene (XPS), and fiberglass batt. Accelerated aging simulation experiments were conducted in an environmental chamber. All materials were subjected to 5 weeks in the chamber and exposed to various temperature and humidity conditions. Thermal conductivity using a heat flow meter apparatus (HFMA) and corresponding Rvalues of each material were calculated. The results indicate that moisture absorption was a major contributor to changes in the thermal properties of the materials. Additional degradation in R-values in ccSPF was caused by loss of blowing agent over time. The results of this research are expected to help formulate an accelerated aging methodology that allows reliable prediction of long-term advanced insulation materials performance.

\section{SUBJECT TERMS}

heating \& cooling, insulation, materials performance, thermal conductivity

\section{SECURITY CLASSIFICATION OF:}

a. REPORT
Unclassified

\author{
b. ABSTRACT \\ Unclassified
}

\section{c. THIS PAGE \\ Unclassified}

17. LIMITATION
OF ABSTRACT
SAR

\begin{tabular}{|c|c|} 
18. NUMBER & 19 \\
OF PAGES & \\
\cline { 2 - 2 } & \\
&
\end{tabular}

19a. NAME OF RESPONSIBLE PERSON

19b. TELEPHONE NUMBER

(include area code) 